\title{
Impact evaluation of a job-training programme for disadvantaged youths : the case of projoven
}

Citation for published version (APA):

Espinoza Peña, H. (2011). Impact evaluation of a job-training programme for disadvantaged youths : the case of projoven. [Doctoral Thesis, Maastricht University]. Boekenplan.

https://doi.org/10.26481/dis.20110126he

Document status and date:

Published: 01/01/2011

DOI:

10.26481/dis.20110126he

Document Version:

Publisher's PDF, also known as Version of record

\section{Please check the document version of this publication:}

- A submitted manuscript is the version of the article upon submission and before peer-review. There can be important differences between the submitted version and the official published version of record.

People interested in the research are advised to contact the author for the final version of the publication, or visit the DOI to the publisher's website.

- The final author version and the galley proof are versions of the publication after peer review.

- The final published version features the final layout of the paper including the volume, issue and page numbers.

Link to publication

\footnotetext{
General rights rights.

- You may freely distribute the URL identifying the publication in the public portal. please follow below link for the End User Agreement:

www.umlib.nl/taverne-license

Take down policy

If you believe that this document breaches copyright please contact us at:

repository@maastrichtuniversity.nl

providing details and we will investigate your claim.
}

Copyright and moral rights for the publications made accessible in the public portal are retained by the authors and/or other copyright owners and it is a condition of accessing publications that users recognise and abide by the legal requirements associated with these

- Users may download and print one copy of any publication from the public portal for the purpose of private study or research.

- You may not further distribute the material or use it for any profit-making activity or commercial gain

If the publication is distributed under the terms of Article $25 \mathrm{fa}$ of the Dutch Copyright Act, indicated by the "Taverne" license above, 


\section{Impact Evaluation of a Job-Training Programme for Disadvantaged Youths: The Case of Projoven}

Henry Espinoza Peña 
(C) Henry Espinoza Peña, Maastricht 2010

All rights reserved. No part of this publication may be reproduced, store in a retrieval system or transmitted in any form, or by any means, electronic, mechanical, photocopying, recording, or otherwise, without the prior permission in writing, from the author.

\section{ISBN 9789086661848}

Published by Boekenplan, Maastricht, the Netherlands. 


\section{Impact Evaluation of a Job-Training Programme for Disadvantaged Youths: The Case of Projoven}

\section{Dissertation}

to obtain the degree of Doctor at the Maastricht University, on the authority of the Rector Magnificus, Prof. dr. G. P. M. F. Mols, in accordance with the decision of the Board of Deans, to be defended in public on Wednesday 26 January 2011, at 14:00 hours

Henry Espinoza Peña 
Supervisor

Prof. dr. Hans Heijke

\section{Co-supervisors}

Prof. dr. Chris de Neubourg

Dr. Denis de Crombrugghe

\section{Assessment Committee}

Prof. dr. Joan Muysken (chairman)

Prof. dr. Andries de Grip

Prof. dr. Win Groot

Prof. dr. Jaap de Koning (Erasmus University Rotterdam)

Prof. dr. Peter Mueser (University of Missouri-Columbia, U.S.) 


\section{Acknowledgements}

Throughout my life, and lately while writing this dissertation, I have felt an enormous support from many people. Family, friends and colleagues have helped me to believe it is possible to circumvent obstacles despite how difficult they looked like. This is a small token of my gratitude to those people.

First, thanks to Chris de Neubourg, Mindel van de Laar and Franziska Gassmann. You gave me the opportunity to pursue my $\mathrm{PhD}$ in the Maastricht Graduate School of Governance (MGSoG). Furthermore, you provided me with teaching opportunities and such a nice work environment which made my efforts more productive.

My gratitude to Hans Heijke and Denis de Crombrugghe for being my supervisors. I must also credit you both for widening my research methods. I always knew what I wanted to do with this thesis. However, you guided me through the "how to". I appreciate it very much. I felt very stimulated by both of you and definitely your suggestions, critics, comments and advices are already helping me not only with this thesis and future research but in a personal level as well.

Thanks to Joan Muysken, Andries de Grip, Wim Groot, Jaap de Koning and Peter Mueser for accepting to be part my assessment committee. My dissertation has benefited a lot from your comments and critics. However, I must recall that any remaining flaw is my entire responsibility. The same applies for the English language used in this dissertation, which was carefully edited by my dear friend Liz Puller.

Big thanks to my football friends Luis Alfredo Perez, Semih Ackomak, Ezequiel Tacsir, Huw Jones, Jan Saito, Arne Henning and all of them who participated intermittently in our matches. Thanks for helping me to have a life away from the computer. Football journeys on Wednesdays and Sundays during these years were simply memorable. We played under the rain, snow, and inclement sun; and I just hope to play with you again.

Much love to all my MGSoG friends who made my life in the school such a great experience. Maha Ahmed, Judit Vall, Marina Petrovic, Treena Wu, Renée Speijcken, Metka Hercog, Kwan Suddhi-Dhamakit, Robert Bauchmüller, Victor Cebotari, Jinjing Li; sharing drinks, dinners, lunches, trips and also once in a while some research ideas with you could not have been better and funnier. I would like to thank Bianca Buligescu for all her lessons and her support, they meant a lot to me. Also, while writing my dissertation I had the chance to meet Annelien Ronda, who I would like to thank for all those pieces of her life she shared with me. Thanks!

Lastly, huge thanks to my family, my father Henry, my mother Zoila, my brother Cristopher, my sister Pamela and my aunt Isabel. Your unconditional love keeps me alive and makes me feel I am never walking alone wherever I am. I dedicate this book to you. 


\section{Contents}

Chapter 1: Introduction .....................................................................................................1

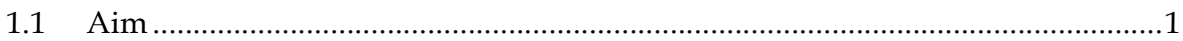

1.2 Outline of the study..............................................................................................

Chapter 2: Projoven's Institutional Framework ......................................................................9

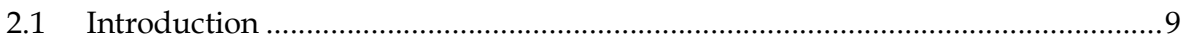

2.2 The General Context........................................................................................... 10

2.3 Vocational Education and Training Market .......................................................12

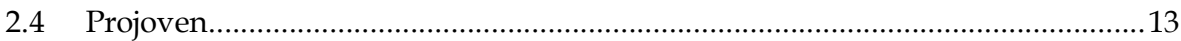

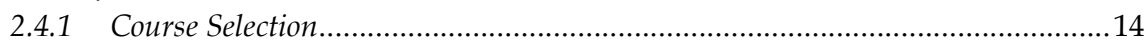

2.4.2 Selection of eligible participants ...................................................................... 16

2.4.3 ECAP selection process ........................................................................... 19

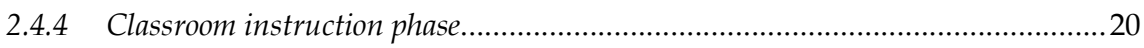

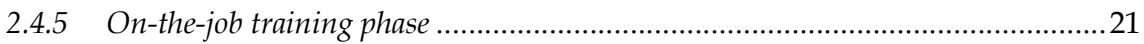

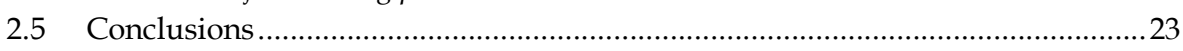

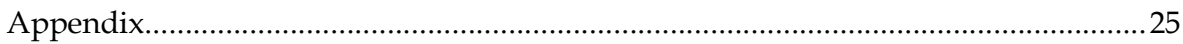

Chapter 3: Projoven Evaluation Data ...................................................................................27

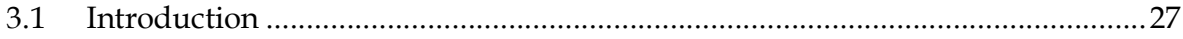

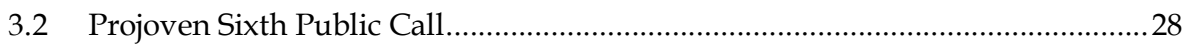

3.3 Dealing with Projoven Pre-Treatment Earnings Dip ..............................................31

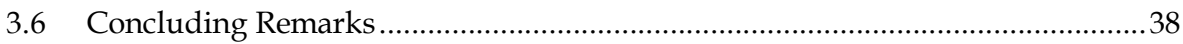

Chapter 4: Evaluation of Projoven Effectiveness................................................................39

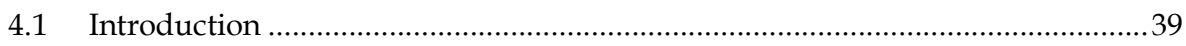

4.2 Youth Job-Training Programmes Effectiveness ………………………………......40

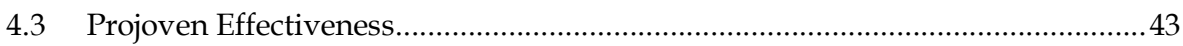

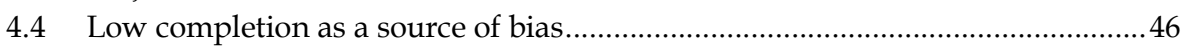

4.5 Empirical framework …………………………………...................................... 49

4.5.1 The effect of participation in the programme .....................................................50

4.5.2 The effect of Projoven internship placement ......................................................53

4.5.3 The effect of Projoven internship completion.....................................................5

4.5.4 Projoven heterogeneous treatment effects...........................................................55

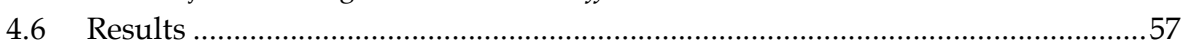

4.6.1 Projoven effects on overall employment .........................................................57

4.6.2 Projoven effects on formal employment, controlling for sample selection...............58

4.6.3 Projoven effects on monthly wages, controlling for sample selection ....................59

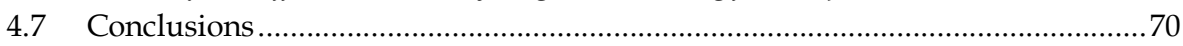

Appendix 
Chapter 5: Determinants of dropout behaviour in Projoven.................................................93

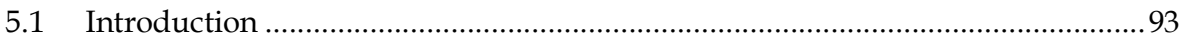

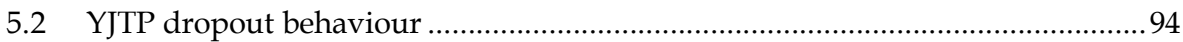

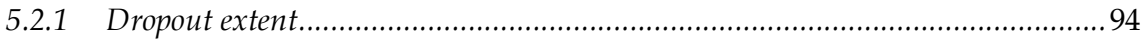

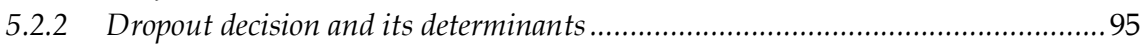

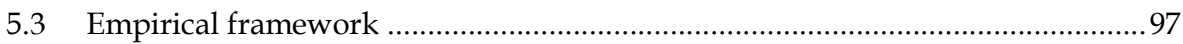

5.3.1 Model 1: Probability of dropping out of a Projoven internship (probit model with sample selection) .......................................................................................... 98

5.3.2 Model 2: Probability of dropping out of a Projoven internship, given different exit

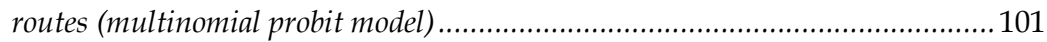

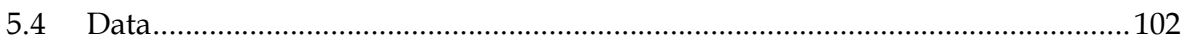

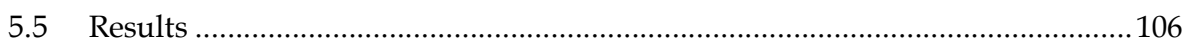

5.5.1 Model 1 - selection equation: Probability of a Projoven internship

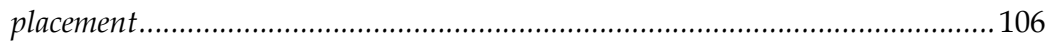

5.5.2 Model 1 - response equation: Probability of dropping out of a Projoven internship .............................................................................................. 108

5.5.3 Model 2: Probability of dropping out of a Projoven internship through different exit

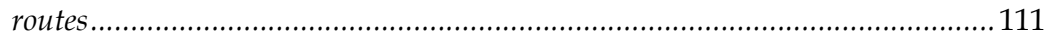

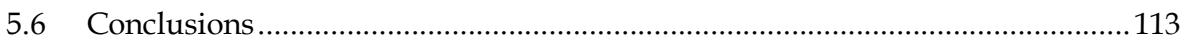

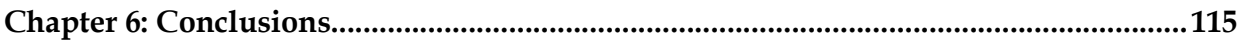

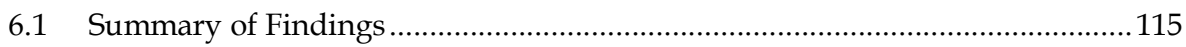

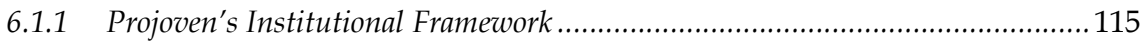

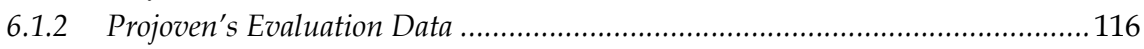

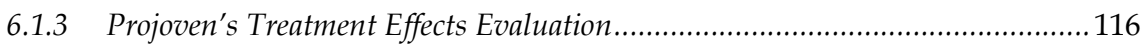

6.1.4 Determinants of Trainees' Decision to Drop Out .......................................... 117

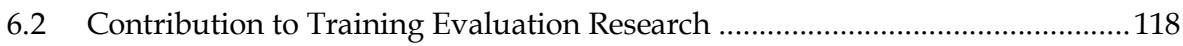

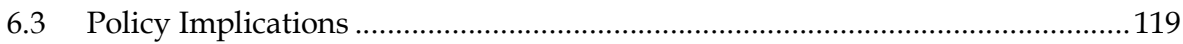

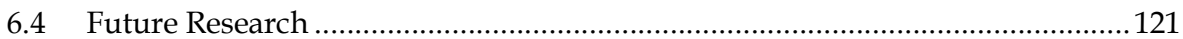

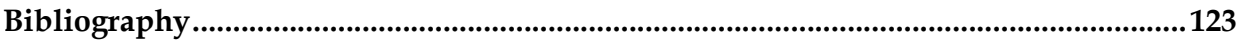

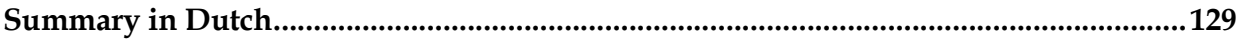

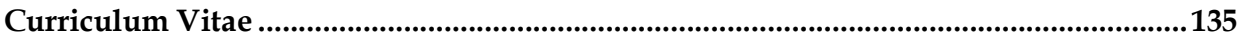

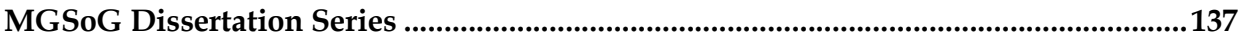




\section{List of Abbreviations}

2SLS: $\quad$ Two-stage least squares.

ATE: $\quad$ Average treatment effect.

CCLJ: $\quad$ Youth training contract (Convenio de capacitación laboral juvenil).

CENFOTUR: The tourism-related firms training centre (Centro de formación en turismo).

CEO: $\quad$ Centres for vocational training (Centro de educación ocupacional).

ECAP: $\quad$ Training provider (Entidades de capacitación).

FSEE: $\quad$ Socio-economic evaluation form (Ficha socioeconomica de evaluación).

IADB: $\quad$ Inter-American Development Bank.

ILO: International Labour Organization.

IMF: $\quad$ International Monetary Fund.

IST: Institutes for tertiary technical education (Instituto superior tecnológico).

JTPA: $\quad$ Job Training Partnership Act.

NGO: Nongovernmental organization.

OLS: $\quad$ Ordinary least squares.

PISA: Programme for international student assessment.

RECAP: $\quad$ Database of training providers (Registro de entidades de capacitación).

S/: $\quad$ Peruvian Nuevos Soles.

SENATI: The industry-related firms training centre (Servicio nacional de adiestramiento en trabajo industrial).

SENCICO: The construction-related firms training centre (Servicio nacional de capacitación para la industria de la construcción). 
List of Abbreviations

VTCESA: Vocational training centres sponsored by economic-sector associations of firms.

YJTP: $\quad$ Youth job-training programme.

YTS: $\quad$ Youth Training Scheme. 


\section{Chapter 1}

\section{Introduction}

\subsection{Aim}

During the 1980s, Latin American economies experienced low rates of economic growth (lower than population growth), high external debt, restricted internal consumption and savings, high inflation, devaluation of local currencies, and expansion of the informal labour market. In response, during the late 1980s and early 1990s, Peru, like other countries in the region, implemented an accelerated process of structural reform, in accordance with the Washington Consensus. ${ }^{1}$ Some of the most dramatic reforms were carried out in the labour markets. The reforms in the Peruvian labour market legislation modified significantly the way employees are hired and dismissed (social security and employment protection conditions). In addition, external shocks such as financial crises (in Asia, Russia and Brazil) and natural disasters (such as the El Niño Phenomenon) impacted the functioning of the labour markets and influenced the effects of the reforms.

It was expected that market-oriented reforms would reduce labour market inefficiencies and non-wage labour costs, increase labour productivity and thereby reduce inflation and boost economic growth. The reforms were successful at decreasing inflation and increasing growth; however, labour market performance was modest. The non-wage labour costs resulting from regulations remain high in the formal sector. As a consequence, firms without the financial means to comply with the regulations resorted to informality or reduced personnel. ${ }^{2}$

In a post-structural-reform scenario, Latin American countries faced serious barriers to improving employment prospects for younger workers, particularly those from disadvantaged backgrounds. The opportunities of younger workers in the labour market are limited under the described circumstances. Even in low-skilled jobs, individuals with larger human capital (in terms of work experience) displace youths seeking a first job. As a consequence, seven out of ten youths work in the informal sector, with no social security coverage, and under precarious conditions. The growing number of young people in intermittent, insecure and low-paid jobs is putting pressure on decision-makers to implement reforms.

\footnotetext{
${ }^{1}$ Washington Consensus describes a set of specific economic policy prescriptions that constitute the "standard" reform package promoted for crisis-wracked developing countries by Washington, D.C.based institutions such as the International Monetary Fund (IMF), the World Bank, and the U.S. Treasury Department in the 1980s.

2 See: Tokman and Martínez (1999); Egger and García (2000); IADB (2001); and Saavedra (2003).
} 
A policy measure targeted at economically disadvantaged youths in Latin America has been the introduction of youth job-training programmes (YJTP). The objective of these programmes is to improve the labour market prospects of economically disadvantaged youths by providing them with basic job readiness skills as well as some trade-specific abilities. Since the early 1990s, such training programmes have been carried out throughout Latin America. YJTPs were implemented in countries including Venezuela (1993), Argentina (1994), Paraguay (1994), Peru (1996), the Dominican Republic (1999), Colombia (2000), Panama (2002) and Haiti (2005). The International Labour Office provided these countries with technical assistance in the design of the programmes, and most of them were funded with loans from the Inter-American Development Bank. YJTPs are based on the dual system of classroom instruction and on-the-job internship. They follow a market-oriented approach, in which governments consign the training activities to private parties. Latin American governments fund training providers to train youths on their own premises and to subsequently place them in internships. The government confines its role to the selection of the best bids from private organisations, through public tenders, and control of the quality of the training offered.

Latin American YJTPs have been extensively evaluated and the general conclusion is that training programmes are effective policy interventions. It has been suggested that these programmes increase youths' chances of being employed and their potential earnings, particularly for young women. Nevertheless, the presence of trainees who do not complete the programme, either because they are not placed in internships or because they drop out voluntarily from the programme, has been ignored in most evaluations. This is crucial because the presence of an important proportion of trainees who do not complete the training (partial treatment) is a characteristic of virtually all training programmes. Taking into account the low completion phenomenon, its causes and implications could challenge the current view of YJTPs' effectiveness. Additionally, it could provide information about how to enhance the effectiveness of these programmes. For instance, apparent positive training outcomes, reported by earlier evaluations which do not consider the presence of trainees with partial treatment, could hide the fact that the training may be effective only if completed. Ignoring this could prevent the programme from concentrating its efforts on finding out the motives and consequences of the low completion phenomenon.

Low completion rates in YJTPs provide evidence that i) training providers do not place all trainees in internships; ii) internships are carried out under precarious conditions ${ }^{3}$; or iii) the programme works better for some types of individuals than for others. Consequently, in order to estimate and understand the programme's effectiveness, it is important to distinguish the effects of the different phases of the programme, to take into account the institutional arrangements of the training (regulations, incentives and enforcement mechanisms) and individual heterogeneity. Some individual characteristics, like work experience, gender or poverty status, could influence the programme's effects, discouraging some of the trainees from completing the training. In addition, if internships are carried out

\footnotetext{
${ }^{3}$ In this study, "not having a written contract" is used as an indicator of precarious working conditions.
} 
under precarious conditions, trainees may drop out for better opportunities. These aspects have been neglected in previous evaluations. Therefore, the relationships between training completion, trainees' heterogeneity and the institutional arrangements of YJTPs on the one hand, and trainees' labour market outcomes on the other hand, remain ambiguous. This thesis aims at filling this gap in the treatment effects literature.

Specifically, this thesis evaluates the effectiveness of the Peruvian YJTP Projoven in terms of both overall and formal employment and in terms of monthly wages. The case chosen for this study is representative of similar training measures in Latin America and has an average dropout rate. Projoven is an ongoing training programme initiated in 1996 and is conducted at least once a year in successive waves or 'public calls'. In thirteen years of operation it has trained around 60,000 individuals. The programme is run by the Peruvian Ministry of Labour. Projoven finances training courses for youths, but the services are provided by training institutions which compete to obtain funding for their course offering. The official goal of the programme is to facilitate the insertion of economically disadvantaged youths (16-24 years old) into the formal labour market by funding basic training in low-skilled occupations. Projoven training is based on two sequential phases: i) three months of classroom instruction which almost all trainees complete, followed by ii) three months of onthe-job training internship which is offered to a majority but not to all trainees.

By integrating the analysis of the institutional framework, individual heterogeneity and the participants' dropout behaviour into the evaluation of Projoven's effectiveness, this thesis will shed light on the following questions:

1. To what extent do the institutional arrangements affect the programme outcomes and hence should be considered in its impact evaluation?

2. How is the estimation of Projoven's effectiveness affected when taking into account simultaneously the presence of trainees with partial treatment, unobservables, and selection into work?

3. Does the programme affect youth differently depending on their work experience, gender or poverty condition?

4. Is training more effective conditionally on completion?

5. What are the factors influencing trainees' dropout behaviour?

This dissertation follows a three-step approach to answer these five research questions. First, a discussion of the institutional framework of Projoven is presented. This discussion proposes a number of elements which should be taken into account in a training programme evaluation, such as: how the programme works and how its regulations generate the incentives for disadvantaged youths to enrol or drop out of training; for training providers to offer high-quality training or internship placements for all trainees; and for training firms to provide internships under proper conditions. Therefore, a deeper analysis of the institutional arrangements and the context under which a programme is conducted is crucial in order to disentangle the reasons of the programme's success (or failure). 
Second, the effects of the programme, in terms of both overall and formal employment and in terms of monthly wages, are estimated. These estimations take into account the nonexperimental nature of the data, the heterogeneity of individuals, selection into work and the presence of trainees with partial treatment. Neglecting the non-experimental nature of the data could bias the estimations of treatment effects because of potential systematic differences between control group individuals and trainees. Taking into account individual heterogeneity is crucial, as the training may affect individuals differently depending on certain characteristics such as poverty status, gender or work experience. In addition, estimating treatment effects which account for partial treatment could yield a different perspective on the YJTP's effectiveness. Amalgamating completers and non-completers may confound different effects. For instance, dropping out implies not obtaining a certificate, which could cast the trainee in a negative light to potential employers.

Finally, the factors affecting trainees' dropout behaviour are analyzed. This study tests whether individual characteristics, regional features or training characteristics influence trainees' decisions to drop out. Individuals with certain characteristics who find that they do not benefit sufficiently from the training to compensate for their opportunity costs will not make the necessary effort to complete the programme. Regional features influence trainees' opportunity costs associated with pursuing training and the availability of internship opportunities. The characteristics of classroom instruction and of internships, revealed to the trainee during the training, modify individual expectations about the returns of the training. Youths may drop out during the training if they realise that the programme is not going to yield the returns they had hoped for.

\subsection{Outline of the study}

This thesis consists of six chapters in which the evaluation of Projoven is conducted, following the three-step approach described earlier. First, Chapter 2 provides background information about the programme and describes its institutional framework. Second, Chapters 3 and 4 are devoted to Projoven's treatment effect evaluation. Chapter 3 describes and discusses the Projoven dataset, and the sixth public call for which detailed data are available. In Chapter 4 a methodology to evaluate Projoven is proposed and applied. The evaluation is conducted in terms of both overall and formal employment and in terms of monthly wages. Third, Chapter 5 identifies and discusses the factors affecting trainees' dropout behaviour. Finally, in Chapter 6 some general conclusions are drawn and potential future research opportunities are suggested.

Chapter 2 studies the extent to which the institutional arrangements should be taken into account in the evaluation of the programme's effectiveness given the context in which the programme is carried out. By presenting how Projoven is designed to work compared to how it actually does work, this chapter suggests three elements which should be accounted for when evaluating the effectiveness of a training programme such as Projoven. First, it 
should be considered that not all the trainees are placed in internships after the classroom instruction phase. Therefore, Projoven's impact evaluation should distinguish between the effects of the two phases of the programme. Second, as $30 \%$ of the trainees placed in internships drop out, Projoven's impact evaluation should account for the presence of trainees with partial treatment. Third, it should be taken into account that both trainees and their employment prospects are heterogeneous. The fact that half of the trainees are working prior to the programme, most likely in the informal sector, has implications for the treatment effect estimations in terms of employment indicators and individual heterogeneity. Evaluating the effect on overall employment may overlook the real potential of the programme, because disadvantaged youths are frequently employed in precarious jobs with low pay and no social rights. Especially in a developing country with a dual labour market, the quality of the employment matters. Labour markets in Latin America are often fragmented into a formal segment, with higher productivity and where all regulations are met; and an informal one, with lower productivity and no regulations. Taking this dualism into account, assessing trainees' employment status in the formal labour market could provide additional evidence of Projoven's effects in terms of employment. In addition, the programme may affect trainees differently depending on their work experience. For instance, training returns could be relatively lower for youths with work experience as they already posses some skills.

Chapter 3 describes Projoven's sixth public call dataset. This dataset combines not only demographic information about trainees and an official control group, but also administrative records on level of training completion. It comprises a baseline survey and three follow-up interviews: at six, twelve and eighteen months after the end of the training. This chapter explains how a new control group was created using propensity score matching with replacement. The objective is to tackle the pre-programme earnings dip in the trainee group which is not observed in the official control group and which may be evidence of systematic differences between the groups, undermining their comparability. The new control group is a subsample of the individuals in the official control group. The tests performed on this new control group suggest that in terms of employment, treatment effects estimations are free of bias; whereas in terms of monthly wages, treatment effects estimations could be upward biased.

In Chapter 4, Projoven's effectiveness is evaluated. It begins with an overview of the literature on the treatment effect evaluation of YJTPs, in particular for Latin America. It includes a discussion of the importance of the low completion phenomenon for treatment effects estimation. The literature review suggests that not accounting for the partial treatment of some trainees could bias the results and the interpretations of the programme's effects. Basically, individuals who complete the training (or are exposed longer to the training) experience higher employment and income gains in comparison with individuals who do not. This chapter estimates the effectiveness of Projoven's sixth public call, in terms of both overall and formal employment and in terms of monthly wage. It accounts for the presence of trainees with partial treatment using fixed effects methods with sample selection correction. Four groups are compared pair-wise: the control group, the dropout group with 
only classroom training, the dropout group with classroom training and internship placement, and the group completing the full programme. The estimations also account for the potential endogeneity of training completion. Using pooled two stages least squares methods with sample selection correction, it is found that in terms of overall and formal employment, the returns of the programme are only short-term effects and are based on internship completion. The programme seems to increase trainees' wages, but these effects diminish over time. When differentiating the effects by types of individuals, it is found that Projoven yields additional returns, in terms of overall employment and wages, for individuals with no work experience prior to enrolment, and these additional returns are constant over time. It should be noted that general equilibrium effects of Projoven on the Peruvian labour market are negligible given the limited coverage of the programme.

The extent of the dropout phenomenon in Projoven and the circumstances under which dropouts are more likely are analyzed in Chapter 5. Using a probit model which controls for a potential selection into internship, the estimations suggest that regional differences and internship conditions (in particular, having a written contract) affect trainees' decisions to drop out. Two different exit-routes are identified and compared to training completion: i) dropping out of training to take another job, and ii) dropping out of training into unemployment or inactivity. Using a multinomial probit model, the estimates suggest that trainees who are male and have prior work experience are less likely to drop out into unemployment, but are more likely to drop out for another job.

Both empirical structures i) Projoven's effectiveness evaluation and ii) the analysis of the factors affecting trainees' dropout behaviour, complement each other in order to shed more light in studying the dropout phenomenon in training programmes. Whereas the first one evaluates the consequences of dropping out, in terms of employment condition and wage gains, the second one provides a profile of trainees who are most likely to drop out. The analysis of the factors affecting trainees' dropout behaviour complements Projoven's effectiveness evaluation by going beyond the consequences of dropping out. It gives some explanation about why trainees drop out even when is not worthy doing so.

Finally, Chapter 6 draws conclusions from the study. The main findings of the thesis are reviewed in this chapter as well as their policy implications and the scope for future research. This thesis contributes to the YJTP treatment effects literature in two ways. First, its contribution lies in examining the impact of the presence of trainees with partial instruction in YJTPs, while appropriately accounting simultaneously for unobservables, potential endogeneity of training completion, trainees' heterogeneity and the institutional arrangements of YJTPs. This approach consists of comparing pair-wise four groups of youths (the control group, the dropout group with only classroom training, the dropout group with classroom training and internship placement, and the group completing the full programme) to avoid potential bias generated by completion levels. In addition, the use of fixed effects accounts for the presence of unobservables; and complemented with random effects allow the effects of the programme to vary, not only over time, but across individual characteristics (gender, poverty status and work experience). Second, this thesis contributes to the existing 
literature by focusing on the determinants of trainees' dropout behaviour accounting for potential selection into internships and allowing the effects of the determinants to vary depending on the exit route (to another job or to unemployment). The few empirical studies that evaluated training programmes accounting for partial treatment did not develop further on why trainees drop out, even though they concluded it is not worthwhile to do so (e.g., Mealli et al., 1996; Heckman et al., 1998; Heckman et al., 2000; Lee and Lee, 2003; FloresLagunes et al., 2007). This thesis seeks to disentangle the reasons behind trainees' dropout behaviour taking into account that trainees who drop out for another job can have a different profile than those who drop out into unemployment. By accounting for potential selection into internship and different exit routes, this study suggests that individual characteristics, regional features and characteristics of the training affect trainees' dropout behaviour. Additionally, it argues that trainees who are male and have prior work experience are less likely to drop out into unemployment, but more likely to drop out for another job. This understanding is crucial as it allows policy makers to enhance the benefits of training by taking into account these factors.

This thesis' findings imply that the programme must be complemented with a better selection of training providers, stricter monitoring mechanisms and focused targeting strategies. To enhance its effectiveness, Projoven should take into account that i) not all trainees receive the same doses of treatment; ii) the effectiveness of the training varies individually based on several socioeconomic factors; and iii) precarious treatment conditions can lead trainees to drop out of the programme. 
Chapter 1. Introduction 


\section{Chapter 2}

\section{Projoven's Institutional Framework}

\subsection{Introduction}

This chapter describes Projoven's institutional framework. Understanding the institutional framework governing a youth job training programme (YJTP) such as Projoven and the context under which it operates is critical to assessing and interpreting under which circumstances the programme could be more (or less) beneficial. By comparing how the programme is supposed to function and how it performs in practice, this chapter suggests three elements that should be taken into account when evaluating the effectiveness of Projoven.

First, since a quarter of trainees are not placed in internships (the second phase of the programme) after finishing the classroom instruction phase, Projoven's impact evaluation should estimate separately the effects of the two training phases of the programme. Labour market outcomes may differ depending on whether the trainee is placed or not in an internship, as the internship phase plays an important role in providing disadvantaged youths with job readiness skills and trade-specific abilities. Some features of Projoven's institutional framework may influence training providers not to place all trainees in internships. For instance, the most valued criteria in Projoven's course selection are (1) maintaining the least unit cost per trainee, and (2) the commitment of the training provider to place at least $60 \%$ of trainees in internships. Competition to offer low-cost courses could incentivise training providers to supply low quality training or not to offer internship placements to all trainees. Providing high-quality training and finding internships for all trainees would increase cost estimates in course proposals, reducing the chances of selection for those training providers.

Second, since $30 \%$ of trainees placed in internships drop out, Projoven's impact evaluation should account for the presence of trainees with only partial treatment. Projoven's effects may differ by trainee level of completion. Trainee dropout behaviour, when not considered, could yield biased estimates of the effects of the programme, particularly when dropouts are systematically different from completers. Disadvantaged youths enrol in the training with the expectation of improving their labour market prospects. Their opportunity cost, working in the informal labour market in precarious conditions, is evidently lower than the minimum wage they are supposed to earn during the internship. However, not all training firms offer proper internship conditions. In this study, "not having a written contract" is used as an indicator of precarious working conditions. Precarious internship conditions may discourage trainees from carrying on with the training. The fact that not all training firms comply with 
Projoven's internship regulations may be explained by the lack of an effective monitoring process during the internship and the transaction costs involved in hiring trainees.

Finally, because Projoven is carried out in a developing country with a dual labour market, its treatment effect evaluation should consider the impact of both formal and informal employment. In Peru, the lack of appropriate welfare programmes forces individuals at the bottom of the income distribution to find precarious jobs in the informal labour market. Around half of Projoven participants are working when they enrol in the programme. By observing only overall employment, without distinguishing between formal and informal jobs, the policymaker might overlook the effects of the programme on the quality component of employment. In this respect, an indicator of the quality of employment, formal labour employment condition, could be more indicative of the effects of the programme on trainee employment prospects. In addition, the presence of individuals employed prior to enrolment in the programme could introduce new sources of individual heterogeneity. The programme may affect individuals differently depending on their prior work experience. Therefore, Projoven treatment effects evaluation should also take into account individual heterogeneity (in terms of work experience and poverty status). For instance, training returns could be lower for youths with work experience if the training merely teaches skills they have already acquired.

The rest of this chapter is organized as follows: Section 2.2 presents the general context in which Projoven is carried out. Section 2.3 describes the vocational education and training market in Peru. A detailed description of Projoven's institutional framework is provided in Section 2.4. Finally, Section 2.5 concludes.

\subsection{The General Context}

Projoven has trained more than 60,000 disadvantaged youths from thirteen Peruvian cities. The programme started in Lima (the capital) and has progressively expanded to more cities. Projoven is conducted in successive waves, or public calls. From 1996 to 2007, the programme has conducted fifteen public calls. This period was characterized by vigorous economic recovery after the implementation of an aggressive structural reform agenda in the early 1990s. After completion of the structural reforms, improvements were obvious in terms of Peru's monetary and fiscal position. Macroeconomic equilibrium was restored and inflation rates were reduced, making Peru one of the fastest growing economies of the region. Unfortunately, these developments were not accompanied by improvements in the labour market, mainly in terms of quality. During the reference period, yearly employment growth was approximately $3.5 \%$, slightly above labour supply growth (3.3\%); however, the quality of the jobs created was quite poor. The proportion of jobs in the informal labour market increased from $45 \%$ to $52 \%$ and employment in firms with more than 100 workers decreased in absolute terms. In addition, an increase in the turnover rate and a decrease in average worker tenure may have contributed to the actual reduction in the levels of firm- 
provided training (from 19\% to $14 \%$ during the reference period). This situation impacted the opportunities available to low-skilled workers, particularly for youths of disadvantaged background.

A total of 3.6 million youths within the age bracket of $15-24$ years (22\% of the Peruvian population) entered the workforce in the period 1997-2007. Despite some improvement in educational attainment, young cohorts typically exhibit higher unemployment rates than adults. During the reference period, the youth unemployment rate was stable at approximately $14 \%$, almost triple the corresponding rate for adults. The youth participation rate was stable at around 55\%, a $20 \%$ lower participation rate compared to adults. It is not surprising that youths have lower participation rates than adults since many are still in the process of acquiring basic human capital (through schooling). However, the proportion of youths neither working nor studying increased over the period, from $19 \%$ to $23 \%$, whereas the proportion of youths engaged exclusively in study slowly declined, from $32 \%$ to $29 \%$.

Perhaps the poor performance of public basic education is limiting the ability of this cohort to pursue tertiary education. The OECD Programme for International Student Assessment (PISA) indicates that student scores in Peruvian public schools are alarmingly low in language, mathematics and science. In reading, for instance, $80 \%$ of Peruvian students are below minimum level one. This means that these students have serious reading deficiencies. As a matter of comparison, Argentina has $44 \%$ of its students below this level, Uruguay $40 \%$, Brazil 50\%, Mexico 52\% and Chile 48\%. ${ }^{1}$ The results in mathematics and science literacy are also low. Peru performed worst in the region in these areas. The outcomes from poor quality education are expressed in the precarious labour market conditions under which Peruvian youths work. Whereas the number of hours worked per week held close to 41 on average during the period 1997-2007, the average real youth wage declined steeply (down $26 \%$ over the period). Additionally, seven out of ten youths worked in the informal labour market, with no social security coverage.

The growing number of young people in intermittent, insecure, and low-paid jobs is putting pressure on decision makers to search for new and more effective policy interventions. The poor quality of public education forces young workers into the informal labour market and reduces their ability to pursue further study. The lack of skills is thought to be one of the key determinants of major social problems for youth. Thus, education programmes have been at the heart of development policies. However, these interventions take a long time to translate into poverty reduction and require further investment in quality improvement. Education programmes may reach youths too late, especially those who are entering or are close to entering the labour market. Given conditions for young people in the labour market, vocational education and training appears to be a suitable option.

\footnotetext{
${ }^{1}$ The average in OECD countries of students below level one is $19 \%$.
} 
Chapter 2. Projoven's Institutional Framework

\subsection{The Vocational Education and Training Market}

The Peruvian regular education system consists of three levels of instruction: primary education, secondary education, and tertiary education. Primary education is carried out in six grades (years); it is mandatory and begins at age six. Secondary education is carried out in five grades (years); its objective is to strengthen the outcomes achieved in primary education and to orient the students toward vocational fields according to their aptitudes. After secondary school, youths may opt for tertiary education (university and non-university technical schools). University studies last at least five years and technical school studies last from three to five years.

Vocational education and training grew as a system separated from regular education. Both systems (vocational education and regular education) show, in practice, a disparity of objectives, little coordination, and very often differing sets of social values (Chacaltana and Sulmont, 2004). Vocational education and training services are defined as courses lasting less than a year designed to prepare individuals for low-skill jobs and to provide them with trade-specific abilities. As a consequence, vocational education and training is seen as an alternative for those who cannot access (or cannot afford financially) tertiary education or for those who drop out of secondary education.

In Peru, the provision of vocational education and training expanded significantly in the 1990s and consists of a heterogeneous supply of private and public institutions. Vocational education and training is provided by Institutes for Tertiary Technical Education (IST) and Vocational Training Centres sponsored by Economic-Sector Associations of firms - VTCESA (SENATI, the industry-related firms training centre; CENFOTUR, the tourism-related firms training centre; SENCICO, the construction-related firms training centre; etc.). Additionally, there are institutions targeting individuals who do not complete secondary education, such as the centres for vocational training (CEO), which are publicly funded, and programmes organized by NGOs.

In contrast to the rapid expansion of institutions providing vocational education and training, the market is still poorly regulated and efforts to introduce quality standards through certification have been extremely slow (Diaz and Jaramillo, 2006). As a consequence, the supply of vocational education and training is heterogeneous. It is composed of diverse types of institutions with dissimilar levels of quality, prices, services and links with the productive sector. On the one hand, this heterogeneity could be beneficial to satisfy the demands of firms that require specific skills and the demands of individuals who have different preferences. On the other hand, this heterogeneity could be detrimental if the differences in quality among institutions imply inequality in accessing job opportunities. According to Saavedra and Chacaltana (2001), disadvantaged youths are more likely to attend vocational education and training institutions of low quality, as they imply low investments in terms of both time and financial resources. 
Vocational education and training could serve as a fundamental tool to improving youth employability. However, the low quality of vocational training services and their limited links with the productive sector may limit the ability of disadvantaged youths to succeed in the labour market. By implementing the YJTP Projoven, the Peruvian government attempts to make available vocational education and training for youths from disadvantaged backgrounds and to stimulate links between the productive sector and the vocational education and training system.

\subsection{Projoven}

Projoven began its operations in 1996 under the umbrella of the labour market policies of the Peruvian Ministry of Labour. The International Labour Organization (ILO) provided technical assistance for the implementation of these measures. Originally the programme was intended to be implemented nationwide. When the ILO proposed the idea and design of Projoven to the Peruvian Ministry of Labour, it had already obtained funding to train 150,000 youths per year over four years. This funding was obtained through a loan from the InterAmerican Development Bank (IADB). Unfortunately, the Ministry of Labour did not obtain the counterpart public funding (approximately 30\%) necessary to secure the IADB loan. Consequently, the funding was reduced to the extent that during the first four years of the programme only 8,220 youths were trained in three cities, with an expenditure of 4.4 million U.S. dollars.

The official goal of the programme is to facilitate the entry of economically disadvantaged youths (16-24 years old) into the formal labour market by funding basic training in low-skill occupations. Additionally, by inviting tenders for training courses depending on, among other factors, internship placement, Projoven attempts to enhance the links between vocational education and training providers and the productive sector. The programme rationale is to provide youths with the hope that by increasing their human capital, they avoid involvement in drugs or criminal activities. In fact, the original design of the programme included modules and workshops related to this issue. This objective was lost as Projoven progressively evolved into a training programme à la Europe or the U.S.

Projoven's training activities are organized into three preparatory phases and two phases of actual instruction. The first two preparatory phases are: (1) selection of courses to be offered, and (2) selection of eligible participants by the programme management unit. The third preparatory phase, referred to as (3) 'ECAP selection process', is selection of trainees by the training providers when there are fewer vacancies than candidates. Following these preparatory phases, the two phases of actual instruction are: (1) classroom instruction and (2) on-the-job training. These phases are discussed in the following subsections. 


\subsubsection{Course Selection}

The course selection process begins when Projoven launches a call for training providers (the so-called ECAP - Entidades de Capacitación). Institutions interested in participating in the programme must register in the database of training providers called RECAP (Registro de Entidades de Capacitación). To be registered in RECAP, potential ECAPs must have a valid licence from the Ministry of Education, possess proper facilities for teaching, and have a track record in vocational training.

The ECAPs registered at RECAP are invited to present course proposals. The courses must be aimed at a low skill level, terminal (training should be sufficient to get a job - no need to be complemented by another type of training/education) and, most importantly, labourdemand oriented (there should be firms requiring workers with this training). Courses include training for: office assistants, call centre operators, pharmacy assistants, hairdressing and cosmetology assistants, inventory assistants, archival assistants, payroll assistants, cloth finisher, counting clerk and clerical assistant, assistants for computer installation and maintenance, textile operators, woodcutting machine operators, sales clerks, housekeepers, house cleaners, carpentry assistants, plumbers' assistants and electricians' assistants, among others.

The courses should be designed for 15 to 25 students per classroom, last between 200 and 300 hours, with four to five contact hours per day spread over four or five days per week, over three months. Proposals are selected based on a grading system that follows an algorithm that chooses the best quality courses at the best competing prices. In practice, the most valued criteria for course selection are: lowest unit cost per student, and the commitment of the ECAP to place at least $60 \%$ of the trainees in internships. The ECAPs must provide Projoven with a document signed by a firm representative that confirms internship vacancies. On average, per public call, between $40 \%$ and $50 \%$ of course proposals are rejected on the basis of these criteria. ECAPs receive a financial compensation based on the costs of the courses per youth trained at their premises. Compensation is reduced for trainees who either are not placed in an internship or do not complete it.

Projoven has supplied 2,164 courses in its first thirteen public calls. The supply of courses per public call, as mentioned above, is driven mainly by budgetary considerations. Over time, the programme has grown, in terms of the number of class groups ${ }^{2}$, as shown in Figure 2.1, until the ninth public call. Afterwards, the programme experienced some difficulties in obtaining funding. As a consequence, a sudden decline is observed in the supply of courses in the tenth public call. Fortunately, the programme obtained new sources of funding and was able to increase the supply of courses almost to the level of the 2000-2001 public calls.

Probably because of the budget constraints and the course selection mechanism, the costs of the programme are relatively low. Training a youth for six months costs the programme US

\footnotetext{
2 The term "class groups" is used to refer to the number of groups in which a class is taught.
} 
$\$ 530$, meaning the monthly cost of the training is less than US $\$ 100$ (Saavedra and Chacaltana, 2001). As is evident in Figure 2.2, the evolution of unit costs per course per trainee seems to follow a slightly decreasing trend. Providing a trainee with a course becomes somewhat cheaper over time. In principle, this could represent evidence of a learning effect. ECAPs may progressively reduce some of their costs by participating continuously. However, of the 333 ECAPs that have provided courses in Projoven, $68 \%$ participated in only one public call, $18 \%$ in two public calls, $7 \%$ in three public calls, and $7 \%$ in four or more public calls.

\section{Figure 2.1}

Number of class groups per public call. Projoven (1996-2005)

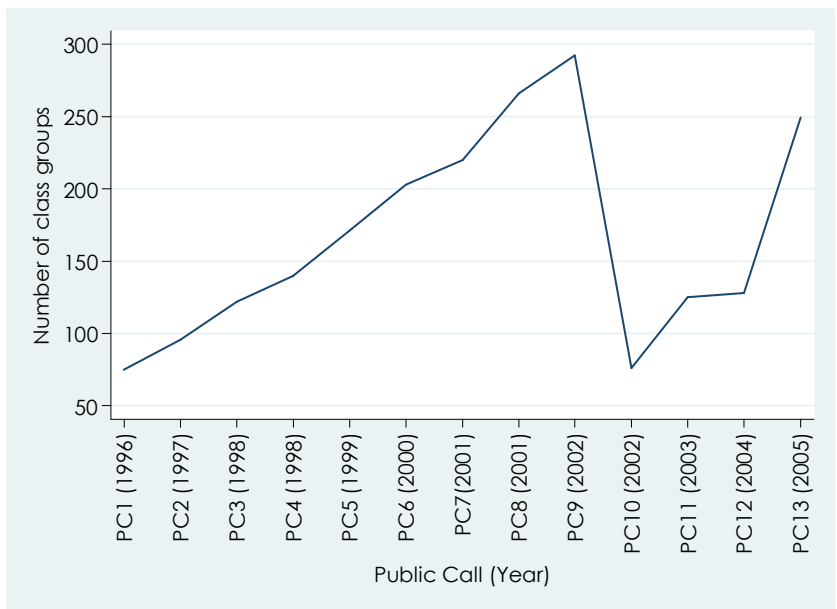

Source: Projoven and further elaboration by the author.

${ }^{*}$ PCi: $i^{\text {th }}$ public call.

\section{Figure 2.2.}

Average ECAP unitary cost per course per trainee per public call. Projoven (1996-2001)

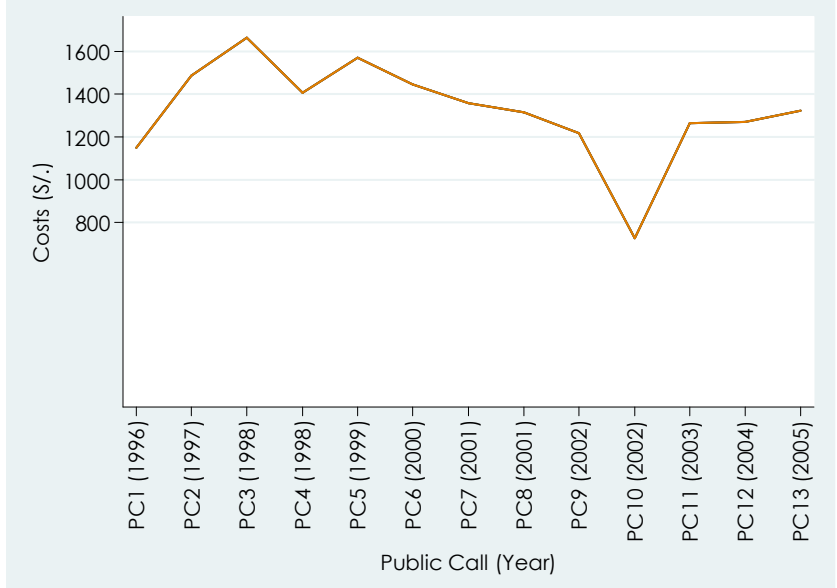

Source: Projoven and further elaboration by the author.

* PCi: ith public call. 
The high proportion of one-time ECAP participants suggests that they are not exploiting learning effects. Perhaps in order to appear as a cost-efficient institution, ECAPs are compromising the quality of training and not making the necessary effort to place all trainees in appropriate internships. Whereas almost all trainees complete the classroom phase and are entitled to pursue an internship, one-quarter of trainees are not placed in internships. Although internship placement is above the $60 \%$ threshold, ideally all trainees should experience the internship phase. This phase plays an important role in providing disadvantaged youths with job readiness skills and trade-specific abilities.

The high proportion of trainees not placed in internships may be explained by institutional arrangements with respect to the selection of courses and ECAP compensation mechanisms. It is possible that the additional compensation for completing two phases does not suffice to cover the marginal costs of placing more trainees in internships. This feature of the course selection mechanism could force training providers to save money by supplying low quality training or by not offering internship placements to all trainees. Providing high-quality training and finding internships for all trainees would increase the cost of the course, reducing the chances of proposal selection.

Distinguishing the treatment effects by training phase is critical in Projoven treatment effect estimations. It will be shown in Chapter 4 that classroom instruction alone yields no returns on trainee labour market outcomes (see also Chacaltana et al., 2003). Although the internship placement performance of ECAPs is above the threshold required by the programme, the fact that not all trainees are placed in internships undermines the programme's effectiveness; this should be taken into account in any evaluation.

\subsubsection{Selection of eligible participants}

Selection of eligible participants follows after course selection. Potential enrolees are targeted based on a poverty map. Projoven's branch offices in the selected cities conduct campaigns to recruit the targeted youth. The target group consists of youths between the ages of 16 and 24, in poverty status, and with low educational attainment (a maximum of secondary education completion). The programme usually places newspaper ads and distributes flyers in strategically selected locations, and invites potential participants and their parents to informational meetings.

Projoven's targeted demographic group was composed of 0.97 million people in 1997, 1.4 million people in 2001, 1.4 million people in 2004, and 0.89 million people in 2007 (See Table 2.1). Consequently, the overall effect of Projoven on the labour market and in the market for vocational training is quite limited. Since 1996, Projoven has benefited only 60,000 youths, less than $7 \%$ of its targeted population regardless of year of reference. The programme is too small to generate a change in the youth labour market and/or in the market for vocational education and training. 
Table 2.1.

Poverty level, in thousands. Urban Peru (1997-2007)

\begin{tabular}{lrrrr}
\hline & $\mathbf{1 9 9 7}$ & \multicolumn{1}{c}{$\mathbf{2 0 0 1}$} & \multicolumn{1}{c}{$\mathbf{2 0 0 4}$} & \multicolumn{1}{c}{$\mathbf{2 0 0 7}$} \\
\hline Total population & $16,064.1$ & $17,560.9$ & $18,240.0$ & $19,001.4$ \\
Below poverty line & $4,706.8$ & $7,305.3$ & $6,675.8$ & $4,845.4$ \\
$\quad$ \%) & 29.3 & 41.6 & 36.6 & 25.5 \\
& & & & \\
Total youths & $3,442.8$ & $3,533.4$ & $3,870.2$ & $3,672.9$ \\
Below poverty line & 970.9 & $1,424.0$ & $1,385.5$ & 899.9 \\
$\quad$ (\%) & 28.2 & 40.3 & 35.8 & 24.5 \\
\hline
\end{tabular}

Source: ENAHO (1997-2005) and further elaboration by the author.

Note: Poverty measures are absolute and are calculated at the household level. Households are referred to as poor if their expenditure per capita does not allow them to afford a basket of goods, which is adjusted by city (defined by the Peruvian National Institute of Statistics - INEI).

Applicants who fulfil the requirements of age, poverty status, and low educational attainment are called back for a detailed evaluation of their eligibility. Potential trainees must fill in a socio-economic evaluation form (FSEE), which collects information about educational attainment, job training experience, labour status, family composition, and living space. Based on this information, Projoven calculates a poverty score. Only participants above a particular poverty threshold are deemed eligible to enrol in the programme. ${ }^{3}$

Table 2.2.

Targeting errors. Projoven (2001-2005)

\begin{tabular}{lcrcc}
\hline $\begin{array}{c}\text { Public } \\
\text { call }\end{array}$ & Year & $\begin{array}{c}\text { Eligible } \\
\text { youths }\end{array}$ & $\begin{array}{c}\text { Undercoverage } \\
\mathbf{( \% )}\end{array}$ & $\begin{array}{c}\text { Leakage } \\
\mathbf{( \% )}\end{array}$ \\
\hline 8th & 2001 & 9,837 & 0.16 & 0.15 \\
9th & 2002 & 10,851 & 0.02 & 0.10 \\
11th & 2003 & 3,977 & 0.60 & 5.98 \\
12th & 2004 & 5,818 & 1.58 & 4.78 \\
13th & 2005 & 11,091 & 0.66 & 5.15 \\
\hline
\end{tabular}

Source: Projoven and further elaboration by the author.

To check for possible targeting errors, the programme interviews a random sample of accredited individuals in their homes. The interview contains the same questions as the FSEE, but the facts can be observed in situ. The rationale here is to uncover problems of leakage and undercoverage. Leakage consists of all those cases that were classified as eligible in the first screening that turned out not to be actually eligible. Undercoverage consists of all those cases that were classified as non-eligible in the first screening that turned out to be eligible. In Table 2.2, it is notable that undercoverage and leakage indicators are below $2 \%$ and $6 \%$, respectively. These figures are rather small in comparison with those of other

\footnotetext{
${ }^{3}$ In order to be eligible, participants should have a poverty score greater than 11 points. The poverty score is based on certain proxies of poverty status without considering income. Table A2.1 of the appendix explains the detailed composition of the poverty score index.
} 
Peruvian social programmes. Alcazar et al. (2003) argue that food programmes and day care programmes targeting children present leakage and undercoverage levels above $40 \%$ and $50 \%$, respectively. Therefore, Projoven seems to be effective in terms of targeting.

The profile of Projoven trainees indicates that the programme attracts the poorest among the poor and that more than $50 \%$ of trainees are employed prior to training. In Table 2.3, it is observed (for public calls of the programme that have been evaluated) that the control groups and trainees are similar in observables such as gender, age, education and employment. These characteristics make both groups eligible at baseline (two to three months prior to training). However, according to the table, trainees seem to be poorer and earn less than their peers in the control groups. ${ }^{4}$ The averages of monthly wages displayed in Table 2.3 are in nominal terms. These wages are also lower than the national averages for youths (around S/. 539 in Lima and S/. 357 in urban Peru).

Table 2.3.

Characteristics of treated individuals and control groups. Projoven (1997-2001)

\begin{tabular}{|c|c|c|c|c|c|c|c|c|}
\hline & \multicolumn{2}{|c|}{$\begin{array}{l}\text { First public call } \\
\text { (1997) }\end{array}$} & \multicolumn{2}{|c|}{$\begin{array}{c}\text { Fourth public call } \\
\text { (1999) }\end{array}$} & \multicolumn{2}{|c|}{$\begin{array}{l}\text { Sixth public call } \\
(2000)\end{array}$} & \multicolumn{2}{|c|}{$\begin{array}{c}\text { Eighth public call } \\
(2001)\end{array}$} \\
\hline & Trainees & $\begin{array}{c}\text { Control } \\
\text { group }\end{array}$ & Trainees & $\begin{array}{c}\text { Control } \\
\text { group }\end{array}$ & Trainees & $\begin{array}{l}\text { Control } \\
\text { group }\end{array}$ & Trainees & $\begin{array}{c}\text { Control } \\
\text { group }\end{array}$ \\
\hline Male (\%) & 43.4 & 43.4 & 44.1 & 43.6 & 48.1 & 49.9 & 46.3 & 45.4 \\
\hline Av. Age & 19.5 & 20.2 & 20.3 & 20.0 & 19.6 & 19.8 & 19.0 & 19.0 \\
\hline $\begin{array}{l}\text { Secondary } \\
\text { education (\%) }\end{array}$ & 85.5 & 83.6 & 82.5 & 80.36 & 79.8 & 79.7 & 49.5 & 45.6 \\
\hline $\begin{array}{l}\text { Employment } \\
(\%)\end{array}$ & 54.0 & 51.8 & 56.7 & 56.0 & 62.8 & 60.9 & 54.7 & 54.8 \\
\hline $\begin{array}{l}\text { Av. monthly } \\
\text { wages (S/.) }\end{array}$ & 209.7 & 300.5 & 179.4 & 211.0 & 238.3 & 315.9 & 166.4 & 239.0 \\
\hline
\end{tabular}

As is evident in Table 2.3, between $54 \%$ and $63 \%$ of trainees are employed prior to enrolment in the programme. A similar range (between $52 \%$ and $61 \%$ ) is observed in the control group. Urgent household needs and the absence of proper welfare programmes force disadvantaged youths to leave school and enter the labour market early. They often end up working in the informal sector under precarious conditions. Trainee employment conditions prior to enrolment in the programme may hold implications for the evaluation of training effectiveness. If trainees were working prior to enrolment in the programme, no (or low) effect would be observed in terms of overall employment. The presence of trainees working prior to enrolment in the programme does not imply that they do not need the programme. Since they work in the informal labour market, the programme should aim at improving the quality of their employment conditions, via the provision of skills. Consequently,

\footnotetext{
${ }^{4}$ Individuals in the control group are selected among eligible youths in the neighbourhood of the trainees. Individuals in the control group are matched one-to-one with the trainees based on the following criteria: sex, age (+/- one year), education level, and poverty score (+/- five points).
} 
employment in the formal labour market could be more indicative of Projoven's effectiveness.

The fact that half of trainees work prior to enrolment in the programme could hold additional implications for Projoven's treatment effects estimations. Training could yield lower returns to individuals with work experience as these individuals have a higher marginal productivity. This makes sense when additional training efforts yield decreasing returns and merely teach skills that youths with work experience already have.

In summary, overall employment alone is not sufficient to measure Projoven's performance. Another qualitative measure of employment, such as formal employment, could provide more evidence as to the effectiveness of the programme. In addition, since the effect of the programme may depend on trainee employment condition prior to training, treatment effect evaluation should take this heterogeneity into account.

\subsubsection{ECAP selection process}

After the selection of eligible participants by the programme, the ECAP selection process of eligible trainees takes place. Eligible youths attend a meeting where they are informed about the available courses. The advantage of matching the courses closely with their skills is pointed out. Next, the potential participants take a vocational test and choose three course options. The test assesses the capacity of the applicant to execute simple arithmetic operations. The rationale for the test is to ascertain that potential trainees match the prerequisites of particular courses. For the most requested courses, Projoven sends up to three potential trainees for every vacancy available in each ECAP, based on trainee preferences and the results of the vocational test. Afterwards, the ECAP selects applicants based on interviews. No additional tests are allowed. Trainees not given their first option are reallocated according to their preferences in less sought-after courses.

According to Projoven (2002), for the ninth public call only $23 \%$ of the participants who started with the programme had enrolled in the course they chose initially. The rest were redistributed among their second or third alternatives. The most desired courses are computer operator, textile operator, cloth finisher, counting clerk and clerical assistant, whereas the less desired courses are sales clerk, housekeeper and house cleaner. The main reasons eligible youths argue for not taking these courses are the fact that the payment for these jobs depends on commissions or that they are carried out in precarious conditions (Projoven, 2002).

The ECAP selection procedure may affect some interim outcomes of the programme. If trainees follow courses they are not interested in, they are more prone to drop out. In fact, the take-up ratio of the programme is quite low. As observed in Figure 2.3, the proportion of eligible individuals actually taking the courses ranges between $42 \%$ and $60 \%$ across public calls. This outcome could be signalling that the information sessions fail to sufficiently guide 
youths with respect to matching courses and capabilities. The low take-up rate diminishes ECAP capacity to cream (select trainees), as sometimes vacancies are difficult to fill. This generally causes delays in the starting dates of the courses.

Figure 2.3.

Take-up rate. Projoven (1996-2005)

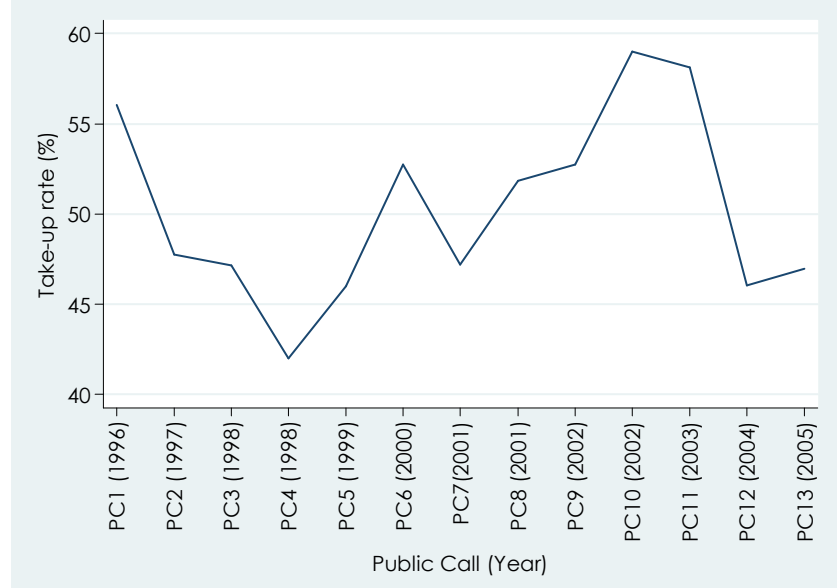

Source: Projoven and further elaboration by the author.

* PCi: $i^{\text {th }}$ public call.

\subsubsection{Classroom instruction phase}

Actual training begins after these preparatory phases. The first training phase, the threemonth classroom instruction, consists of training courses in standard settings in the form of classes and workshops. Projoven assumes tuition costs and pays the trainees' stipends to cover transportation and food expenses. This amount can be marginally higher for women with children, in order to encourage their participation. Participants are also covered by basic health insurance financed by Projoven during the instruction period. Practically all trainees complete the classroom phase of the programme; on average, only $3 \%$ of trainees drop out of this phase, for reasons related mainly to health. Classroom phase completion is not conditional on further examinations. Attendance is the only requirement.

The courses must follow the job competence approach stated by Projoven in its manual. A job competence involves skills and aptitudes to solve problems and fabricate products (or perform services) within a particular occupation. Course design must be based on the training needed for a specific trade. To elaborate the design, the programme states that ECAPs should use interviews with firms and workers performing that trade in their geographical area. Overly specific training could jeopardise employment opportunities for trainees after the programme since it would not be transferable to another firm. 
An extensive analysis of the Projoven courses is carried out by Chacaltana et al. (2003). That study concluded that, in some cases, it is not possible to develop the required vocational competences given a time frame of three months. Chacaltana et al. (2003) present the example of the curriculum of a Projoven course of operator for textile machines, which they compared with what is needed for the same course in a well-known technical school. These authors conclude that the classroom instruction necessary for training in operating textile machines takes longer than three months. Technical schools even provide additional preparatory courses before embarking on the use of textile machines - without them it may not be possible to grasp the knowledge necessary to operate a textile machine.

\subsubsection{On-the-job training phase}

The final phase of the programme is a three-month on-the-job training internship. All participants who complete the classroom instruction, with attendance being the only requirement, are entitled in principle to start the on-the-job training phase. During the internship, the trainees should be under the supervision of a tutor. The assigned internship must consist of activities that complement the training received during the classroom phase. The ECAPs are responsible for the compatibility of course content with the internship.

Projoven establishes that training firms must hire trainees under a youth training contract (convenios de capacitación laboral juvenil - CCLJ). The CCLJ is designed for young lowskilled workers between ages 16 and 24 (Projoven's target group). The contract establishes that a working day cannot last more than eight hours and the trainee should not work more than 48 hours per week. The term of the contract should not last more than six months. With respect to pay, the wage should not be lower than the minimum wage. ${ }^{5}$ The contract may be extended for an additional six months after documenting proof of the need for the extension in terms of the trainee's education. CCLJ contracts are exempted from the usual social security contributions. Firms can also deduct from taxes their expenditures on wages paid under this modality. All trainees hired under the CCLJ must be covered with an insurance policy against diseases and accidents.

Projoven's requirement of the use of CCLJ contracts may increase training firms' transaction costs and thereby diminish trainee's opportunities to be placed in internships. The official minimum wage, required by Projoven during the internship, is higher than what an unskilled worker is willing to work for as an unregistered worker (black payroll). In the labour market, there are individuals available and able to work for less than the minimum wage for the same types of jobs that trainees would be performing. This is especially true outside Lima. In addition, CCLJ agreements are meant to last a maximum of only six months. They may be extended for an additional six months after a bureaucratic procedure. If training is not seen as an investment in human capital, it is very unlikely that firms will retain trainees longer than six months. If trainees stay longer, the firm should hire them on a regular basis, and this, in terms of non-wage labour costs, is relatively more expensive. Non-

\footnotetext{
${ }^{5}$ In the case of part-timers, the payment will be prorated.
} 
wage labour costs account for $30 \%$ of gross wages. Increments in transaction costs cause the effective post-training period to be shortened (Arulampalam et al., 1997). In fact, less than $7 \%$ of trainees remain at their training firm more than six months after the end of the internship.

Although Projoven states that trainees must be hired under a CCLJ contract, there are indications that not all training firms comply with this regulation. In Table 2.4, it is evident that in the sixth public call, in Lima and Chiclayo, $19 \%$ and $27 \%$, respectively, of the trainees worked without a written contract during the internship phase. Working without a written contract implies no insurance coverage and is also synonymous with long working hours, no wage payment guarantee, and an unsafe work environment (Velazco, 2004).

Table 2.4.

Trainees by type of contract. Projoven (2000)

\begin{tabular}{lcc}
\hline & Lima & Chiclayo \\
\hline & 100 & 100 \\
Total (\%) & & \\
With a written contract & 52.4 & 16.4 \\
$\quad$ Finished internship & 10.0 & 15.5 \\
$\quad$ Did not finish internship & & \\
Without a written contract & 1.9 & 5.5 \\
$\quad$ Finished internship & 17.5 & 21.8 \\
$\quad$ Did not finish internship & 18.3 & 40.9 \\
No internship & \multicolumn{2}{c}{} \\
\hline Source: Follow-up survey Projoven sixth public call and further elaboration by the author.
\end{tabular}

Projoven lacks an effective enforcement system to supervise the development of the internship phase. Training firms are not accountable to Projoven directly. It is the ECAP that is responsible for proper development of the internship. The programme penalizes ECAPs with a lower payment if trainees do not complete the two phases of the programme. The programme interviews a sample of trainees and training firm managers. However, no penalty is stipulated if a trainee is performing a task not related to the classroom phase, the trainee is not adequately supervised during the internship, or (s)he is not hired under a written contract.

A possible consequence of internships carried out under precarious conditions (without a contract) can be observed in Projoven's dropout rates. Approximately $30 \%$ of trainees placed in internships drop out. This is critically important, as Chacaltana et al. (2003) and Chapter 4 of this dissertation argue that the training must be completed in order to yield returns. As discussed in Chapter 5, the absence of a written contract is one of the predominant factors affecting the individual likelihood to drop out of Projoven internships. This voluntary dropout phenomenon could imply a source of bias in the programme's treatment effects estimation, and therefore should be accounted for in the Projoven treatment effect evaluation. 


\subsection{Conclusions}

Understanding Projoven's institutional framework is important, as this framework describes the systemic relationships between training interventions and the circumstances under which they are more (or less) beneficial. This chapter reaches three general conclusions about critical elements of the institutional framework of Projoven. These conclusions should be taken into account in programme evaluation because they may explain some of the findings about the effectiveness of the programme.

First, Projoven's impact evaluation should account for the fact that not all trainees are placed in internships. Prioritising training providers with low unit costs per course might be beneficial in terms of programme efficiency, but not in terms of, for instance, programme effectiveness, among other considerations. Low-cost courses not only compromise training quality, but may reduce the chances that trainees will be placed in internships. The financial compensation mechanisms and the relatively low official threshold may fail to motivate ECAPs to make the necessary effort to place all trainees in proper internships. Distinguishing training effects by phase could shed new light on the effectiveness of the training.

Second, in addition to evaluating the various programme phases, it is important to consider the level of completion of those training phases. In Projoven, 30\% of trainees placed in internships drop out. The fact that trainees voluntarily receive different 'doses' of training (and drop out) should be accounted for in the evaluation of Projoven's impact.

Third, in a developing-country context with a dual labour market, a training programme evaluation should consider alternative indicators of performance. Overall employment may not suffice as an indicator to evaluate the impact of the programme if, say, half of the trainees were employed prior to enrolment in the programme (mainly in the informal sector). In such case, the observed effects in terms of employment would be attenuated. A better indicator of the programme's performance with respect to employment would be formal employment. In addition, the presence of trainees employed prior to the programme indicates that different sources of individual heterogeneity should be considered. The effects of the programme may depend on trainees' prior work experience. Projoven's treatment effect evaluation should account for this level of individual heterogeneity.

This study warns training practitioners and researchers that institutional and implementation characteristics may be systematically associated with training outcomes. In the case of Projoven, its impact evaluation could be affected by the fact that not all trainees are placed in an internship, that a fraction of trainees drop out of the programme, that an alternative definition of employment should be considered, and that the programme may yield differing returns depending on the trainee's work experience. This chapter also shows the need for a better monitoring system for Projoven. Economically disadvantaged youth need to be provided not only with training but with hope that the accumulation of skills will pay off. This is not observed because training firms seldom retain trainees, and in $25 \%$ of cases do not even offer them a contract during the internship. Enforcement mechanisms 
Chapter 2. Projoven's Institutional Framework

should ensure the fulfilment of training and internship agreements. The goal is to offer higher quality internships in order to improve trainee labour market outcomes. 


\section{Appendix}

Table A2.1.

Poverty score index composition.

\begin{tabular}{|c|c|c|c|c|c|c|c|c|}
\hline Item & Category 1 & Score & Category 2 & Score & Category 3 & Score & Category 4 & Score \\
\hline $\begin{array}{l}\text { Household } \\
\text { Floor }\end{array}$ & Dirt & 4 & Wood & 3 & Cement & 2 & Vinyl & 0 \\
\hline $\begin{array}{l}\text { Household } \\
\text { ceiling }\end{array}$ & Residuals & 4 & Cardboard & 3 & Plastic, wood & 2 & $\begin{array}{l}\text { Cement, } \\
\text { concrete }\end{array}$ & 0 \\
\hline $\begin{array}{l}\text { Household } \\
\text { walls }\end{array}$ & Cardboard & 4 & Wood & 3 & $\begin{array}{l}\text { Brick } \\
\text { uncompleted }\end{array}$ & 2 & $\begin{array}{l}\text { Brick } \\
\text { completed }\end{array}$ & 0 \\
\hline $\begin{array}{l}\text { Source of } \\
\text { Potable water }\end{array}$ & $\begin{array}{l}\text { River or } \\
\text { tanker }\end{array}$ & 4 & Well & 3 & $\begin{array}{l}\text { Outdoor } \\
\text { public } \\
\text { network }\end{array}$ & 1 & $\begin{array}{l}\text { Indoor } \\
\text { public } \\
\text { network }\end{array}$ & 0 \\
\hline Toilet & No toilet & 4 & latrine & 3 & $\begin{array}{l}\text { Outdoor } \\
\text { public } \\
\text { network }\end{array}$ & 2 & $\begin{array}{l}\text { Indoor } \\
\text { public } \\
\text { network }\end{array}$ & 0 \\
\hline Overcrowding ${ }^{\mathrm{a}}$ & $>=5$ & 4 & $>=4$ and $<5$ & 3 & $>=3$ and $<4$ & 2 & $<3$ & 0 \\
\hline $\begin{array}{l}\text { Household } \\
\text { head education } \\
\text { level }\end{array}$ & $\begin{array}{l}\text { No } \\
\text { education or } \\
\text { uncompleted } \\
\text { primary }\end{array}$ & 4 & $\begin{array}{l}\text { Secondary } \\
\text { education }\end{array}$ & 2 & $\begin{array}{l}\text { Uncompleted } \\
\text { tertiary } \\
\text { education }\end{array}$ & 1 & $\begin{array}{l}\text { Completed } \\
\text { tertiary } \\
\text { education }\end{array}$ & 0 \\
\hline $\begin{array}{l}\text { Dependency } \\
\text { ratiob }\end{array}$ & $>=3$ & 4 & $>=2$ and $<3$ & 2 & $<2$ & 0 & & \\
\hline
\end{tabular}

Source: Burga (2003).

Notes: a Ratio household size / number of rooms.

$\mathrm{b}$ Ratio non-working household members / number working household members. 
Chapter 2. Projoven's Institutional Framework 


\section{Chapter 3}

\section{Projoven Evaluation Data}

\subsection{Introduction}

In this chapter, the characteristics of the dataset used to evaluate the Projoven training programme are reviewed. Because the data reveal the existence of a pre-programme earnings dip which can bias the treatment effects estimations, a way to deal with this phenomenon is presented. Basically, a new control group that is a subsample of the individuals in the official control group is created using propensity score matching with replacement. The rationale is to create a more comparable control group to identify Projoven's treatment effects. In addition, this chapter checks how sensitive the estimates are under the presence of unobservables, calculating the Rosenbaum (1995) bounds.

The Projoven sixth public call data set is used for this study's estimations since is the most complete one available. This unique data set combines not only demographic information about trainees and the control group, but also administrative records on the level of training completed. It allows matching individual trainees with their specific training provider. Moreover, this was the only data set with the characteristics required for this study. Although the programme possesses data for other public calls (for the first, second, fourth and eighth) its availability is limited. The author attempted to acquire the other data sets by all means available. Unfortunately, whether the transparency of information has been blocked for political motives or simply due to staff negligence, acquiring the data was not possible. Díaz and Jaramillo (2006) argue that the Programme's evaluation data has not been well kept. These authors sustain that important portions of information are missing. In particular, in the first and second public calls employment histories were collected during baseline data field work, but never put in magnetic format. A similar problem occurs in the third follow-up survey of the eighth public call, whereby data were gathered in the field work, but delays in processing the questionnaires into magnetic format meant that programme officers put them into storage but they were ultimately lost during office relocation. Given these circumstances, most of the existing studies evaluating Projoven's impact have been conducted or sponsored by the programme or by former employees of the institution.

This chapter has four sections. After the introduction, Section 3.2 provides a general description of the sixth public call, describing the different levels of participation, how the control group was built, and the presence of a pre-treatment earnings dip among trainees. Section 3.3 presents a potential way of dealing with the pre-treatment earnings dip of Projoven participants. Finally, Section 3.4 gives some concluding remarks. 


\subsection{Projoven Sixth Public Call}

The Projoven sixth public call data set consists of a baseline survey, conducted in November 1999 (two to three months prior to programme commencement), and three follow-up comparison surveys at intervals of six months (May 2001); twelve months (November 2001); and eighteen months (May 2002) after the end of the internships. Consequently, it is possible to observe individuals at four points in time. ${ }^{1}$

In the sixth public call, Projoven trained 3,651 youths in the urban areas of five Peruvian cities: Lima, Trujillo, Chiclayo, Arequipa and Cusco. To assess its impact Projoven selects randomly 1,014 trainees from all trained youths. Thus, the Projoven sixth public call data set includes 1,014 participants and an equal number of control group individuals. Only $2.2 \%$ of sampled trainees failed to complete classroom training. Some $19.1 \%$ of trainees completed the classroom phase but were not placed in training firms by the ECAPs. Some $21.7 \%$ of trainees completed the classroom training phase, but not the on-the-job training phase. The remaining $57 \%$ of trainees completed both phases of Projoven.

Participants who dropped out within the first three months of the programme are excluded from the estimation sample $(2.2 \%)$ since it is unlikely that the programme yields measurable returns to trainees after such a short period and their number is too small to draw specific inferences. Thus, in the estimation sample any participation in the programme implies completion of at least the classroom phase. This study will, however, allow the training effect to vary by completion level of the internship.

To construct its official control group, Projoven selects three comparable individuals per trainee, all required to be eligible and to satisfy enrolment requirements of age, poverty status and educational attainment. The selection of control group individuals begins two months after training begins. The programme searches for potential controls in the same neighbourhoods as the actual trainees, or in the closest possible neighbourhoods within the same district. The rationale for this is that neighbourhood characteristics control for unobservable factors such as geographic segregation, transportation costs, firm location, and so on, which may affect the likelihood of finding employment, and the potential outcomes of the training programme (Chong and Galdo, 2006). According to Friedlander and Robins (1995), the selection of control group individuals from the same geographic areas as the actual trainees produces treatment effect estimators that are close to the experimental ones. Projoven matches individuals in the control group with the trainees based on sex, age, labour status, poverty score and education level. To be an adequate control for a participant trainee, an individual must:

\footnotetext{
${ }^{1}$ Although the classroom training courses start at the same time, some delays occur before on-the-job training begins. Consequently, not all internships conclude at the same time. This affects the time at which follow-up surveys are carried out.
} 
- be of the same sex as the participant,

- be within a two-year age range around that of the participant,

- be within a five-point range with regard to the poverty score, and

- have the same education level as the trainee.

All criteria must be satisfied simultaneously. Next, among the three controls selected per beneficiary, Projoven cleans and matches them one-to-one using a Mahalanobis metric approach. ${ }^{2}$ The group selected with this one-to-one matching is the one which is called "official control group" in this study. Unfortunately, the information about the other potential control group individuals was not available for similar reasons as those explained at the beginning of the chapter.

Projoven's control matching is based on individual information at baseline (November 1999, two to three months prior to programme start). In the first two columns, [A] and [B], of Table 3.1, it is observed that Projoven's official control group and treatment group are almost exactly matched in terms of cities of origin, education level, poverty score, labour status and age. However, there are notable differences in labour income and working hours along with other variables. For instance, the difference in household income per capita suggests that the treated group is poorer than the control group. Paradoxically, the poverty score suggests the opposite. The poverty score is composed of poverty indicators other than income (Chapter 2). Additionally, being a non-wage family-business worker, not being married, not having children, and parents' higher education level seem to encourage enrolment in training. Another substantial difference between groups A and B relates to monthly wages prior to training. The average monthly wage for the control group is nearly $50 \%$ more than the equivalent measure for the treated group. Such differences cast doubt on the validity of comparing the treatment and control groups for the evaluation of the training programme's impact. This phenomenon is sometimes referred to as evidence of Ashenfelter's dip. ${ }^{3}$ In a famous article, published in 1978, Orley Ashenfelter evaluated the impact on earnings of the Manpower Development and Training Act (MDTA). He observed that trainee earnings tend to fall (absolutely and relatively), compared to the control group, the year immediately prior to treatment. Heckman and Smith (1999) argue that this represents evidence of sample selection and is a characteristic of virtually all training programmes, which occurs despite the substantial variation in eligibility rules among training programmes.

The occurrence of such a pre-programme dip suggests that part of the observed increase in earnings that seems to follow a training programme may be explained as a return to a permanent path of earnings, temporarily interrupted by a transitory downward shock. Trainees may self-select into the programme because they have, precisely, lower earnings.

\footnotetext{
${ }^{2}$ Under this method, every trainee $i$ is matched with the control individual $j$ whose Mahalanobis distance is minimum. Mahalanobis distance: $\sqrt{\left(S_{i}-S_{j}\right)^{t} \Sigma^{-1}\left(S_{i}-S_{j}\right)}$, where $S_{i}$ is a vector containing the variables subject to matching for individual $i$, in this case sex, age, poverty score and education, and $\sum$ is an estimate of the variance-covariance matrix of the variables in $S_{i}$ and $S_{j}$.

${ }^{3}$ See Ñopo and Saavedra (2003), Ñopo et al. (2002), Projoven (2004), and Projoven (2005).
} 
Consequently, before and after comparisons of trainee earnings might be seriously misleading evidence on the effect of training on earnings.

Table 3.1.

Baseline summary statistics [2-3 months before training]. Projoven sixth public call.

\begin{tabular}{|c|c|c|c|c|c|c|c|c|}
\hline & \multicolumn{2}{|c|}{$\begin{array}{c}\text { Official control } \\
\text { group [A] }\end{array}$} & \multicolumn{2}{|c|}{$\begin{array}{c}\text { Treated group } \\
{[\mathrm{B}]}\end{array}$} & \multicolumn{2}{|c|}{$\begin{array}{l}\text { New control } \\
\text { group }[\mathrm{C}]\end{array}$} & \multicolumn{2}{|c|}{$\begin{array}{c}p \text {-value [mean } \\
\text { differences] }^{\mathrm{c}}\end{array}$} \\
\hline & Mean & $\begin{array}{l}\text { Std. } \\
\text { dev. }\end{array}$ & Mean & $\begin{array}{l}\text { Std. } \\
\text { dev. }\end{array}$ & Mean & $\begin{array}{l}\text { Std. } \\
\text { dev. }\end{array}$ & $\begin{array}{c}\text { [A] vs. } \\
{[\mathrm{B}]}\end{array}$ & $\begin{array}{c}\text { [B] vs. } \\
{[C]}\end{array}$ \\
\hline Total & \multicolumn{2}{|c|}{1,014} & \multicolumn{2}{|c|}{992} & \multicolumn{2}{|c|}{992} & & \\
\hline \multicolumn{9}{|l|}{ City } \\
\hline Arequipa & 0.20 & $(0.40)$ & 0.21 & $(0.41)$ & 0.21 & $(0.41)$ & 0.804 & 1.000 \\
\hline Chiclayo & 0.12 & $(0.33)$ & 0.11 & $(0.31)$ & 0.11 & $(0.31)$ & 0.509 & 1.000 \\
\hline Cusco & 0.12 & $(0.32)$ & 0.12 & $(0.32)$ & 0.12 & $(0.32)$ & 0.858 & 1.000 \\
\hline Lima & 0.36 & $(0.48)$ & 0.36 & $(0.48)$ & 0.36 & $(0.48)$ & 0.963 & 1.000 \\
\hline Trujillo & 0.20 & $(0.40)$ & 0.20 & $(0.40)$ & 0.20 & $(0.40)$ & 0.938 & 1.000 \\
\hline Age (years) & 19.76 & $(2.35)$ & 19.60 & $(2.44)$ & 19.72 & $(2.41)$ & 0.133 & 0.301 \\
\hline Female & 0.51 & $(0.50)$ & 0.52 & $(0.50)$ & 0.55 & $(0.50)$ & 0.790 & 0.163 \\
\hline Poverty score & 18.95 & $(2.95)$ & 16.71 & $(4.13)$ & 18.78 & $(2.97)$ & 0.000 & 0.000 \\
\hline Household income per capita (S/.) & 150.27 & $(85.28)$ & 127.40 & $(91.31)$ & 129.79 & $(77.95)$ & 0.000 & 0.476 \\
\hline Child & 0.24 & $(0.43)$ & 0.14 & $(0.35)$ & 0.15 & $(0.36)$ & 0.000 & 0.487 \\
\hline Married & 0.22 & $(0.41)$ & 0.10 & $(0.30)$ & 0.12 & $(0.32)$ & 0.000 & 0.253 \\
\hline Years schooling & 10.45 & $(1.30)$ & 10.45 & $(1.34)$ & 10.42 & $(1.34)$ & 1.000 & 0.558 \\
\hline Father tertiary education & 0.08 & $(0.27)$ & 0.12 & $(0.33)$ & 0.10 & $(0.30)$ & 0.001 & 0.085 \\
\hline Mother tertiary education & 0.03 & $(0.17)$ & 0.06 & $(0.25)$ & 0.04 & $(0.18)$ & 0.000 & 0.005 \\
\hline \multicolumn{9}{|l|}{ Labour market status } \\
\hline Employed & 0.60 & $(0.49)$ & 0.60 & $(0.49)$ & 0.60 & $(0.49)$ & 0.964 & 1.000 \\
\hline Formally employed ${ }^{a}$ & 0.05 & $(0.23)$ & 0.05 & $(0.22)$ & 0.05 & $(0.23)$ & 0.690 & 0.879 \\
\hline Unemployed & 0.29 & $(0.46)$ & 0.27 & $(0.44)$ & 0.26 & $(0.44)$ & 0.183 & 0.839 \\
\hline Inactive & 0.10 & $(0.30)$ & 0.13 & $(0.34)$ & 0.13 & $(0.34)$ & 0.052 & 0.790 \\
\hline \multicolumn{9}{|l|}{$\begin{array}{l}\text { Transitions (\%) (from October } 1999 \\
\text { to November 1999) }\end{array}$} \\
\hline Unemployed/OLF -> employed & 0.08 & $(0.27)$ & 0.08 & $(0.28)$ & 0.10 & $(0.29)$ & 0.872 & 0.269 \\
\hline $\begin{array}{l}\text { Employed -> Unemployed/OLF } \\
\text { Unemployed/OLF -> }\end{array}$ & 0.04 & $(0.20)$ & 0.04 & $(0.20)$ & 0.03 & $(0.17)$ & 0.911 & 0.230 \\
\hline Unemployed/OLF & 0.41 & $(0.49)$ & 0.46 & $(0.50)$ & 0.42 & $(0.49)$ & 0.025 & 0.161 \\
\hline Employed -> employed & 0.47 & $(0.50)$ & 0.42 & $(0.49)$ & 0.45 & $(0.50)$ & 0.018 & 0.222 \\
\hline No work experience & 0.28 & $(0.45)$ & 0.37 & $(0.48)$ & 0.35 & $(0.48)$ & 0.000 & 0.242 \\
\hline Non-wage family-business worker & 0.07 & $(0.25)$ & 0.13 & $(0.34)$ & 0.17 & $(0.37)$ & 0.000 & 0.039 \\
\hline \multicolumn{9}{|l|}{ Wages $^{b}(S / .2001)$} \\
\hline Monthly & 238.71 & $(148.21)$ & 158.93 & $(134.78)$ & 173.65 & $(135.14)$ & 0.000 & 0.053 \\
\hline Hourly & 1.49 & $(1.05)$ & 1.12 & $(0.92)$ & 1.23 & $(1.07)$ & 0.000 & 0.049 \\
\hline Working hours ${ }^{\mathrm{b}}$ (week) & 55.21 & $(139.06)$ & 46.76 & $(114.75)$ & 42.30 & $(83.67)$ & 0.249 & 0.444 \\
\hline
\end{tabular}

a The operative definition of formal employment used in this study considers jobs which satisfy at least one of the following conditions: having a written contract or with access to social security, or with access to accident/health insurance.

$\mathrm{b}$ Only considering individuals working in the reference period.

${ }^{\mathrm{c}}$ Ho: Means differences $=0$.

Source: Projoven.

This phenomenon of a pre-programme earnings dip amongst the trainees is also notable in the fourth, eighth, and tenth public call surveys of Projoven. There are no clear reasons as to 
the origin of this earnings dip; however, Jaramillo and Diaz (2006) suggest that the presence of the pre-programme earnings dip could be related to the time when baseline data are collected. Trainees and control group individuals are both interviewed during the initial weeks of the classroom instruction phase. This timing of the baseline survey may induce systematic but mechanical differences in earnings between trainees and controls. The baseline survey collects information about individual characteristics and their labour market outcomes during the two to three months before treatment. However, given that in most cases trainees already know that they have been selected as such one month before they begin their training courses, their employment status and earnings may be observationally different just because they begin to leave their jobs once they realize they have been admitted into the programme. Thus, it is possible that differences in terms of wages are in part a mechanical result of the timing of the baseline survey fieldwork.

\subsection{Dealing with Projoven Pre-Treatment Earnings Dip}

To the extent that the pre-programme earnings dip constitutes evidence of systematic differences between the treatment and control groups prior to training, it undermines their comparability. Ashenfelter (1978) suggests using an (even) earlier period as the baseline to circumvent possible biases caused by the pre-programme earnings dip. ${ }^{4}$ Unfortunately, in the Projoven dataset, there is no earlier period available. To deal with the pre-treatment wage difference in Projoven data, Nopo and Saavedra (2003); Nopo et al. (2002); Projoven (2004); and Projoven (2005) suggest carrying out an additional individual matching process. This additional matching procedure is adopted in this study to create a more comparable control group.

The matching technique aims to produce a control group of modest size that is similar to the treated group in terms of the distribution of observed characteristics (Rosenbaum and Rubin, 1985). The drawback of this method is that there may be exact matches for only a fraction of trainees (matching one-to-one without replacement). Discarding treated individuals is not an option, especially as the unmatched treated individuals may differ systematically from the matched treated individuals. ${ }^{5}$ In addition, the methodology used in this study to evaluate the effects of Projoven implies reducing sample size in order to compare different groups by level of training completion, which also includes trainees groups. Having smaller groups of trainees by level of completion implies less variation and could affect the reliability of Projoven's treatment effects estimate.

\footnotetext{
${ }^{4}$ According to Ashenfelter (1978), in presence of a decline of earnings before the training period, let's say $t$, the choice of the "base period" is critical. If the decline in earnings occurs in the period preceding the training $(t-1)$, and it is transitory, it does not introduce any bias using as a base period the period before the one when the decline takes place, for instance $t-2$. Whereas, if the decline is permanent, the training effect will be understated by the amount of the decline regardless of the base period chosen.

${ }^{5}$ Leuven and Oosterbeek (2006) discuss the problems inherent in small control groups.
} 
In this study, a new control group using propensity-score matching with replacement is formed to avoid losing some individuals in the treatment group. This new control group is a sub-sample of the official control group. Although matching with replacement leads to higher variance estimators, it produces higher match quality (Abadie and Imbens, 2002). Propensity score matching with replacement also implies that a control unit could be matched with one or more treated individuals.

Propensity score matching synthesises all the observables $\left(X_{i}\right)$ into a single score, the socalled propensity score (Rosenbaum and Rubin, 1983). Similar treated and non-treated individuals are matched based on observables $\left(X_{i}\right)$ which include labour force status transitions, as suggested by Heckman and Smith (1999). To ensure a better match on wages, 20 subsamples (by city, employment status and wages) are created, for which matching based on propensity score is applied. In Table 3.2, the distribution of the groups is shown to confirm the common support property. Basically, there are enough controls per treated individuals in every subsample. The propensity score function is estimated using the complete sample.

Table 3.2.

Common support groups matching methods to conform control group. Projoven sixth public call.

\begin{tabular}{clccc}
\hline Group & \multicolumn{1}{c}{ Characteristics } & Control & Participants & Total \\
\hline Group 1 & Arequipa, not employed & 56 & 59 & 115 \\
Group 2 & Chiclayo, not employed & 60 & 48 & 108 \\
Group 3 & Cusco, not employed & 40 & 43 & 83 \\
Group 4 & Lima, not employed & 177 & 170 & 347 \\
Group 5 & Trujillo, not employed & 69 & 74 & 143 \\
Group 6 & Arequipa, monthly wage $<=100$ & 47 & 100 & 147 \\
Group 7 & Chiclayo, monthly wage $<=100$ & 16 & 31 & 47 \\
Group 8 & Cusco, monthly wage $<=100$ & 20 & 26 & 46 \\
Group 9 & Lima, monthly wage $<=100$ & 29 & 69 & 98 \\
Group 10 & Trujillo, monthly wage $<=100$ & 16 & 39 & 55 \\
Group 11 & Arequipa, 100 $<$ monthly wage $<=300$ & 68 & 39 & 107 \\
Group 12 & Chiclayo, 100 $<$ monthly wage $<=300$ & 40 & 27 & 67 \\
Group 13 & Cusco, 100 $<$ monthly wage $<=300$ & 38 & 32 & 70 \\
Group 14 & Lima, 100 $<$ monthly wage $<=300$ & 86 & 85 & 171 \\
Group 15 & Trujillo, 100 $<$ monthly wage $<=300$ & 75 & 46 & 121 \\
Group 16 & Arequipa, monthly wage $>300$ & 34 & 7 & 41 \\
Group 17 & Chiclayo, monthly wage $>300$ & 6 & 4 & 10 \\
Group 18 & Cusco, monthly wage $>300$ & 19 & 16 & 35 \\
Group 19 & Lima, monthly wage $>300$ & 76 & 37 & 113 \\
Group 20 & Trujillo, monthly wage $>300$ & 42 & 40 & 82 \\
Total & & $\mathbf{1 0 1 4}$ & $\mathbf{9 9 2}$ & \\
\hline
\end{tabular}

Propensity score matching assumes that Projoven selection into treatment (undertaking Projoven training) is based on observables. Additionally, it requires the overlap condition, which states that for each value of $X_{i}$ observed for a treated case $i$, there are nontreated cases with the same values. The overlap condition is represented as: 
[Eq. 3.1] $0<\operatorname{Pr}\left[\right.$ Projoven $\left._{i}=1 \mid X_{i}\right]<1$.

Another assumption required is the conditional mean independence assumption

[Eq. 3.2] $E\left[Y_{i}^{0} \mid\right.$ Projoven $\left._{i}=1, X_{i}\right]=E\left[Y_{i}^{0} \mid\right.$ Projoven $\left._{i}=0, X_{i}\right]=E\left[Y_{i}^{0} \mid X_{i}\right]$,

which implies that the potential outcome of the individual $i$ when (s)he has not undertaken Projoven training $\left(Y_{i}^{0}\right)$ does not determine participation. The propensity score is a conditional probability measure of training participation given $X_{i}$ and is denoted $p\left(X_{i}\right)$, where

[Eq. 3.3] $p\left(X_{i}\right)=\operatorname{Pr}\left[\operatorname{Projoven}_{i}=1 \mid X_{i}\right]$.

Table 3.3.

Propensity score estimation. Probit model. Dependent variable: participating in Projoven at baseline [Projoven $=1$ ]. Conditioned on being eligible for the training.

\begin{tabular}{|c|c|c|}
\hline & $\begin{array}{c}\text { Marginal } \\
\text { effects }\end{array}$ & Std. err. \\
\hline Ln hh income per capita & $-0.050^{*}$ & $(0.027)$ \\
\hline Lowest quartile hh income per capita & $0.063^{*}$ & $(0.038)$ \\
\hline Age & $0.014^{* * *}$ & $(0.005)$ \\
\hline Household size & -0.004 & $(0.005)$ \\
\hline Female & 0.000 & $(0.024)$ \\
\hline Married & $-0.171^{* * *}$ & $(0.039)$ \\
\hline Child & -0.060 & $(0.043)$ \\
\hline Years schooling & -0.013 & $(0.009)$ \\
\hline Father tertiary education & $0.071^{*}$ & $(0.040)$ \\
\hline Mother tertiary education & $0.165^{\star * *}$ & $(0.060)$ \\
\hline Additional training course & $0.098^{* \star *}$ & $(0.027)$ \\
\hline Unemployed/OLF -> employed & 0.008 & $(0.043)$ \\
\hline Employed -> unemployed/OLF & 0.023 & $(0.058)$ \\
\hline $\begin{array}{l}\text { Unemployed/OLF -> } \\
\text { unemployed/OLF }\end{array}$ & $-0.074^{* *}$ & $(0.036)$ \\
\hline No work experience (\%) & $0.175^{* * *}$ & $(0.037)$ \\
\hline Non-wage family business worker & $0.203^{* \star *}$ & $(0.038)$ \\
\hline Num observations & \multicolumn{2}{|c|}{2006} \\
\hline Wald X²(16) & \multicolumn{2}{|c|}{151.97} \\
\hline Log likelihood & \multicolumn{2}{|c|}{-1307.72} \\
\hline Pseudo $\mathrm{R}^{2}$ & \multicolumn{2}{|c|}{0.0594} \\
\hline
\end{tabular}

The propensity score is predicted using a probit model. Table 3.3 reports the probit regression for participation in Projoven conditionally on eligibility. The regression results 
suggest that poverty condition (lower household income and lowest quartile), not being married, parents' higher education level, following other training courses, not being chronically unemployed, not having work experience, and being a non-wage family-business worker seem to encourage enrolment in training. Propensity score matching ensures a better comparability of treatment groups by selecting similar control groups. The variables monthly wages, employment status and cities were excluded from the propensity score estimation. By splitting the sample based on wages, employment status and city, the variation of the propensity score given these variables has been already accounted for.

A fourth important assumption playing a role in propensity score matching is the balancing condition

[Eq. 3.4] Projoven $_{i} \perp X_{i} \mid p\left(X_{i}\right)$.

The balancing condition expresses that for individuals with the same propensity score, or in the neighbourhood, the assignment to treatment is random and should look identical in terms of $X_{i}$ (Cameron and Trivedi, 2005).

Based on the previous assumptions, Rosenbaum and Rubin (1983) show that conditional on the propensity score, the outcome of the treatment is independent of the participation, as if participation was randomized. In other words, the matching process, by creating a new control group, makes the participation in the programme independent of the outcome. The latter is a crucial condition to evaluate the effect of the treatment as it circumvents the nonrandom assignment into the treatment (self-selection into treatment). Figure 3.1 displays the distribution of the estimated propensity scores.

Figure 3.1.

Kernel densities propensity score (predicted probability of participating in the training). Control group and participants in Projoven sixth public call.
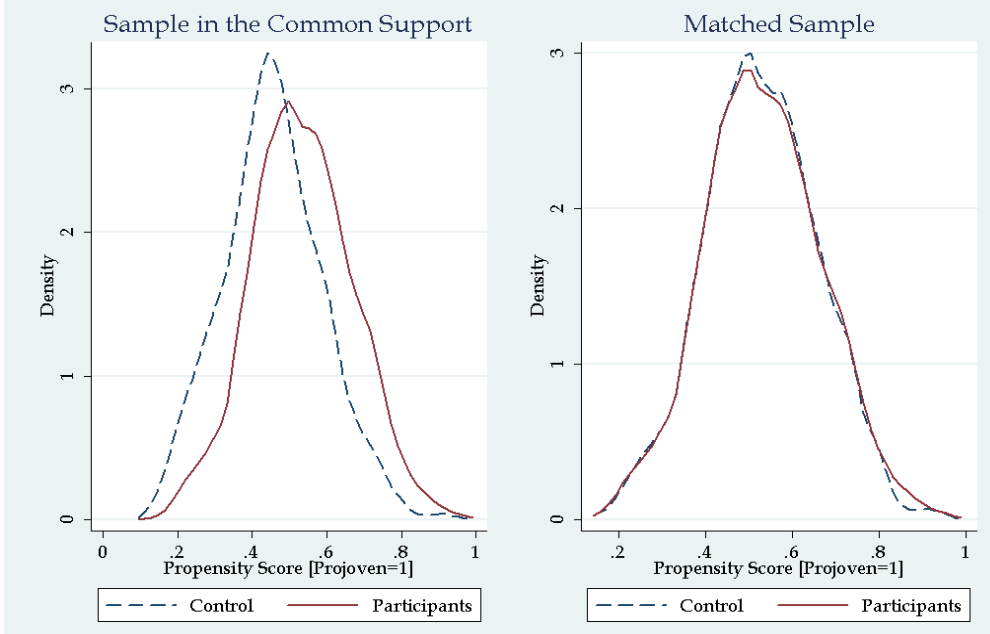
Column [C] of Table 3.1 gives data for the new control group resulting from the one-to-one matching with replacement based on the propensity score. In Table 3.1, 992 individuals are counted in the control group, but there are actually only 488 individuals - some are repeated. It is observed that the differences in wages between the treatment and control groups decline. Furthermore, the groups are more similar with respect to household income per capita, having a child, being married and having an employment history prior to training. Henceforth, "control group" refers to the newly created control group.

The newly generated control group is similar in observables to the treated individuals. Propensity-score matching assumes that because the distribution of observables is similar, it is likely that the distribution of unobservables is also similar. However, the presence of unobservables, which affects both the outcome and selection into training, cannot be easily disregarded. Systematic differences not explained by the nature of the quasi-experiment constitute evidence that the non-experimental design failed to produce quasi-randomization.

A test for systematic differences prior to training between the newly created control group and the treated individuals is applied. The test consists of a regression of employment condition and monthly wages on individual characteristics and training participation. The rationale of both regressions is to observe in the coefficient of the Projoven variable if the difference between trainees and control group are significant. Both regressions predict unconditional outcomes. For a matter of comparisons, and simplicity, no adjustment for sample selection was considered when modelling monthly wages. However, if a correction for sample selection is applied, the Projoven coefficient remains significant but its magnitude is reduced by $30 \%$.

Table 3.4 shows the results of these regressions. Whereas in the case of employment no systematic differences prior to training are found (Projoven coefficient not statistically different from zero), in the case of monthly wages significant differences between treatment and control groups are observed (Projoven coefficient statistically different from zero). In addition, based on the sign of the corresponding variables' coefficients it could be inferred that the youths with higher wages are those with more years of schooling, have more work experience, are male and do not work in microenterprises (synonymous for informal work).

The results of the test of systematic differences prior to training suggest that if the labour market outcome to evaluate is employment, fixed-effects estimators would yield consistent results; but if one evaluates monthly wages, the results may be biased. Nevertheless, it is still possible to test how sensitive these estimates are given the potential presence of unobservables. 
Table 3.4.

Baseline OLS estimates. Test of systematic differences prior to training [new control group and treatment individuals sample].

\begin{tabular}{|c|c|c|c|c|c|c|c|c|}
\hline & \multicolumn{4}{|c|}{ Dep. var. overall employment } & \multicolumn{4}{|c|}{ Dep. var. In monthly wages } \\
\hline & Coef. & $\begin{array}{l}\text { Std. } \\
\text { err. }\end{array}$ & Coef. & $\begin{array}{l}\text { Std. } \\
\text { err. }\end{array}$ & Coef. & $\begin{array}{l}\text { Std. } \\
\text { err. }\end{array}$ & Coef. & $\begin{array}{l}\text { Std. } \\
\text { err. }\end{array}$ \\
\hline Projoven & 0.000 & $(0.032)$ & -0.004 & $(0.030)$ & $-0.242^{* * *}$ & $(0.077)$ & $-0.211^{* * *}$ & $(0.068)$ \\
\hline Years schooling & & & $0.027^{* *}$ & $(0.013)$ & & & $0.042^{*}$ & $(0.025)$ \\
\hline Potential experience & & & $0.039^{* * *}$ & $(0.006)$ & & & $0.065^{\star * *}$ & $(0.014)$ \\
\hline Female & & & $-0.201^{* * *}$ & $(0.035)$ & & & $-0.256^{\star \star *}$ & $(0.069)$ \\
\hline Child & & & $0.255^{\star * *}$ & $(0.065)$ & & & & \\
\hline Child ${ }^{*}$ Female & & & $-0.135^{\star}$ & $(0.075)$ & & & & \\
\hline Married & & & $-0.153^{* * *}$ & $(0.058)$ & & & & \\
\hline Ln hh income per capita & & & $0.037^{* *}$ & $(0.017)$ & & & & \\
\hline Previous job-training & & & & & & & & \\
\hline course & & & 0.011 & $(0.034)$ & & & -0.016 & $(0.070)$ \\
\hline Tenure & & & & & & & 0.001 & $(0.001)$ \\
\hline Commerce sector & & & & & & & -0.08 & $(0.080)$ \\
\hline Manufacturing sector & & & & & & & -0.042 & $(0.086)$ \\
\hline Micro enterprise & & & & & & & $-0.561^{* * *}$ & $(0.066)$ \\
\hline Arequipa & & & $0.206^{* * *}$ & $(0.041)$ & & & $-0.536^{* * *}$ & $(0.094)$ \\
\hline Chiclayo & & & 0.031 & $(0.053)$ & & & -0.161 & $(0.110)$ \\
\hline Cusco & & & 0.047 & $(0.046)$ & & & -0.063 & $(0.131)$ \\
\hline Trujillo & & & 0.059 & $(0.043)$ & & & 0.027 & $(0.087)$ \\
\hline Constant & $0.603^{* * *}$ & $(0.028)$ & 0.076 & $(0.163)$ & $4.932^{\star * *}$ & $(0.066)$ & $4.867^{\star * *}$ & $(0.298)$ \\
\hline Number of observations & \multicolumn{2}{|c|}{2006} & \multicolumn{2}{|c|}{2006} & \multicolumn{2}{|c|}{1182} & \multicolumn{2}{|c|}{1126} \\
\hline Wald test & \multicolumn{2}{|c|}{$\mathrm{F}(1,1501)=0.00$} & \multicolumn{2}{|c|}{$F(13,1501)=14.10$} & \multicolumn{2}{|c|}{$F(1,894)=9.89$} & \multicolumn{2}{|c|}{$F(13,846)=26.65$} \\
\hline R-squared & \multicolumn{2}{|c|}{0.000} & \multicolumn{2}{|c|}{0.1191} & \multicolumn{2}{|c|}{0.017} & \multicolumn{2}{|c|}{0.2921} \\
\hline
\end{tabular}

The treatment effect literature (Rosenbaum, 1995; and Lee, 2005, Chapter 5) suggests several techniques to assess the impact of unobservables in treatment effect estimations. In this study, the Rosenbaum approach is used to measure how biases of various magnitudes might alter results. This approach does not indicate whether biases are present or what magnitude of bias is acceptable. Rather, it indicates how large the bias caused by unobservables (hidden bias) must be in order to alter our conclusions.

Rosenbaum's sensitivity analysis starts with the premise that hidden bias is present if two individuals $j$ and $k$ (one receiving treatment and the other not) with the same observed covariates $x\left(x_{j}=x_{k}\right)$ have different probability $\pi$ of receiving the treatment $\left(\pi_{j} \neq \pi_{k}\right)$. Now, let $j$ and $k$ be paired together. The odds that individuals $j$ and $k$ receive the treatment are, respectively, $\pi_{j} /\left(1-\pi_{j}\right)$ and $\pi_{k} /\left(1-\pi_{k}\right)$, and the odds ratio is the ratio of these odds. Following Rosenbaum (1995), if we know that this odds ratio for individuals with the same covariates is at most some number $\Gamma \geq 1$, then 
[Eq. 3.5] $\frac{1}{\Gamma} \leq \frac{\pi_{j}\left(1-\pi_{k}\right)}{\pi_{k}\left(1-\pi_{j}\right)} \leq \Gamma$ for all $j, k$ with $x_{j}=x_{k}$.

If $\Gamma=1$, the results are free of hidden bias. If $\Gamma=2$, two individuals with similar covariates could differ in their odds of receiving the treatment, so one could be twice as likely as the other to receive the treatment. A sensitivity analysis would consider several possible values of $\Gamma$ and show how the inferences might change accordingly (Rosenbaum, 1995).

Table 3.5 gives the sensitivity analysis for Projoven sixth public call data. For five values of $\Gamma$, the table gives the upper and lower bounds on the significance level. If $\Gamma=2$, one person in a pair may be two times as likely to undertake training as the other because they have different values of the unobserved covariate $r$. In the case $\Gamma=2$, the significance level might be less than 0.0001 or it might be as high as 0.0078 , but for all $r \in R$, the null hypothesis of no effect of training on employment is not plausible. The null hypothesis of no effect begins to become plausible for at least some $r \in R$ with $\Gamma=3$. To attribute the higher employment rate to an unobservable covariate rather than to an effect of training, that unobserved covariate would need to produce a threefold increase in the odds of undertaking training, and it would need to be a near-perfect predictor of employment. Consequently, the association between training and employment cannot be attributed to small hidden biases, but is somewhat more sensitive to bias than examples provided in Rosenbaum (1995). ${ }^{6}$

Table 3.5.

Rosenbaum (1995) sensitivity analysis for Projoven sixth Public call effect on employment [6 months after training]. Range of significance levels for hidden biases of various magnitudes.

\begin{tabular}{ccc}
\hline$\Gamma$ & Minimum & Maximum \\
\hline & & \\
1 & $<0.0001$ & $<0.0001$ \\
2 & $<0.0001$ & 0.0078 \\
3 & $<0.0001$ & 0.6848 \\
4 & $<0.0001$ & 0.9924 \\
5 & $<0.0001$ & 0.9999 \\
\hline
\end{tabular}

The results presented in Table 3.5 suggest that the effects of Projoven are not especially sensitive to the presence of hidden bias. Values of $\Gamma$ close to 1 could lead to inferences that differ significantly from those obtained assuming the study is free of hidden bias. A study is insensitive if extreme values of $\Gamma$ are required to alter the inference. Rosenbaum's analysis assumes matching without replacement. The availability of panel data for the Projoven sixth public call allows us to circumvent the possible distorted effect of time-constant unobservables in the estimation of Projoven treatment effects.

\footnotetext{
${ }^{6}$ Rosenbaum (1995) considers a high degree of insensitivity to hidden bias when the null hypothesis of no effect begins to become plausible for at least $\Gamma=5$.
} 


\subsection{Concluding Remarks}

Projoven's sixth public call data set is the most complete data set available for the study of the estimation of the programme treatment effects. This data follows a non-experimental design and control group individuals are chosen based on similarities in terms of gender, education and poverty with respect to the trainees. The official match seemed to be effective in terms of these observables. Nevertheless, significant differences are detected between the trainee group and control group, mainly in terms of wages. This pre-treatment earnings dip is often referred to as Ashenfelter's dip and it is a characteristic of virtually all training programmes.

The presence of a pre-treatment earnings dip could be evidence of systematic differences between treated and non-treated individuals and it undermines the reliability of treatment effects estimates. To ensure a better comparability of trainees with respect to the official control group in Projoven, a new control group has been generated.

This study proposes propensity score matching with replacement to create a new control group. After this procedure, systematic differences have been significantly reduced. In addition, a Rosenbaum sensitivity analysis suggests that the effects of Projoven are not especially sensitive to the presence of hidden bias. Nevertheless, in the case of wages some differences still persist. Consequently, estimations of Projoven effects on trainees' wages must be taken cautiously. 


\section{Chapter 4}

\section{Evaluation of Projoven Effectiveness}

\subsection{Introduction ${ }^{1}$}

While training programmes are regarded as effective in Latin America, they suffer from substantial dropout rates. In Peru, the dropout rate is around $40 \%$. This rate ranges from $51 \%$ in Uruguay to $74 \%$ in Chile, $77 \%$ in Panama and $60 \%$ in the Dominican Republic. The dropout phenomenon has been neglected in most YJTP evaluation. Estimating treatment effects which account for trainees with partial instruction could yield a different perspective on YJTP effectiveness. Amalgamating completers and non-completers may confound differing effects. On the one hand, dropping out might imply not obtaining a certificate, which could cast the trainee in a negative light to potential employers. In such a case, training participation cannot be regarded as beneficial. On the other hand, there are cases where dropping out is justified by the sudden emergence of appropriate job opportunities. Thus, there is the potential to erroneously attribute some outcomes to the programme. The theoretical relationship between non-completion of YJTPs and trainee labour market outcomes remains ambiguous and its relevance is therefore an empirical question.

By evaluating the impact of Projoven, this chapter aims to shed light on the effectiveness of YJTPs in the presence of dropouts with partial treatment. It takes into account the institutional framework discussion in Chapter 2 and the non-experimental nature of the data treated in Chapter 3. Thus, this chapter's evaluation accounts for unobservables, sample selection, individual heterogeneity and potential endogeneity of training completion. Projoven's impact is evaluated in terms of trainees' overall and formal employment, and in terms of monthly wages.

A four-step approach is followed to evaluate Projoven's impact on trainees' labour market outcomes. First, prior findings of the impact evaluation literature are reviewed, particularly for Latin American programmes. The objective is to observe which common characteristics of the programmes have been taken into account in impact evaluation and how the potential bias generated by the non-experimental design of the data sets and the low completion of the programmes has been dealt with. This review suggests that Latin American YJTPs yield positive returns in terms of overall and formal employment and high returns (above 12\%) in terms of wages. Nevertheless, the presence of trainees with partial instruction has been ignored.

\footnotetext{
1 This chapter is based on de Crombrugghe, D., H. Espinoza and H. Heijke (2010) "Job-training programmes with low completion rates: The case of Projoven-Peru". Working Paper ROA-RM2010/4, Research Centre for Education and the Labour Market (ROA), Maastricht.
} 
Second, this chapter provides an overview of other studies evaluating Projoven. Using differences-in-differences methods with propensity score matching techniques, prior studies found that Projoven yields employment and income gains on trainees. Nevertheless, Projoven effectiveness is open to question as no specification tests were provided regarding the presence of unobservables, and only in two studies the low completion phenomenon was taken into account.

Third, a literature review of the low completion phenomenon as a source of bias in treatment effects estimations is presented. Not accounting for the presence of trainees with partial treatment could yield biased estimations of the programme's effects. Therefore, the literature on YJTP evaluation approaches the low completion phenomenon from three angles: i) assuming dropout is a random event; ii) evaluating the effect of the time of exposure to training; and iii) using traditional non-experimental methods. Regardless of the method the general conclusion is that YJTPs are more effective conditionally on completion or the longer the trainee is exposed to training.

Fourth, a method to estimate Projoven's treatment effects accounting for low compliance, unobservables and individual heterogeneity is presented and applied. Four groups are compared pairwise: the control group, the dropout group with only classroom training, the dropout group with classroom training and internship placement, and the group completing the full programme. It is found that in terms of overall and formal employment, the programme yields returns only in the short term and conditionally on internship completion. The programme seems to increase trainees' wages, but these effects diminish over time. In addition, Projoven is relatively more effective for individuals with no work experience prior to enrolment.

This chapter is organized as follows: Section 4.2 provides a general background of YJTPs effectiveness, in particular for Latin America. Section 4.3 reviews previous findings regarding Projoven's effectiveness. Section 4.4 presents an overview of different sources of bias for not accounting for low completion and how the treatment evaluation literature has dealt with this issue. Section 4.5 introduces the empirical framework to evaluate Projoven. The results are reported in Section 4.6. Finally, Section 4.7 draws some conclusions.

\subsection{Youth Job-Training Programmes Effectiveness}

The objective of impact evaluation is to determine whether a social programme yields the expected outcomes on the treated population, and whether these outcomes are attributable to the programme (Heckman and Smith, 1997). Of particular interest is whether programme participants are better off than they would have been in the absence of the programme. There emerges the fundamental evaluation problem that no individual can be observed simultaneously in two mutually exclusive states, factual and counterfactual. One way to 
circumvent this problem is to create a control group to function as a substitute for the counterfactual. A control group can be created using either an experimental or a nonexperimental design.

A purely experimental design is based on the random assignment of the eligible population-in practice, a sample thereof-into beneficiaries of the programme (the treatment group) and non-beneficiaries of the programme (the control group). Thus, the treatment effect is the average difference in the outcomes of the two groups, as treatment assignment is statistically independent of the outcomes. In a non-experimental design, the treatment is assigned in a non-random way. Individuals as similar as possible in observable covariates to the treated individuals are selected and function as control units. Often in practice, this control group is constructed only after the policy intervention.

The consistency of estimators based on non-experimental designs, in comparison with experimental ones, has been widely discussed. On the one hand, LaLonde (1986) points out that only experimental evaluations yield consistent average treatment effect (ATE) estimators, and demonstrates that estimators using a non-experimental control group differ from those using experimental data. On the other hand, Heckman and Hotz (1989) and Dehejia and Wahba (1999) show how this LaLonde argument can break down if there are systematic differences between the treatment and control groups in observed as well as unobserved characteristics. Once Dehejia and Wahba (1999) control for systematic differences between non-experimental treatment and control groups (using LaLonde's approach to select the same controls), the ATE estimators are close to those obtained with experimental data.

One major concern is that differences between treatment and control groups in nonexperimental designs remain unobserved or are due to self-selection into treatment. Individual decisions to comply with treatment could be related to its benefits. The literature on policy evaluation offers diverse methods to circumvent the limitations of nonexperimental design. ${ }^{2}$ Despite the development of sophisticated evaluation methods in a large number of studies, uncertainty persists about which kind of training works best, the appropriate doses of training, the individual characteristics which are most important for training effectiveness and aggregate (general equilibrium) programme effects (Friedlander et al., 1997).

Friedlander et al. (1997) review prior evidence on the effects of YJTPs. These authors conclude that job-training programmes generally yield modest positive effects on employment and earnings for adult men and women, but fail to produce positive effects for youth. Heckman et al. (1999) compare YJTPs in the U.S. and in Europe; they find that in the U.S., YJTPs have no effect on earnings of economically disadvantaged youth and only a modest effect on employment rates. In Europe, results are similar with respect to earnings

\footnotetext{
${ }^{2}$ For a review on methodologies used to evaluate policy interventions with non-experimental data, see Heckman and Robb (1989); Friedlander and Robins (1995); Heckman and Smith (1997); and Heckman and Hotz (1989).
} 
but more positive regarding employment levels. American studies use experimental designs more frequently than European studies. Political constraints and universal entitlement to social programmes make non-experimental designs the rule in Europe.

YJTPs in Latin America are found to combine positive and statistically significant effects on earnings with small but significant effects on employment, particularly for young women (Betcherman et al., 2004; Ibarrarán and Rosas, 2008). As in Europe and the U.S., YJTPs in Latin America share the dual-system of classroom instruction and on-the-job internship, but with the phases occurring sequentially (first classroom instruction and then on-the-job internship) instead of simultaneously. In Europe and the U.S., YJTPs combine two to three days of classroom instruction with two to three days of on-the-job internship. In addition, in Latin America the training phases have a shorter duration (max. four months by training phase).

Table 4.1 summarises the findings regarding the effectiveness of some Latin American YJTPs in terms of overall and formal employment, and in terms of wages. Four of these evaluations follow a non-experimental design and the remaining two follow an experimental design. In Chile and Panama, the comparison control groups were chosen ex-post among eligible nonparticipants. In Argentina, the control group units were youths registered in the programme but who did not participate. In Mexico the control group was generated with information from a national survey. The studies applying experimental methods, Colombia and Dominican Republic, select randomly their comparison group individuals among those youths who applied to the programme.

Table 4.1.

Summary of Findings. YJTPs effectiveness in Latin America

\begin{tabular}{|c|c|c|c|c|c|c|}
\hline \multirow[t]{2}{*}{ Programme } & \multirow[t]{2}{*}{ Period } & \multirow[t]{2}{*}{ Beneficiaries } & \multirow[t]{2}{*}{ Ev. Method } & \multicolumn{2}{|c|}{ Effects on Employment } & \multirow{2}{*}{$\begin{array}{c}\text { Effects on } \\
\text { wages }\end{array}$} \\
\hline & & & & Overall & Formal & \\
\hline $\begin{array}{l}\text { Proyecto Joven } \\
\text { (Argentina) }\end{array}$ & 1994-1998 & 280,000 & $\begin{array}{l}\text { Non } \\
\text { Experimental }\end{array}$ & $0 \%-11 \%$ & $0 \%-3 \%$ & n.s. \\
\hline Chile Joven (Chile) & 1992-1997 & 100,000 & $\begin{array}{l}\text { Non } \\
\text { Experimental }\end{array}$ & $18 \%-22 \%$ & $15 \%-23 \%$ & $22 \%-25 \%$ \\
\hline $\begin{array}{l}\text { Jóvenes en Acción } \\
\text { (Colombia) }\end{array}$ & 2000-2005 & 100,000 & Experimental & $\begin{array}{l}5 \% \text { women, } \\
\text { none men }\end{array}$ & $\begin{array}{l}6 \%-7 \% \\
\text { women; } 5 \%- \\
9 \% \text { men }\end{array}$ & $\begin{array}{l}22 \% \text { women, } \\
10 \% \text { men }\end{array}$ \\
\hline $\begin{array}{l}\text { Juventud y Empleo } \\
\text { (Dominican Republic) }\end{array}$ & From 1999 & 30,000 up to 2006 & Experimental & n.s. & & $17 \%$ \\
\hline PROBECAT (Mexico) & From 1984 & $\begin{array}{l}\sim 5 \text { million } \\
(1984-2000)\end{array}$ & $\begin{array}{l}\text { Non } \\
\text { Experimental }\end{array}$ & $12 \%-30 \%$ & $\begin{array}{l}10 \%-20 \% \\
\text { since } 2002\end{array}$ & n.s. \\
\hline $\begin{array}{l}\text { PROCAJOVEN } \\
\text { (Panama) }\end{array}$ & From 2002 & 11,400 & Nat. Experiment & $\begin{array}{l}13 \%(20 \% \\
\text { women, n.s. } \\
\text { men) }\end{array}$ & $\begin{array}{l}11 \%(14 \% \\
\text { women, } 5 \% \\
\text { men.) }\end{array}$ & $12 \%-30 \%$ \\
\hline
\end{tabular}

n.s.: not significant.

Source: Ibarrarán and Rosas (2008). For Dominican Republic: Card et al. (2007); for Colombia, Atanasio et al. (2008); for Panama, Ibarraran and Rosas (2007); for Chile, Aedo and Pizarro (2004); for Argentina, Alzua and Brassolio (2006); for Mexico, Delajara et al. (2006). 
Methods used in these evaluations differ depending on the nature of the design. In the case of experimental evaluations, ordinary least squares regressions (with data reweighting by the likelihood to be selected as treatment) were applied. For the Colombian case, training providers fixed effects (with dummies) were also considered. None of these studies practised a special treatment to deal with the presence of trainees with partial instruction.

For the studies using non-experimental designs, propensity score matching techniques, in both cross-sectional differences and in difference-in-difference settings, were applied. Whereas the cross-sectional differences technique assumes the absence of unobservable bias, the difference-in-difference technique attempts to control for time-invariant unobservables. In the case of Panama, reweighting and ordinary least squares regressions were also applied. As in the case of the experimental evaluations, none of these studies practised a special treatment to deal with the presence of trainees with partial instruction.

In Latin America, YJTPs programmes seemed to be effective in increasing trainees overall employment prospects. The returns range from $0 \%$ (Argentina) to 30\% (Mexico). Furthermore, the programmes are definitely more effective for women. In all the cases which distinguish treatment by gender, women are better off than men. The same pattern is observed in the case of formal employment, although with lower returns, and wages. Except for Argentina and Mexico, the returns in terms of wages are positive and by far significantly larger than any observed in developed countries.

The literature in treatment evaluation gives a threefold explanation of the dissimilar effectiveness of YJTPs in developed and developing countries. Firstly, YJTPs in low-income labour markets training have more potential because skilled workers are not available (Betcherman et al., 2004). Trained individuals as scarce human resource are highly appreciated by firms in developing countries. Second, the availability of social assistance, unemployment insurances and other varieties of vocational training programmes in developed countries affects the outcomes of the comparison groups in a different way than in developing countries which have no social protection mechanisms. Should substitutes for the training programme be available (social assistance, counselling, etc.), then the experimental effect of the programme can be zero or negative, even if the effect of training relative to no training at all is large and positive (Heckman et al., 2000). Finally, the presence of an informal labour market in developing countries could explain these outcomes. Sources of employment are always available (Calderón-Madrid, 2006).

\subsection{Projoven Effectiveness}

Since its initiation, Projoven has used a non-experimental impact evaluation component. This evaluation component has used a selection of trainees and control groups in six out of fifteen public calls of the programme. Numerous studies have evaluated Projoven effectiveness in terms of employment and earnings. These studies have applied diverse evaluation methods, 
such as: before-and-after comparisons, differences-in-differences, cross-section-based estimators, and propensity score matching techniques. A summary of outcomes is given in Table 4.2. These studies report small improvements in employment prospects of up to $8 \%$, but these are mostly insignificant, along with more substantial income gains -in one case exceeding $100 \%$. The results, in terms of magnitude, are similar to those observed for other YJTPs in Latin America.

Table 4.2.

Estimated effects of Projoven on overall employment and wages.

\begin{tabular}{|c|c|c|c|c|c|c|c|c|}
\hline \multirow[t]{2}{*}{ Study } & \multirow{2}{*}{$\begin{array}{c}\text { Public } \\
\text { call }\end{array}$} & \multicolumn{3}{|c|}{ Effect on employment } & \multicolumn{3}{|c|}{ Effect on monthly wages } & \multirow[t]{2}{*}{ Technique } \\
\hline & & $6 \mathrm{M}$ & $12 \mathrm{M}$ & $18 \mathrm{M}$ & $6 \mathrm{M}$ & $12 \mathrm{M}$ & $18 \mathrm{M}$ & \\
\hline Galdo (1998) & 1 & & & & $60 \% * * *$ & & & B\&A \\
\hline Burga (2003) & 2 & $8.2 \% *$ & $25.9 \% * * *$ & $11.8 \% * * * *$ & $28.7 \% *$ & $41.8 \% * * *$ & $28.6 \% *$ & PSMK \\
\hline Chacaltana and Sulmont & 2 & & & & $44.8 \%$ * & $29.4 \%$ & $40.2 \% * *$ & OLS \\
\hline$(2004)$ & 4 & & & & $38 \% * *$ & $54.5 \% * * *$ & $50.6 \% * * *$ & \\
\hline Nopo et al. $(2002)^{b}$ & 6 & $6.0 \% * * *$ & & & $18 \% * *$ & & & PSMNN \\
\hline $\begin{array}{l}\text { Nopo and Saavedra } \\
(2003)^{c}\end{array}$ & 6 & $-1.7 \%$ & $-1.9 \%$ & $3.2 \%$ & $43.4 \%$ & $30.3 \%$ & $37.8 \%$ & PSMK \\
\hline Chacaltana et al. (2003) ${ }^{b}$ & 6 & & & & $12 \%$ * & n. r. & $13 \%$ * & OLS \\
\hline Projoven $(2004)^{c}$ & 8 & $2.7 \%$ & $2.6 \%$ & & $46.0 \%$ & $40.3 \%$ & & D-D \\
\hline Projoven $(2005)^{c}$ & 10 & $2.0 \%$ & & & $-3.0 \%$ & & & PSMK \\
\hline \multirow[t]{5}{*}{ Díaz and Jaramillo (2006) } & 1 & $-2.0 \%$ & $1.0 \%$ & $8.0 \%$ & $88.2 \% * * *$ & $88.0 \% * * *$ & $81.0 \% * * *$ & PSMK \\
\hline & 2 & $4.0 \%$ & $8.0 \%$ & $1.0 \%$ & $74.9 \% * * *$ & $111.8 \% * * *$ & $53.2 \% * *$ & \\
\hline & 4 & $3.0 \%$ & $4.0 \%$ & $3.0 \%$ & $44.5 \% * * *$ & $45.1 \% * * *$ & $64.0 \% * * *$ & \\
\hline & 6 & $3.0 \%$ & $-2.0 \%$ & $2.0 \%$ & $33.0 \% * * *$ & $33.0 \% * * *$ & $44.4 \% * * *$ & \\
\hline & 8 & $5.0 \%$ & $6.0 \%$ & & $57.3 \% * * *$ & $65.5 \% * * *$ & & \\
\hline \multirow[t]{5}{*}{ Chong and Galdo (2006) } & 1 & & & & $70 \% *$ & $24 \%$ & $58 \% *$ & LLME \\
\hline & 2 & & & & $52 \% *$ & $73 \% * *$ & $61 \% * *$ & \\
\hline & 4 & & & & $40 \% *$ & $11 \%$ & $34 \%$ & \\
\hline & 6 & & & & $33 \% *$ & $-5 \%$ & $20 \%$ & \\
\hline & 8 & & & & $67 \% * * *$ & $89 \% * * *$ & & \\
\hline \multicolumn{9}{|c|}{${ }^{*} p<0.10,{ }^{* *} p<0.05,{ }^{* * *} p<0.01$} \\
\hline \multicolumn{9}{|l|}{ Notes: } \\
\hline \multicolumn{9}{|c|}{$\begin{array}{l}6 \mathrm{M}: 6 \text { months after the programme; } 12 \mathrm{M}: 12 \text { months after the programme; } 18 \mathrm{M}: 18 \text { months after the programme } \\
\text { n. r.: Not reported. }\end{array}$} \\
\hline \multicolumn{9}{|c|}{ B\&A: Before-and-after comparison. } \\
\hline \multicolumn{9}{|c|}{ D-D: Diff-in-Diff (simple version). } \\
\hline \multicolumn{9}{|c|}{ PSMK: Diff-in-Diff with propensity score matching kernel estimator. } \\
\hline \multicolumn{9}{|c|}{ PSMNN: Diff-in-Diff with propensity score matching nearest neighbour. } \\
\hline \multicolumn{9}{|c|}{ LLME: Diff-in-Diff with local linear matching estimator. } \\
\hline \multicolumn{9}{|c|}{ a The effect on employment refers to the effect on hours worked. } \\
\hline \multicolumn{9}{|c|}{ b The effect on wages refers to the effect on hourly wages. } \\
\hline These studies do not rep & nda & errors. & & & & & & \\
\hline
\end{tabular}

The results of the evaluation studies presented in Table 4.2 are not strictly comparable across the different public calls (Díaz and Jaramillo, 2006). The economic circumstances were different in each public call and may have also influenced the outcomes observed. Yet, some patterns could be identified. For instance, the differences observed among the estimates in the aforementioned studies illustrate and confirm the sensitivity of treatment-effect estimates to specification assumptions. Heckman and Smith (1997) explain that treatment effect 
estimators are highly dependent on model specifications. This is more evident when analyzing studies which utilised the same dataset. Studies using the same data set (Chacaltana and Sulmont, 2004 and Burga, 2003 for the second Public call; or Díaz and Jaramillo, 2006 and Chong and Galdo, 2006 for multiple public calls) found very different estimates of Projoven's treatment effects.

All the studies identify the presence of a pre-treatment earnings dip; however, only some of these studies control for selection into treatment and a pre-treatment earnings dip. None of these studies consider methods that allow for the presence of unobservables, such as instrumental variables or fixed-effects estimators. Only some studies, such as Burga (2003), Chong and Galdo (2006), and Diaz and Jaramillo (2006) use differences-in-differences estimators in a propensity-score matching context to deal with time-invariant unobservables. Actually matching is the method most commonly used to deal with the Ashenfelter's dip and selection into training. Implicitly, they assume based on observables (main assumption of propensity score matching techniques), that time-invariant unobservables are balanced between the treated group and the control group.

Regarding individual heterogeneity, almost all studies consider different sources of heterogeneity of treatment, such as gender or hometown. However, they ignore if the programme is more effective for those youths with no work experience or for the poorest trainees. The presence of an informal labour market makes relevant the consideration of heterogeneity by poverty status and work experience (see Chapter 2). The low completion rates of Projoven are also neglected in most of the studies. Only Chacaltana et al. (2003) and Chong and Galdo (2006) present estimations that, to some extent, do consider the impact of Projoven's low completion rate.

Using data from the sixth public call, Chacaltana et al. (2003) run cross-sectional OLS regressions of relative changes in hourly wages controlling for demographic variables, labour-related variables and participation in Projoven. These regressions estimate Projoven's effects six, twelve and eighteen months post-programme. The low completion factor is taken into account via dummy variables that split Projoven's effect into two parts. The first dummy is activated for individuals who completed the first phase of Projoven but not the second. The second dummy is activated once the trainee has fully completed the training sequence. Chacaltana et al. (2003) find that the programme leads to increases in participants' monthly wages of about $18 \%$ to the extent that they completed the entire training sequence, but only in the short-run (six months post-programme). These authors find no effects on trainee earnings after twelve months of either classroom instruction or on-the-job training internship. One must note that Chacaltana et al. (2003) do not control for any pre-programme earnings dip, for selection into work or for possible endogeneity of training completion.

Chong and Galdo (2006), using data from the first, second, fourth, sixth and eighth public calls of Projoven, apply a differences-in-differences approach with local linear propensity score matching. They find positive and statistically significant returns in terms of monthly wages, which are larger for trainees who completed both phases of the programme in 
comparison with trainees who completed only the first phase. These authors take into account a pre-programme earnings dip in their matching process, but training completion is considered as if randomly assigned.

Evidence from Projoven evaluations suggests that the programme yields positive returns with respect to trainee employment conditions and earnings. Nevertheless, the nonexperimental design of these evaluations and the low completion phenomenon threaten the validity of these results. Questions remain about whether programme effects remain positive once simultaneous corrections for sample selection and completion are considered.

\subsection{Low Completion as a Source of Bias}

Observational studies face not only the risk of potential hidden bias (unobservables), but differing individual levels of completion could bring about new sources of bias. Amalgamating completers and non-completers may confound differing effects. On the one hand, dropping out might imply not obtaining a certificate, which could cast the trainee in a negative light to potential employers. In such case, training participation cannot be regarded as beneficial. On the other hand, there are cases where dropping out is justified by the sudden emergence of appropriate job opportunities. Thus, there is the potential to erroneously attribute some outcomes to the programme. Due to the presence of dropouts with partial treatment, regressions based on a Roy-model-type equation will not estimate an effective average treatment effect (ATE) but rather an "average intention to treat" (AIT) effect (Heckman et al., 1998).

Figure 4.1 illustrates the difference between treatment effects for full and partial compliers. The effect of full treatment, denoted $\gamma+\pi$, compares to the effect of partial treatment, denoted $\gamma$. By ignoring the existence of two doses of treatment (corresponding to completers and dropouts), one would find an average difference between the outcomes of treated individuals (completers and dropouts) and the control group of $A I T=\gamma+\rho \pi$, where $\rho$ represents the proportion of completers (full compliers) and $\pi$ represents the additional treatment effect experienced by full compliers. One could underestimate the effects of the programme if the effects of the programme materialize only conditionally on completion $(\gamma \leq 0, \pi>0)$. If the programme is not effective, we could attribute to the programme the wrong effect if the dropouts are better off $(\pi \leq 0, \gamma>0)$. Moreover, other cases such as when both dropouts and completers are worse off $(\pi<0, \gamma<0)$, or when both groups are better off $(\pi>0, \gamma>0)$ could overestimate negatively or positively the effects of the programme, respectively. Failing to account for the low completion rate may bias the estimated effect of the programme. 
Figure 4.1.

Programme treatment effects by completion level

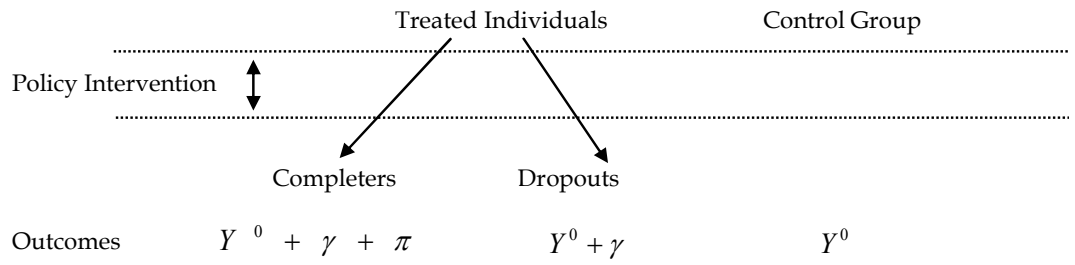

The literature on YJTP evaluation approaches the low completion phenomenon in three ways: i) assuming dropout as a random event; ii) evaluating the effect of the time of exposure to training; and iii) using traditional non-experimental methods. First, some studies implicitly take dropout as a random phenomenon. By ignoring dropouts with partial treatment, some studies assume that dropout is independent from the programme's outcome. As such, its exclusion from the treatment effects estimations would not yield any bias on the rest of the parameters of interest. However, this could be a strong assumption. Some of the trainees drop out when a job offer appears. In that case, the dropout decision would not be independent of the programme's outcome. Therefore, some tests would be needed to confirm the randomness assumption of training completion.

Second, some studies do not consider the treatment as a binary variable equal to one if participation in training occurs, and equal to zero if no participation occurs. These studies instead evaluate the effect of the length of exposure to training. For instance, using duration models with the competing risk framework it is possible to evaluate alternative transitions from the duration of training to employment, unemployment or inactivity. This approach is used by Mealli et al. (1996) to evaluate the effects of the Youth Training Scheme (YTS) in the U.K. These authors found that early termination is associated with a lower probability of transition into employment. There is an important distinction between youths who stay in the YTS and those who leave the programme early. The completers have much better employment prospects. This also has implications regarding the training providers. The authors suggest that completers are usually matched with better training providers.

Another approach which evaluates the effects of time spent in training is based on Hirano and Imbens (2004). This procedure, called generalized propensity score, consists in four steps. In the first step, it estimates by ordinary least squares (OLS) the conditional lognormal distribution of the treatment $T_{i}$ (time exposed to training) given the covariates $X_{i}$ : that is, the estimated model is $\ln \left(T_{i}\right) \sim N\left(\varphi_{0}+\varphi_{1} X_{i}, \sigma^{2}\right)$.

In the second step, a generalized propensity score function $\left(R_{i}\right)$ is estimated from the coefficients of the first regression: 
[Eq. 4.1] $\hat{R}_{i}=\frac{1}{\sqrt{2 \pi \hat{\sigma}^{2}}} \exp \left(-\frac{1}{2 \hat{\sigma}^{2}}\left(\ln \left(T_{i}\right)-\hat{\varphi}_{0}+\hat{\varphi}_{1} X_{i}\right)^{2}\right)$

In the third step, the conditional expectation of the outcome $\left(Y_{i}\right)$ given the observed treatment (time exposed to training) and the estimated $R_{i}$ is modelled with OLS

[Eq. 4.2] $\left.E\left|Y_{i}\right| T_{i}, \hat{R}_{i}\right]=\omega_{0}+\omega_{1} T_{i}+\omega_{2} T_{i}^{2}+\omega_{3} \hat{R}_{i}+\omega_{4} \hat{R}_{i}^{2}+\omega_{5} T_{i} \cdot \hat{R}_{i}$

In the fourth and last step, this approach estimates the dose response function at treatment level $t$ by averaging the regression function [Eq. 4.2] over the distribution of the generalized propensity score (holding $t$ constant):

[Eq. 4.3] $E[Y(t)]=\frac{1}{N} \sum_{i=1}^{N}\left[\hat{\omega}_{0}+\hat{\omega}_{1} t+\hat{\omega}_{2} t^{2}+\hat{\omega}_{3} \hat{r}\left(t, X_{i}\right)+\hat{\omega}_{4} \hat{r}\left(t, X_{i}\right)^{2}+\hat{\omega}_{5} t \hat{r}\left(t, X_{i}\right)\right]$

Different values of the dose response function corresponding to different values of the treatment can be estimated. Thus, the dose response function provides an insight into the causal effects of receiving different levels of exposure to the training.

Using this methodology, Flores-Lagunes et al. (2007) found that, relative to the nonparticipant baseline, the estimated marginal effects of an additional week of training in the YJTP Job Corps in the U.S. are positive and increase with the length of exposure; however, the marginal effect declines after approximately 52 weeks of enrolment in the programme (although still positive effects are observed). Using the same method, Kluve et al. (2007) found similar results for training programmes in Germany. Additionally, this method allows consideration for some levels of individual heterogeneity. Flores-Lagunes et al. (2007) estimated that the impact of the programme on Hispanics is larger and persistent over time in comparison with whites and black American youths.

The approaches based on time exposed to training demonstrated that the length of training matters in terms of employment prospects and earnings. However, there are still some limitations to be accounted for. Kluve et al. (2007) and Flores-Lagunes (2007) assumed that the length of enrolment is randomly assigned conditional on observable characteristics. If the decision to take up training is based on unobservables, results may be biased. In addition, Mealli et al. (1996) exclude the control group from their estimations. Thus, it is not possible to assess the effect of the programme in the absence of it.

Next to models including random drop-outs and models analysing the duration of the training, there is a third approach to deal with partial treatment or low completion in YJTPs. Heckman et al. (1998) and Heckman et al. (2000) advocate the use of non-experimental techniques to estimate training programmes' treatment effects in the presence of dropouts, even when experimental data are available. Based on the analysis of the training 
programmes funded under the Job Training Partnership Act (JTPA) in the U.S., Heckman et al. (2000) conclude that unadjusted (by dropout) treatment effects estimates understate the effect of the training. These authors question the reported poor performance of this programme (JTPA classroom instruction) because previous evaluations did not account for substitution and dropout. These authors report estimates of the full treatment effects of the JTPA classroom instruction on the fully treated in terms of earnings using cross-section estimates, instrumental variables, propensity score matching and Rosenbaum's bounds. They use data from the trainees and control group before, during and after the training. Heckman et al. (2000) found that the training yields large and positive returns on trainees' earnings conditioned on completion relative to no training. Although the methods presented by these authors are based on different identification assumptions, the main conclusion holds. However, it should be recalled that the dropout problem analysed in Heckman et al. (2000) occurs before the treatment. In other words, trainees drop out before starting the programme. If dropouts receive partial instruction, the methods discussed in Heckman et al. (1998) and Heckman et al. (2000) produce inconsistent estimates of the impact of full treatment on the fully treated.

In terms of using non-experimental methods, Lee and Lee (2003) propose the use of propensity score matching techniques but accounting for partial compliance. These authors evaluate the effects of a Korean job-training programme for adult women. They compare three groups on a pairwise basis: the control group, the dropouts with partial treatment and the completers. Lee and Lee's (2003) empirical findings suggest that the treatment is bad, mainly because the dropouts consist of job-founders. This approach implicitly assumes that selection into training is based on observables. Consequently, rich datasets are needed to deal with the threat of selectivity bias.

In this study a combination of non-experimental methods is used to deal with the potential low-completion bias. First, propensity score matching techniques are used to ensure that treated and non-treated youths are comparable (Chapter 3). Second, a pairwise comparison as suggested in Lee and Lee (2003) is used, but with fixed-effects methods. In addition, the completion is allowed to be endogenously determined as suggested by Heckman et al. (2000). In the next section this will be explained in detail.

\subsection{Empirical Framework}

A methodology to estimate Projoven's treatment effect on trainees' overall and formal employment, as well as monthly wages, is developed in this section. This study does not evaluate the effect of Projoven on trainees' hourly wages since this variable is not directly observed in the data. Whereas information regarding monthly wages is requested directly in Projoven's questionnaire, hourly wages should be manually constructed. To build the variable hourly wages, it is necessary to divide wages by hours worked. Unfortunately, there is a mismatch in the time base of hours worked and wages. The variable hours worked is 
collected based on the week prior to the interview, which does not coincide with the period in which wages are collected (the month immediately before the interview). This is problematic because most disadvantaged youths work in the informal labour market where they could work long hours some weeks and few hours other weeks.

To mitigate the effects of different sources of bias (training completion and self-selection into treatment) four groups are compared pairwise: i) the control group with no treatment [G1] ii) the dropout group with only classroom instruction and no internship placement [G2], iii) the dropout group with classroom instruction and internship placement [G3], and iv) the treatment group with the full treatment (classroom instruction and internship) [G4]. Group composition is based on individual completion levels, as represented in Figure 4.2. ${ }^{4}$

The distribution of individuals over different completion levels allows classifying Projoven's effects on trainees' labour market outcomes (overall and formal employment, and monthly wages) in three categories: (1) the effect of participation in the programme, (2) the effect of internship placement, and (3) the effect of internship completion. These estimations account also for the potential endogeneity of phase completion, sample selection and unobserved heterogeneity. Additionally the treatment effect is allowed to vary over time and with respect to particular individual characteristics (e.g., gender, working experience prior to training and per-capita household income).

Figure 4. 2.

Evaluation sample. Projoven sixth public call.

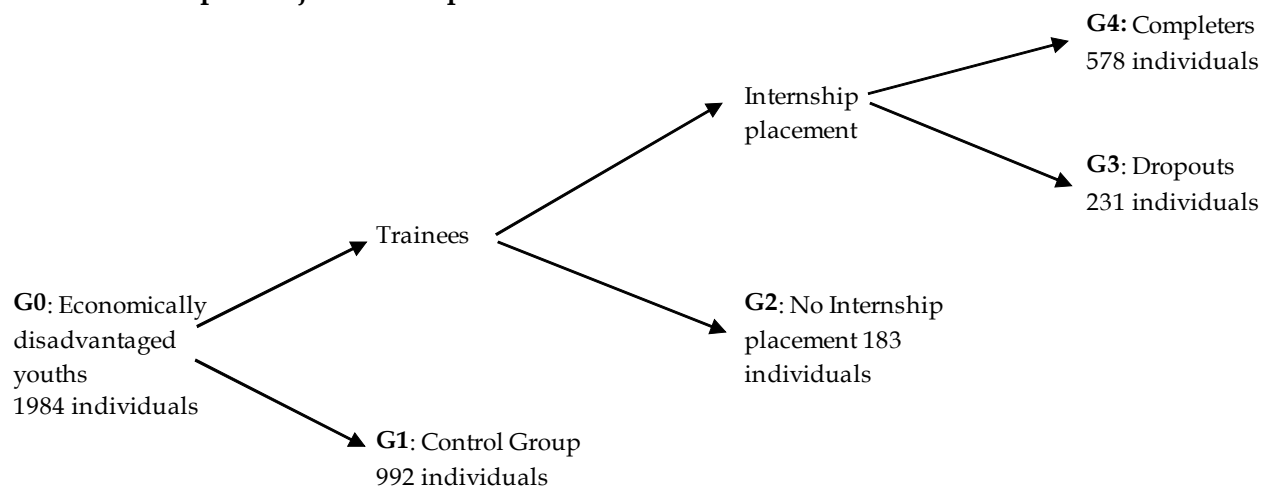

Source: Projoven. Further elaboration by the author.

\subsubsection{The effect of participation in the programme}

To identify the effect of Projoven participation, we compare [G2] vs. [G1], [G3] vs. [G1], and [G4] vs. [G1]. A general specification of individual labour market outcomes is given by:

\footnotetext{
${ }^{3}$ This control group has been created based on a matching with replacement procedure. See Chapter 3 for details.

${ }^{4}$ In this figure the 22 trainees who dropped out within the first three months of the programme have been excluded from the evaluation sample as explained in Chapter 3.
} 
[Eq. 4.4] $Y_{i t}=X_{i t} \alpha+$ Projoven $_{\mathrm{it}} \beta_{1}+\eta_{i}+\delta_{t}+\varepsilon_{i t}$,

where

$Y_{i t}=$ labour market outcome (overall or formal employment or wages) of individual $i$ in period $t$;

$X_{i t}=$ a row vector of measured individual characteristics affecting labour market outcomes; Projoven $_{\mathrm{it}}=$ a dummy variable measuring programme participation (1: only for trainees in the post-training periods; 0: for control groups in all the periods and for trainees in the period prior to the programme);

$\eta_{i}=$ an error term specific to individual $i$ and constant over time;

$\delta_{t}=$ an error term specific to period $t$, and constant across individuals;

$\varepsilon_{i t}=$ an idiosyncratic error term specific to individual $i$ at period $t$; and with $\alpha$ being a column vector of unknown parameters and $\beta_{1}$ being the unknown programme effect.

The time dimension of the panel consists of four time periods: Nov-99, May-01, Nov-01, and May-02. This represents baseline before Projoven, 6 months after the end of Projoven, 12 months after the end of Projoven and 18 months after the end of Projoven, respectively.

To identify Projoven's effects, one of the underlying assumptions is that the error term $\varepsilon_{i t}$ is serially uncorrelated, implying that treatment outcomes on period $t$ are not affected by previous outcomes (in period $t-1$, for instance). This assumption is usually not satisfied in panel applications. It is likely that if employment condition (or wages) is overpredicted in one period for a given youth, then it is likely to be overpredicted in other periods. Failure to control for this error correlation leads to underestimation of standard errors. However, it is still possible to obtain cluster-robust standard errors under the weaker assumption that errors are independent across individuals and that $N \rightarrow \infty$. Specifically, $E\left(\varepsilon_{i t}, \varepsilon_{j s}\right)=0$ for $i \neq j, E\left(\varepsilon_{i t}, \varepsilon_{i s}\right)$ is unrestricted, and $\varepsilon_{i t}$ may be heteroskedastic. In this study, robust standard errors have been clustered by members of the control group in order to allow for correlation of the errors.

The presence of unobservables constant over time, $\eta_{i}$, can be circumvented by using fixedeffects (FE) estimators. These also allow for correlation between the unobservables and the explanatory variables, such as Projoven. In the case of labour market outcomes prediction, it is very likely that there are potential time-invariant unobservables which are correlated with the regressors and with the errors.

If individual effects are not fixed, then the pooled ordinary least squares (OLS) and random effects (RE) estimators would be more appropriate to estimate Projoven's effects. Whether fixed effects are present can be tested by using a Robust Hausman test which allows the error term to be heteroskedastic. This test uses the artificial regression approach described by Wooldridge (2002, pp. 290-91), in which a random effects equation is reestimated, 
augmented with additional variables consisting of the original regressors transformed into deviations-from-mean form. The test statistic is a Wald test of the significance of these additional regressors. A large-sample chi-squared test statistic is reported with no degreesof-freedom corrections in Annexes Tables. In all the cases, the test rejects the null hypothesis concluding that RE or pooled models are not appropriate. ${ }^{5}$

A threefold strategy for estimating the effects of Projoven participation is used. First, to estimate the effect on overall employment, a linear probability model (LPM) with fixedeffects estimators is utilised, as in:

[Eq. 4.5] $Y_{i t}=X_{i t} \alpha+\operatorname{Projoven}_{i t} \beta_{1}+D 12_{t} * \operatorname{Projoven}_{i t} \beta_{2}+D 18_{t} * \operatorname{Projoven}_{i t} \beta_{3}+D 12_{t} \delta_{1}+$ $D 18_{t} \delta_{2}+\eta_{i}+\varepsilon_{i t}$

where D12 and D18 are time dummies corresponding to the periods twelve and eighteen months after the end of the training, respectively. In all the models, the base periods are Nov-99 and May-01. Two base periods are chosen, as the treatment variable takes the value zero for all individuals (treatment and controls) before the programme (Nov-99). The interaction of D12 and D18 dummies and the Projoven variable allows the treatment to vary over time. Thus, the effect of Projoven sixth public call participation after six months, after twelve months and after eighteen months are represented by $\beta_{1} ; \beta_{1}+\beta_{2}$; and $\beta_{1}+\beta_{3}$, respectively.

Next, to estimate Projoven's effects on formal employment, an LPM with fixed-effects estimator that corrects for sample selection (Wooldridge, 1995) is used. The objective of using sample selection is because formal employment status is only observed for individuals who are actually working. Individuals in the labour force could be systematically different from those who are inactive, particularly in the case of economically disadvantaged youths. Through counselling and encouragement of individuals to enter the labour force, Projoven could select certain youths, for example more motivated ones, into employment. This could potentially introduce some sample selection bias in the estimation of Projoven treatment effects.

Wooldridge's (1995) estimations follow a two-step approach. First, a standard Tobit regression of hours worked on observable covariates for each time period is estimated. Second, the residuals of these estimations are included as additional regressors in [Eq. 4.5], which is estimated using fixed-effects estimators. The variables being married, having a child and the natural log of household income per capita (without the individual) are excluded from the outcome equation [Eq. 4.5] but included in the selection equation. These variables have been traditionally used in labour economics in the context of wage equations and are valid instruments because they affect the selection into work, but not wages directly. It could be argued that these variables, for instance, having a relatively high household income or having a child, may increase individuals' reservation wages. However, in the case of the

${ }^{5}$ The test is implemented by the Stata user-written command "xtoverid" (Schaffer and Stillman, 2010). 
Projoven dataset where all individuals are unskilled youths in poverty status, their urgent financial needs may have depressed their reservation wages in such a way that the potential influence of any further variation of these variables (household income, marriage and child) on treatment outcomes (wages or formal employment condition) through reservation wages is minimal (or negligible). These individuals are so poor that having another child may not modify anymore their reservation wages, but it would definitely affect the time they have available for working.

Finally, to estimate Projoven effects on monthly wages a fixed effect estimator that corrects for sample selection is used. This approach follows Wooldridge's (1995) procedure as in the case of Projoven effects on formal employment. The idea of using a sample selection correction is to disentangle pure wage effects from employment effects. Wages could increase because training increases trainees' hours worked or their likelihood of being employed. In addition, it should be considered that wages are only observed for youths who are employed and these individuals could, potentially, be systematically different from those who are unemployed. Sample selection correction allows taking into account selectivity issues and observing pure wage effects.

\subsubsection{The effect of Projoven internship placement}

Internship placement is observed only in the case of trainees. Consequently, control group individuals are excluded from these estimations. The identification of Projoven's internship placement effect is based on the comparison of [G3] vs. [G2], and [G4] vs. [G2]. To estimate the effects of internship placement on employment, an LPM fixed-effects estimator is used. In the case of effects on formal employment and monthly wages, the sample selection correction approach for fixed effects suggested by Wooldridge (1995) is utilised.

In this specification it is assumed that internship placement is independent of trainee labour market outcomes, because internship placement does not depend on a trainee decision. Internship placement is a process that depends entirely on the ECAP's ability to network and place students. Internships are regulated paid positions that stipulate that every trainee must receive at least the minimum wage and health insurance. The minimum wage is higher than the market wage for disadvantaged youths, which implies a high opportunity cost for trainees if they decide to drop out. Thus, internship placement could be considered exogenous. Additionally, Lee (2005, Chapter 5, Section 2) suggests that if the results are coherent with other auxiliary findings, one may claim that the assignment, in this case into internship, is not affected by unobservables. For instance, trainees who drop out of the internship should not have different outcomes than trainees who were not assigned into internships. The estimated coefficient of internship placement in the comparison of [G3] and [G2] is not statistically different from zero (See Panel B of Tables 4.3, 4.4 and 4.5). This lends support the initial assumption of random assignment into internships. Nevertheless, in this study internship placement is also allowed to be endogenous. 
To allow for potential endogeneity of internship placement, a pooled, two-stage least squares estimation is used, as suggested by Semykina and Wooldridge (2005). This method accounts for both possible endogeneity of internship placement and sample selection. The sample selection correction is necessary in the formal employment and monthly wage models. The Semykina and Wooldridge approach follows a two-step procedure. First, it estimates probit regressions of employment condition in every period, adding Mundlak terms as regressors. ${ }^{6}$ From this, standard inverse Mills ratios are estimated. Second, it models the trainees' labour market outcomes using pooled two-stage least squares, adding as regressors the inverse Mills ratios and Mundlak terms for those individuals whose labour market outcomes are observed. The sample selection correction is excluded in the estimations of the effects of internship completion on overall employment.

For internship placement, categorical variables indicating the type of ECAP serve as instruments - that is, CEO, NGO, VTCESA, firms, IST and universities. Firms and IST are aggregated in one category and used as the base category, because those are the types of vocational training providers which present higher returns in terms of their graduates' labour market outcomes (Saavedra and Chacaltana, 2001).

The validity of ECAP type dummies as instrumental variables depends on two conditions. First, ECAP types should not influence changes on the trainees' labour market outcomes, except indirectly via internship placement (exogeneity). It is observed that trainees do not know beforehand in which type of ECAP they will end up. Trainees do not have a direct influence on the type of ECAP as less than $20 \%$ of trainees are granted their first choice (Projoven, 2002). Therefore, the allocation of trainees to ECAP types will be considered random (independent of the labour market outcomes).

Second, ECAP types are supposed to influence the trainees' likelihood to be placed in an internship (relevance). In principle, all trainees are entitled to pursue the internship phase after the classroom phase. However, placement depends on the ECAP's capacity and it is observed that some ECAP types are better able to do so. Firms, IST and CEOs are the most successful at placing trainees in internships $(100 \%, 95 \%$ and $92 \%$, respectively). They are followed by NGO, universities and VTCESA with 78\%, 71\% and 60\% internship placements, respectively. Thus, ECAP types are considered good predictors of internship placement.

\footnotetext{
${ }^{6}$ Mundlak terms consist of within-group means of several independent variables. In our case, these include: potential experience, household income per capita, being married, and having a child. With this strategy, unobserved heterogeneity is assumed to consist of two parts. The first part is uncorrelated with the observed variables. The second part is assumed to vary linearly with the group means, whereby a possible correlation between the independent variables and the unobserved heterogeneity is accounted for (Mundlak, 1978). The correlation between Mundlak terms and the exogenous variables does not affect our Projoven coefficients. We include in the Appendix (Table A4.18-Table A4.23) the results of the estimations using differently defined Mundlak terms (initial values instead of time averages), and without the use of Mundlak terms. We observe that Projoven internship placement effect and Projoven internship completion effect vary very little with respect to the results with Mundlak terms.
} 
The pooled two-stage least squares model with sample selection correction is set up as follows:

[Eq. 4.6] $Y_{i t}=X_{i t} \alpha+$ Internship $_{i t} \beta_{1}+D 12_{t} *$ Internship $_{i t} \beta_{2}+D 18_{t} *$ Internship $_{i t} \beta_{3}+$ $\sum_{t=1}^{4} \kappa_{t} \hat{\lambda}_{i t}+\bar{Z}_{i} \xi+D 12_{t} \delta_{1}+D 18_{t} \delta_{2}+\varepsilon_{i t}$

where Internship is a dummy variable measuring internship placement (1: for trainees in the post-training periods placed in internships; 0: otherwise and for all individuals in the baseline period), $\bar{Z}_{i}$ represents a row vector containing the Mundlak terms, and $\hat{\lambda}_{i t}$ represents the estimated inverse Mills ratios. Thus, the effect of the Projoven internship after six months, after twelve months and after eighteen months is represented as $\beta_{1} ; \beta_{1}+\beta_{2}$; and $\beta_{1}+\beta_{3}$, respectively.

\subsubsection{The effect of Projoven internship completion}

Internship completion is observed only for trainees who are placed in internships. Therefore the evaluation sample in this case consists of trainees placed in internships ([G4] and [G3]). To evaluate the effects of internship completion on overall employment, the same techniques applied to evaluate the effects of internship placement are used. Additionally, the estimate also allows for endogeneity of internship completion. As in the previous case, ECAP type dummies are used as instrumental variables.

The logic behind the choice of ECAP type as instrumental variables is similar to the internship placement case regarding the instrument exogeneity but slightly different regarding the instrument's relevance. As previously mentioned, in the absence of the programme, trainees are most likely unemployed or working in the informal labour market. In theory, the internship conditions, in terms of wages, are more favourable than the alternatives trainees have. However, in practice this may not be the case, and trainees drop out as internship conditions do not indicate chances to improve their labour market prospects (Chapter 2). Therefore, under the assumption that better ECAP types place trainees in better (or proper) internships, ECAP type could also explain the likelihood to complete the internship. In fact, it is observed that the proportion of trainees who complete the internship is higher for those from IST, firms, CEOs and NGOs (100\%, 92\%, 90\% and 87\% respectively). They are followed by universities and VTCESA with 78\% and 50\% completers, respectively. Thus, ECAP types are considered good predictors of internship completion.

\subsubsection{Projoven heterogeneous treatment effects}

This study tests whether Projoven participation, Projoven internship placement and Projoven internship completion effects vary across particular individual characteristics. For that purpose, multiplicative dummies of Projoven participation (or, Projoven internship 
placement or Projoven internship completion) with some individual characteristics are added. Among such characteristics, the following are considered: gender, work experience condition prior to training, and whether the trainee is in the lowest quartile of household income per capita prior to training.7 The selection of these variables is based on the discussion in Chapter 2 on individual heterogeneity. The model is set up as follows:

[Eq. 4.7] $Y_{i t}=X_{i t} \alpha+$ Projoven $_{i t} *\left\{\left[\beta_{1}+D 12_{t} \beta_{2}+D 18_{t} \beta_{3}\right]+\right.$

$$
\begin{aligned}
& \text { Fem }_{i} *\left[\beta_{4}+D 12_{t} \beta_{5}+D 18_{t} \beta_{6}\right]+ \\
& \text { Noexp }_{i} *\left[\beta_{7}+D 12_{t} \beta_{8}+D 18_{t} \beta_{9}\right]+ \\
& \text { Quart } \left._{i} *\left[\beta_{10}+D 12_{t} \beta_{11}+D 18_{t} \beta_{12}\right]\right\}+
\end{aligned}
$$$$
\eta_{i t}+\varepsilon_{i t}
$$

where Fem is a dummy variable indicating whether an individual is female, Noexp indicates whether an individual has no experience prior to training, and Quart signals whether the individual is in the lowest quartile of household income per capita prior to training. Thus, the additional effects of the programme for women after six months, after twelve months and after eighteen months are represented by $\beta_{4} ; \beta_{4}+\beta_{5}$; and $\beta_{4}+\beta_{6}$, respectively. In the case of trainees with no work experience prior to training, the estimated additional effects of the programme after six months, after twelve months and after eighteen months are represented by $\beta_{7} ; \beta_{7}+\beta_{8}$; and $\beta_{7}+\beta_{9}$, respectively. Finally, in the case of trainees in the lowest household income per capita quartile prior to training, the estimated additional effects of the programme after six months, after twelve months and after eighteen months are represented by $\beta_{10} ; \beta_{10}+\beta_{11}$; and $\beta_{10}+\beta_{12}$, respectively.

In order to allow for the inclusion of variables that do not change over time, random effects estimators are used. For consistency, these estimations are conditioned on the previous fixedeffects results, using as a dependent variable the residuals (with individual effects) of the estimations of Projoven's effects in terms of both overall and formal employment and in terms of monthly wages. As explanatory variables, Projoven interactions with time and with corresponding individual characteristics are considered. The reason to use interactions of the treatment with gender, work experience and household income quartile instead of separate regressions for each category has to do with the methods employed in the estimations and the sample size. In this study a pair-wise comparison of four groups is considered in order to circumvent potential biases of training completion. If separate regressions were considered, it will not be possible to identify some of the effects because not enough variation is observed for some categories in some groups.

\footnotetext{
7 The inclusion of additional dummies for other income quartiles do not modify the results obtained when only considering the lowest quartile.
} 


\subsection{Results}

Tables 4.3, 4.4, and 4.5 display the estimated effects of Projoven's sixth public call on overall employment, formal employment, and monthly wages, respectively. All three tables show the effects of the training over time and include three panels: A) Effects of Projoven participation, B) Effects of internship placement, and C) Effects of internship completion. These tables are complemented by Tables $4.6,4.7$ and 4.8 , which present the effects of Projoven's sixth public call on overall employment, formal employment, and monthly wages, respectively, allowing for endogeneity of internship placement and internship completion. Tables 4.9, 4.10 and 4.11 allow for the treatment to vary across particular individual characteristics but using a more restrictive specification: random effects estimators. Consequently, the estimates in Tables 4.9, 4.10 and 4.11 are presented as indicative of Projoven's treatment effects across individual characteristics. In all the cases, robust standard errors have been clustered by members of the control group in order to allow for correlation of the errors.

\subsubsection{Projoven effects on overall employment}

Table 4.3 sets forth the effects of Projoven's sixth public call on overall employment. ${ }^{8}$ It is observed that relative to the no-programme situation, Projoven participation fails to yield permanent returns on employment at any level of completion (Panel A). However in the short term (six months post-training), the programme increases by $9 \%$ the likelihood of individual employment, but only for trainees who complete the internship (Panel A, [G4] vs. [G1] first column). This effect diminishes over time to the extent of becoming negative in the long-run (eighteen months post-training).

The internship placement effects estimates are found to be not significant over time (Panel B). The fact that the comparison of [G3] and [G2] generates no significant effects shows that internship placement could be regarded as if randomly assigned. The only difference between individuals in [G3] with respect to [G2] is that the [G2] individuals are not placed in internships. Since [G3] individuals did not complete the training, one would not expect a positive reward. These results also hold when allowing for internship placement to be endogenous as shown in Table 4.6. Only for completers [G4] positive effects are found, around $21 \%$. In addition, the Durbin-Wu-Hausman test cannot reject the hypothesis of the exogeneity of internship placement; and according to the Stock and Yogo's (2005) the null hypothesis of weak instrument is rejected (See tables A4.8, and A4.9 for details on the tests). The same performance regarding the exogeneity of internship placement and the relevance of the instruments is observed in the estimations of formal employment and monthly wages.

\footnotetext{
8 Table 4.3 is a summary table. Complete regression results are reported in Appendix Tables A4.1, A4.2, and A4.3.
} 
In the case of internship completion, it is observed that Projoven increases employment likelihood by 10\% (Table 4.3, Panel C, [G4] vs. [G3], first column). The effects of internship completion hold in the medium-term, twelve months post-training, and disappear in the long-term, eighteen months post-training (Panel C, [G4] vs. [G3], second and third columns). The returns are similar when allowing the treatment to be endogenous (Table 4.6, Panel B, [G4] vs. [G3]). ${ }^{9}$ However, the returns are of a different magnitude (17\%), just slightly insignificant, and do not vary significantly in the medium- or long-term. It must be taken into account that the Durbin-Wu-Hausman test cannot reject the hypothesis of the exogeneity of internship completion; and according to Stock and Yogo (2005) the null hypothesis of weak instrument is rejected (See Tables A4.10 for details on the tests). The same performance regarding the exogeneity of internship placement and the relevance of the instruments is observed in the estimations of formal employment and monthly wages.

Table 4.9 reports the effects of Projoven's sixth public call while allowing for heterogeneous treatment across certain individual characteristics. ${ }^{10}$ It is observed that the training yields no additional returns to women nor to individuals in the lowest household income per capita quartile prior to training (Panels A, B and C). However, Projoven increases the employment likelihood of individuals with no working experience prior to training at any level of completion. These effects seem to be persistent and are greater in the long-term (eighteen months post-programme), conditioned on completion of both training phases.

In summary, with respect to employment condition, Projoven yields limited returns. Only individuals who complete the treatment [G4] experience positive and significant returns compared to non-participants [G1] and compared to dropouts [G3], but these returns diminish over time. The effects of the programme are greater and persistent over time for those individuals with no work experience prior to training, regardless of their level of completion.

\subsubsection{Projoven effects on formal employment, controlling for sample selection}

Table 4.4 sets forth the estimated effects of Projoven's sixth public call on formal employment, corrected for sample selection. ${ }^{11}$ The programme fails to yield any returns on trainees' formal employment condition when compared to non-participants [G1]. The coefficients estimated in Panel A are not significant.

Internship placement with respect to no internship placement increases the likelihood of employment in the formal labour market. However, these effects are not statistically

\footnotetext{
9 Table 4.6 is a summary table. Complete regression results are reported in Appendix Tables A4.8, A4.9, and A4.10.

${ }^{10}$ Table 4.9 is a summary table. Complete regression results are reported in Appendix Tables A4.11, A4.12, and A4.17.

${ }^{11}$ Table 4.4 is a summary table. Complete regression results are reported in Appendix Tables A4.3, A4.4, and A4.5.
} 
significant (Panel B). Allowing internship placement to be endogenous shows similar results, but of different magnitude. Table 4.7 shows estimated effects larger than those in Table 4.4, but these are not significant. ${ }^{12}$

Comparison of [G4] and [G3] confirms that internship completion is rewarded more than dropping out. The returns obtained remain constant over time. No evidence of additional significant effects is found in the medium- and long-term (Table 4.4, Panel C, [G4] vs. [G3], second and third columns). The same results hold when allowing internship completion to be endogenous; however, the effects almost double in magnitude (Table 4.7, Panel C).

In the case of heterogeneous treatment, significant and positive effects are only found for those individuals with no work experience prior to training and for those in the lowest household income per capita quartile (Table 4.10). ${ }^{13}$ In the case of trainees with no work experience, these effects are conditioned on training completion compared to trainees not placed in internships (Table 4.10, Panel B, [G4] vs. [G2]). In the case of trainees in the lowest quartile, the effects are greater for the dropouts with internship placement [G3] compared to the non-participants [G1] (Table 4.10, Panel A, [G3] vs. [G1]).

In summary, the programme fails to yield returns with respect to formal employment. However, internship completion is rewarded more than dropping out in this respect. The effects of internship completion are persistent over time. As in the case of overall employment, Projoven produces additional returns to those individuals with no work experience and, in addition, to those in the lowest household income per capita quartile.

\subsubsection{Projoven effects on monthly wages, controlling for sample selection}

Table 4.5 sets forth the estimated effects Projoven's sixth public call on monthly wages corrected for sample selection. ${ }^{14}$ Panel A shows that compared to non-participants [G1], Projoven increases trainee wages by more than $30 \%$ despite of the level of completion. These effects diminish significantly over time for programme completers [G4]. As discussed previously, these results must be taken only as suggestive because of the systematic differences between trainees and the control group prior to training, in terms of wages (See Chapter 3).

Panel B shows that internship placement yields no significant returns on monthly wages compared to the no-internship placement situation; the effects are even negative in the medium- and long-term (Panel B, [G4] vs. [G2], second and third columns). The results

\footnotetext{
12 Table 4.7 is a summary table. Complete regression results are reported in Appendix Tables A4.8, A4.9, and A4.10.

${ }^{13}$ Table 4.10 is a summary table. Complete regression results are reported in Appendix Tables A4.13, A4.15, and A4.17.

${ }^{14}$ Table 4.5 is a summary table. Complete regression results are reported in Appendix Tables A4.3, A4.6, and A4.7.
} 
change only in terms of magnitude when allowing internship placement to be endogenous (Table 4.8). ${ }^{15}$ Only in the case of [G3] positive returns are observed 12 months after the programme. However, it must be recalled that the endogenous specification is not more efficient even though the power of the instruments (See Tables A4.8 and A4.9).

Completing the Projoven internship relative to dropping out is definitively worthwhile, although the effects are not persistent and diminish over time. Controlling for internship completion endogeneity (Table 4.8, Panel B) does not change this assessment; only its magnitude and level of significance differ.

Table 4.11 reports estimates of the effects of Projoven's sixth public call on monthly wages, allowing for heterogeneous treatment across particular individual characteristics. ${ }^{16}$ It is observed that in comparison to non-participants and dropouts, Projoven yields additional returns for those trainees with no work experience prior to the training and for those in the lowest household income per capita quartile. These effects are persistent over time. For women, the programme is effective only in the long-run (eighteen months post-training), conditioned on completion ([G4]), compared to dropouts ([G2] and [G3]).

To summarize, with respect to monthly wages, Projoven can be regarded as an effective programme. The programme generates positive and significant returns for all trainees in comparison to non-participation [G1], but these effects diminish over time. Additionally, completing the training [G4] is rewarded more than dropping out [G3]. Finally, the effects of the programme are greater for those individuals with no work experience prior to training and for those in the lowest household income per capita quartile. For women, positive effects are observed only in the long-term conditioned on completion.

15 Table 4.8 is a summary table. Complete regression results are reported in Appendix Tables A4.8, A4.9, and A4.10.

16 Table 4.11 is a summary table. Complete regression results are reported in Appendix Tables A4.14, A4.16, and A4.17. 
Table 4.3.

Projoven sixth public call effects on overall employment by level of completion. Linear probability model - fixed effect estimations.

\begin{tabular}{|c|c|c|c|}
\hline & $\begin{array}{c}\text { Effects } \\
\text { after } 6 \\
\text { months } \\
{\left[\hat{\beta}_{1}\right]}\end{array}$ & $\begin{array}{c}\text { Additional } \\
\text { effects after } \\
12 \text { months } \\
{\left[\hat{\beta}_{2}\right]}\end{array}$ & $\begin{array}{c}\text { Additional } \\
\text { effects after } \\
18 \text { months } \\
{\left[\hat{\beta}_{3}\right]}\end{array}$ \\
\hline \multicolumn{4}{|c|}{ A. Effects of Projoven participation } \\
\hline [G2] vs. [G1] & $\begin{array}{c}0.033 \\
(0.059)\end{array}$ & $\begin{array}{l}-0.036 \\
(0.051)\end{array}$ & $\begin{array}{l}-0.069 \\
(0.056)\end{array}$ \\
\hline [G3] vs. [G1] & $\begin{array}{l}-0.006 \\
(0.054)\end{array}$ & $\begin{array}{l}-0.068 \\
(0.045)\end{array}$ & $\begin{array}{l}-0.018 \\
(0.054)\end{array}$ \\
\hline [G4] vs. [G1] & $\begin{array}{c}0.091^{* *} \\
(0.044)\end{array}$ & $\begin{array}{c}-0.105^{\star * *} \\
(0.036)\end{array}$ & $\begin{array}{c}-0.125^{\star * *} \\
(0.043)\end{array}$ \\
\hline \multicolumn{4}{|c|}{ B. Effects of Projoven internship placement } \\
\hline [G3] vs. [G2] & $\begin{array}{l}-0.041 \\
(0.062)\end{array}$ & $\begin{array}{l}-0.033 \\
(0.056)\end{array}$ & $\begin{array}{c}0.051 \\
(0.057)\end{array}$ \\
\hline [G4] vs. [G2] & $\begin{array}{c}0.055 \\
(0.054)\end{array}$ & $\begin{array}{l}-0.063 \\
(0.048)\end{array}$ & $\begin{array}{l}-0.049 \\
(0.048)\end{array}$ \\
\hline \multicolumn{4}{|c|}{ C. Effects of Projoven internship completion } \\
\hline [G4] vs. [G3] & $\begin{array}{l}0.103^{*} \\
(0.061)\end{array}$ & $\begin{array}{l}-0,014 \\
(0.051)\end{array}$ & $\begin{array}{l}-0.109^{*} \\
(0.059)\end{array}$ \\
\hline
\end{tabular}

${ }^{*} p<0.10,{ }^{* *} p<0.05,{ }^{* * *} p<0.01$.

[G1]: Control group (992 individuals).

[G2]: Dropout group with only classroom training and no internship placement (183 individuals).

[G3]: Dropout group with classroom training and internship placement (231 individuals).

[G4]: Treatment group with the full treatment (578 individuals).

Robust standard errors clustered by individuals in parentheses.

[ $\hat{\beta}_{1}$ ] represents the treatment effect 6 months after the training; with [ $\hat{\beta}_{2}$ ], [ $\hat{\beta}_{3}$ ] additional effects in the following periods.

The time dimension of the panel consists of four time periods: Nov-99, May-01, Nov-01, and May-02. This represents baseline before Projoven, 6 months after Projoven, 12 months after Projoven, and 18 months after Projoven, respectively. In all models, the base periods are Nov-99 and May-01. Two base periods are chosen, as the treatment variable takes the value zero for all individuals (treatment and controls) before the programme (Nov-99).

Table 4.3 is a summary table. Completed regression results are reported in Appendix Tables A4.1, A4.2 and A4.3. 
Table 4.4.

Projoven sixth public call effects on formal employment by level of completion. Linear probability model fixed-effects estimates with sample selection correction (Wooldridge, 1995).

\begin{tabular}{|c|c|c|c|}
\hline & $\begin{array}{c}\text { Effects } \\
\text { after } 6 \\
\text { months } \\
{\left[\hat{\beta}_{1}\right]}\end{array}$ & $\begin{array}{c}\text { Additional } \\
\text { effects after } 12 \\
\text { months } \\
{\left[\hat{\beta}_{2}\right]}\end{array}$ & $\begin{array}{c}\text { Additional } \\
\text { effects after } 18 \\
\text { months } \\
{\left[\hat{\beta}_{3}\right]}\end{array}$ \\
\hline \multicolumn{4}{|c|}{ A. Effects of Projoven participation } \\
\hline [G2] vs. [G1] & $\begin{array}{l}-0.046 \\
(0.085)\end{array}$ & $\begin{array}{l}-0.020 \\
(0.070)\end{array}$ & $\begin{array}{l}-0.123^{*} \\
(0.069)\end{array}$ \\
\hline [G3] vs. [G1] & $\begin{array}{c}0.012 \\
(0.075)\end{array}$ & $\begin{array}{l}-0.011 \\
(0.055)\end{array}$ & $\begin{array}{l}-0.078 \\
(0.058)\end{array}$ \\
\hline [G4] vs. [G1] & $\begin{array}{c}0.081 \\
(0.065)\end{array}$ & $\begin{array}{l}-0.010 \\
(0.047)\end{array}$ & $\begin{array}{l}-0.071 \\
(0.049)\end{array}$ \\
\hline \multicolumn{4}{|c|}{ B. Effects of Projoven internship placement } \\
\hline [G3] vs. [G2] & $\begin{array}{c}0.032 \\
(0.094)\end{array}$ & $\begin{array}{c}0.031 \\
(0.077)\end{array}$ & $\begin{array}{c}0.036 \\
(0.074)\end{array}$ \\
\hline [G4] vs. [G2] & $\begin{array}{c}0.092 \\
(0.076)\end{array}$ & $\begin{array}{c}0.048 \\
(0.067)\end{array}$ & $\begin{array}{c}0.067 \\
(0.063)\end{array}$ \\
\hline \multicolumn{4}{|c|}{ C. Effects of Projoven internship completion } \\
\hline [G4] vs. [G3] & $\begin{array}{l}0.187^{*} \\
(0.097)\end{array}$ & $\begin{array}{r}-0.014 \\
(0.077)\end{array}$ & $\begin{array}{l}-0.029 \\
(0.071)\end{array}$ \\
\hline
\end{tabular}

${ }^{*} p<0.10,{ }^{* *} p<0.05,{ }^{* * *} p<0.01$

[G1]: Control group (992 individuals).

[G2]: Dropout group with only classroom training and no internship placement (183 individuals).

[G3]: Dropout group with classroom training and internship placement (231 individuals).

[G4]: Treatment group with the full treatment (578 individuals).

Robust standard errors clustered by individuals in parentheses.

[ $\hat{\beta}_{1}$ ] represents the treatment effect 6 months after the training; with [ $\hat{\beta}_{2}$ ], [ $\hat{\beta}_{3}$ ] additional effects in the following periods.

The time dimension of the panel consists of four time periods: Nov-99, May-01, Nov-01, and May-02. This represents baseline before Projoven, 6 months after Projoven, 12 months after Projoven and 18 months after Projoven, respectively. In all models, the base periods are Nov-99 and May-01. Two base periods are chosen, as the treatment variable takes the value zero for all individuals (treatment and controls) before the programme (Nov-99).

Table 4.4 is a summary table. Completed regression results are reported in Appendix Tables A4.3, A4.4, and A4.5. 
Table 4.5.

Projoven sixth public call effects on monthly wages by level of completion. Fixed-effects estimates with sample selection correction (Wooldridge, 1995).

\begin{tabular}{|c|c|c|c|}
\hline & $\begin{array}{c}\text { Effects } \\
\text { after } 6 \\
\text { months } \\
{\left[\hat{\beta}_{1}\right]}\end{array}$ & $\begin{array}{c}\text { Additional } \\
\text { effects after } 12 \\
\text { months } \\
{\left[\hat{\beta}_{2}\right]}\end{array}$ & $\begin{array}{c}\begin{array}{c}\text { Additional } \\
\text { effects after } 18 \\
\text { months } \\
{\left[\hat{\beta}_{3}\right]}\end{array} \\
\end{array}$ \\
\hline \multicolumn{4}{|c|}{ A. Effects of Projoven participation } \\
\hline [G2] vs. [G1] & $\begin{array}{c}0.332^{* * *} \\
(0.135)\end{array}$ & $\begin{array}{l}-0.025 \\
(0.096)\end{array}$ & $\begin{array}{c}0.105 \\
(0.098)\end{array}$ \\
\hline [G3] vs. [G1] & $\begin{array}{c}0.341^{* * *} \\
(0.124)\end{array}$ & $\begin{array}{c}0.106 \\
(0.084)\end{array}$ & $\begin{array}{c}0.126 \\
(0.095)\end{array}$ \\
\hline [G4] vs. [G1] & $\begin{array}{c}0.382^{* * *} \\
(0.095)\end{array}$ & $\begin{array}{c}-0.140^{* *} \\
(0.063)\end{array}$ & $\begin{array}{l}-0.089 \\
(0.066)\end{array}$ \\
\hline \multicolumn{4}{|c|}{ B. Effects of Projoven internship placement } \\
\hline [G3] vs. [G2] & $\begin{array}{c}0.087 \\
(0.143)\end{array}$ & $\begin{array}{c}0.073 \\
(0.109)\end{array}$ & $\begin{array}{l}-0.017 \\
(0.109)\end{array}$ \\
\hline [G4] vs. [G2] & $\begin{array}{c}0.109 \\
(0.124)\end{array}$ & $\begin{array}{l}-0.163^{*} \\
(0.088)\end{array}$ & $\begin{array}{c}-0.268^{\star * *} \\
(0.090)\end{array}$ \\
\hline \multicolumn{4}{|c|}{ C. Effects of Projoven internship completion } \\
\hline [G4] vs. [G3] & $\begin{array}{l}0.351^{* *} \\
(0.139)\end{array}$ & $\begin{array}{c}-0.263^{* *} \\
(0.110)\end{array}$ & $\begin{array}{c}-0.354^{* * *} \\
(0.112)\end{array}$ \\
\hline
\end{tabular}

${ }^{*} p<0.10,{ }^{* *} p<0.05,{ }^{* * *} p<0.01$.

[G1]: Control group (992 individuals).

[G2]: Dropout group with only classroom training and no internship placement (183 individuals).

[G3]: Dropout group with classroom training and internship placement (231 individuals)

[G4]: Treatment group with the full treatment (578 individuals).

Robust standard errors clustered by individuals in parentheses.

[ $\hat{\beta}_{1}$ ] represents the treatment effect 6 months after the training; with [ $\hat{\beta}_{2}$ ], [ $\hat{\beta}_{3}$ ] additional effects in the following periods.

The time dimension of the panel consists of four time periods: Nov-99, May-01, Nov-01, and May-02. This represents baseline before Projoven, 6 months after Projoven, 12 months after Projoven, and 18 months after Projoven, respectively. In all models, the base periods are Nov-99 and May-01. Two base periods are chosen, as the treatment variable takes the value zero for all individuals (treatment and controls) before the programme (Nov-99).

Table 4.5 is a summary table. Completed regression results are reported in Appendix Tables A4.3, A4.6, and A4.7. 
Table 4.6.

Projoven sixth public call effects on overall employment by level of completion. Heterogeneous treatment over time and endogenous treatment. Pooled linear probability model - two-stage least squares estimates.

\begin{tabular}{ccc}
\hline $\begin{array}{c}\text { Effects } \\
\text { after 6 } \\
\text { months } \\
{\left[\hat{\beta}_{1}\right]}\end{array}$ & $\begin{array}{c}\text { Additional } \\
\text { effects after 12 } \\
\text { months }\end{array}$ & $\begin{array}{c}\text { Additional } \\
\text { effects after 18 } \\
\text { months }\end{array}$ \\
\hline$\left.\hat{\beta}_{2}\right]$ & {$\left[\hat{\beta}_{3}\right]$} \\
\hline
\end{tabular}

\begin{tabular}{lccc} 
A. Effects of Projoven internship placement \\
[G3] vs. [G2] & 0.185 & 0.076 & -0.22 \\
& $(0.415)$ & $(0.275)$ & $(0.341)$ \\
[G4] vs. [G2] & $0.215^{*}$ & -0.112 & -0.105 \\
& $(0.115)$ & $(0.093)$ & $(0.172)$ \\
\multicolumn{4}{r}{ B. Effects of Projoven internship completion }
\end{tabular}

[G4] vs. [G3] $\quad 0.172 \quad-0.111 \quad 0.036$

${ }^{*} p<0.10,{ }^{* *} p<0.05,{ }^{* * *} p<0.01$.

$(0.157)$

(0.137)

[G1]: Control group (992 individuals).

[G2]: Dropout group with only classroom training and no internship placement (183 individuals).

[G3]: Dropout group with classroom training and internship placement (231 individuals).

[G4]: Treatment group with the full treatment (578 individuals).

Robust standard errors clustered by individuals in parentheses.

[ $\hat{\beta}_{1}$ ] represents the treatment effect 6 months after the training; with [ $\hat{\beta}_{2}$ ], [ $\hat{\beta}_{3}$ ] additional effects in the following periods.

The time dimension of the panel consists of four time periods: Nov-99, May-01, Nov-01, and May-02. This represents baseline before Projoven, 6 months after Projoven, 12 months after Projoven, and 18 months after Projoven, respectively. In all the models, the base periods are Nov-99 and May-01. Two base periods are chosen, as the treatment variable takes the value zero for all individuals (treatment and controls) before the programme (Nov-99).

Table 4.6 is a summary table. Completed regression results are reported in Appendix Tables A4.8, A4.9 and A4.10. 
Table 4.7.

Projoven sixth public call effects on formal employment by level of completion. Heterogeneous treatment over time and endogenous treatment. Pooled linear probability model - two-stage least squares estimates with sample selection correction (Semykina and Wooldridge, 2006).

\begin{tabular}{ccc}
$\begin{array}{c}\text { Effects } \\
\text { after } \mathbf{6} \\
\text { months }\end{array}$ & $\begin{array}{c}\text { Additional } \\
\text { effects after } \\
\mathbf{1 2} \text { months }\end{array}$ & $\begin{array}{c}\text { Additional } \\
\text { effects after } \\
\mathbf{1 8} \text { months }\end{array}$ \\
{$\left[\hat{\beta}_{1}\right]$} & {$\left[\hat{\beta}_{2}\right]$} & {$\left[\hat{\beta}_{3}\right]$} \\
\hline
\end{tabular}

A. Effects of Projoven internship placement

$\begin{array}{lccc}\text { [G3] vs. [G2] } & 0.198 & -0.034 & -0.072 \\ & (0.350) & (0.357) & (0.361) \\ \text { [G4] vs. [G2] } & 0.485 & -0.129 & -0.151 \\ & (0.300) & (0.237) & (0.301)\end{array}$

B. Effects of Projoven internship completion

$\begin{array}{lccc}\text { [G4] vs. [G3] } & 0.327^{* *} & 0.070 & -0.142 \\ & (0.153) & (0.150) & (0.223)\end{array}$

${ }^{*} p<0.10,{ }^{* *} p<0.05,{ }^{* * *} p<0.01$.

[G1]: Control group (992 individuals).

[G2]: Dropout group with only classroom training and no internship placement (183 individuals).

[G3]: Dropout group with classroom training and internship placement (231 individuals).

[G4]: Treatment group with the full treatment (578 individuals).

Robust standard errors clustered by individuals in parentheses.

[ $\hat{\beta}_{1}$ ] represents the treatment effect 6 months after the training; with [ $\hat{\beta}_{2}$ ], [ $\hat{\beta}_{3}$ ] additional effects in the following periods.

The time dimension of the panel consists of four time periods: Nov-99, May-01, Nov-01 and May-02. This represents baseline before Projoven, 6 months after Projoven, 12 months after Projoven, and 18 months after Projoven, respectively. In all models the base periods are Nov-99 and May-01. Two base periods are chosen, as the treatment variable takes the value zero for all individuals (treatment and controls) before the programme (Nov-99).

Table 4.7 is a summary table. Completed regression results are reported in Appendix Tables A4.8, A4.9 and A4.10. 
Table 4.8.

Projoven sixth public call effects on monthly wages by level of completion. Heterogeneous treatment over time and endogenous treatment. Pooled two-stage least squares estimates with sample selection correction (Semykina and Wooldridge, 2006).

\begin{tabular}{ccc}
\hline $\begin{array}{c}\text { Effects } \\
\text { after 6 } \\
\text { months } \\
{\left[\hat{\beta}_{1}\right]}\end{array}$ & $\begin{array}{c}\text { Additional } \\
\text { effects after 12 } \\
\text { months }\end{array}$ & $\begin{array}{c}\text { Additional } \\
\text { effects after } \\
\left.\text { [ } \hat{\beta}_{2}\right]\end{array}$ \\
\hline
\end{tabular}

A. Effects of Projoven internship placement

$\begin{array}{lccc}\text { [G3] vs. [G2] } & -0.165 & 0.591^{* *} & 0.23 \\ & (0.255) & (0.261) & (0.259) \\ \text { [G4] vs. [G2] } & 0.632 & 0.034 & -0.115 \\ & (1.076) & (0.904) & (0.931)\end{array}$

B. Effects of Projoven internship completion

[G4] vs. [G3] $\quad 0.695 \quad-0.497 \quad-0.286$

${ }^{*} p<0.10,{ }^{* *} p<0.05, * * * p<0.01$.

[G1]: Control group (992 individuals).

[G2]: Dropout group with only classroom training and no internship placement (183 individuals).

[G3]: Dropout group with classroom training and internship placement (231 individuals).

[G4]: Treatment group with the full treatment (578 individuals).

Robust standard errors clustered by individuals in parentheses.

[ $\hat{\beta}_{1}$ ] represents the treatment effect 6 months after the training; with $\left[\hat{\beta}_{2}\right],\left[\hat{\beta}_{3}\right]$ additional effects in the following periods.

The time dimension of the panel consists of four time periods: Nov-99, May-01, Nov-01, and May-02. This represents baseline before Projoven, 6 months after Projoven, 12 months after Projoven, and 18 months after Projoven, respectively. In all the models, the base periods are Nov-99 and May-01. Two base periods are chosen, as the treatment variable takes the value zero for all individuals (treatment and controls) before the programme (Nov-99).

Table 4.8 is a summary table. Completed regression results are reported in Appendix Tables A4.8, A4.9, and A4.10. 
Table 4.9.

Projoven sixth public call effects on overall employment by level of completion. Heterogeneous treatment over time and across individual characteristics. Linear probability model - random effects estimates.

\begin{tabular}{|c|c|c|c|c|c|c|c|c|}
\hline $\begin{array}{c}\text { Effects } \\
\text { females } \\
\text { after } 6 \\
\text { months }\end{array}$ & $\begin{array}{c}\text { Add. } \\
\text { effects } \\
\text { females } \\
\text { after } 12 \\
\text { months }\end{array}$ & $\begin{array}{c}\text { Add. } \\
\text { effects } \\
\text { females } \\
\text { after } 18 \\
\text { months }\end{array}$ & $\begin{array}{c}\text { Effects } \\
\text { indivs. no } \\
\text { work } \\
\text { experience } \\
\text { after } 6 \\
\text { months }\end{array}$ & $\begin{array}{c}\text { Add. } \\
\text { effects } \\
\text { indivs. no } \\
\text { work } \\
\text { experience } \\
\text { after } 12 \\
\text { months }\end{array}$ & $\begin{array}{c}\text { Add. } \\
\text { effects } \\
\text { indivs. no } \\
\text { work } \\
\text { experience } \\
\text { after } 18 \\
\text { months }\end{array}$ & $\begin{array}{c}\text { Effects } \\
\text { indivs. } \\
\text { lowest } \\
\text { quartile } \\
\text { after } 6 \\
\text { months }\end{array}$ & $\begin{array}{c}\text { Add. } \\
\text { effects } \\
\text { indivs. } \\
\text { lowest } \\
\text { quartile } \\
\text { after 12 } \\
\text { months }\end{array}$ & $\begin{array}{c}\text { Add. } \\
\text { effects } \\
\text { indivs. } \\
\text { lowest } \\
\text { quartile } \\
\text { after } 18 \\
\text { months }\end{array}$ \\
\hline$\left[\hat{\beta}_{4}\right]$ & {$\left[\hat{\beta}_{5}\right]$} & {$\left[\hat{\beta}_{6}\right.$ ] } & [ $\hat{\beta}_{7}$ ] & {$\left[\hat{\beta}_{8}\right]$} & {$\left[\hat{\beta}_{9}\right.$ ] } & {$\left[\hat{\beta}_{10}\right]$} & {$\left[\hat{\beta}_{11}\right]$} & {$\left[\hat{\beta}_{12}\right]$} \\
\hline
\end{tabular}

\begin{tabular}{|c|c|c|c|c|c|c|c|c|c|}
\hline \multicolumn{10}{|c|}{ A. Effects of Projoven participation } \\
\hline \multirow[t]{2}{*}{ [G2] vs. [G1] } & -0.079 & 0.084 & 0.011 & $0.167^{\star \star *}$ & -0.01 & 0.003 & -0.013 & -0.052 & -0.01 \\
\hline & $(0.067)$ & $(0.073)$ & $(0.077)$ & $(0.068)$ & $(0.079)$ & $(0.082)$ & $(0.077)$ & $(0.083)$ & $(0.084)$ \\
\hline \multirow[t]{2}{*}{ [G3] vs. [G1] } & $-0.114^{*}$ & 0.100 & 0.084 & $0.148^{* *}$ & -0.074 & 0.085 & 0.012 & -0.026 & -0.055 \\
\hline & $(0.065)$ & $(0.067)$ & $(0.070)$ & $(0.068)$ & $(0.068)$ & $(0.076)$ & $(0.071)$ & $(0.068)$ & $(0.080)$ \\
\hline \multirow[t]{2}{*}{ [G4] vs. [G1] } & $-0.069^{*}$ & -0.013 & 0.000 & $0.243^{* * *}$ & -0.043 & $0.093^{*}$ & 0.029 & 0.023 & 0.007 \\
\hline & $(0.039)$ & $(0.041)$ & $(0.046)$ & $(0.048)$ & $(0.047)$ & $(0.050)$ & $(0.052)$ & $(0.052)$ & $(0.053)$ \\
\hline \multicolumn{10}{|c|}{ B. Effects of Projoven internship placement } \\
\hline \multirow[t]{2}{*}{ [G3] vs. [G2] } & -0.095 & 0.102 & 0.106 & 0.108 & -0.067 & 0.105 & 0.009 & -0.020 & -0.032 \\
\hline & $(0.065)$ & $(0.067)$ & $(0.070)$ & $(0.068)$ & $(0.069)$ & $(0.076)$ & $(0.069)$ & $(0.068)$ & $(0.079)$ \\
\hline \multirow[t]{2}{*}{ [G4] vs. [G2] } & -0.049 & 0.000 & 0.041 & $0.241^{* \star *}$ & -0.038 & $0.106^{* *}$ & 0.014 & 0.027 & 0.018 \\
\hline & $(0.039)$ & $(0.042)$ & $(0.045)$ & $(0.048)$ & $(0.048)$ & $(0.050)$ & $(0.051)$ & $(0.052)$ & $(0.053)$ \\
\hline \multicolumn{10}{|c|}{ C. Effects of Projoven internship completion } \\
\hline \multirow[t]{2}{*}{ [G4] vs. [G3] } & -0.051 & 0.01 & 0.056 & $0.282^{* * *}$ & -0.034 & $0.118^{* *}$ & 0.017 & 0.031 & 0.030 \\
\hline & $(0.041)$ & $(0.042)$ & $(0.046)$ & $(0.050)$ & $(0.048)$ & $(0.050)$ & $(0.055)$ & $(0.052)$ & $(0.053)$ \\
\hline
\end{tabular}

[G1]: Control group (992 individuals).

[G2]: Dropout group with only classroom training and no internship placement (183 individuals).

[G3]: Dropout group with classroom training and internship placement (231 individuals).

[G4]: Treatment group with the full treatment (578 individuals).

Robust standard errors clustered by individuals in parentheses.

[ $\hat{\beta}_{4}$ ] represents the interactions with the "female" dummy 6 months after the training; with [ $\hat{\beta}_{5}$ ],

$\left[\hat{\beta}_{6}\right.$ ] additional effects in the following periods.

[ $\hat{\beta}_{7}$ ] represents the interactions with the "no work experience" dummy 6 months after the training; with [ $\hat{\beta}_{8}$ ], [ $\hat{\beta}_{9}$ ] additional effects in the following periods.

[ $\hat{\beta}_{10}$ ] represents the interactions with the "lowest quartile" dummy 6 months after the training; with [ $\left.\hat{\beta}_{11}\right]$, $\hat{\beta}_{12}$ ] additional effects in the following periods.

The time dimension of the panel consists of four time periods: Nov-99, May-01, Nov-01, and May-02. This represents baseline before Projoven, 6 months after Projoven, 12 months after Projoven and 18 months after Projoven, respectively. In all the models, the base periods are Nov-99 and May-01. Two base periods are chosen, as the treatment variable takes the value zero for all individuals (treatment and controls) before the programme (Nov-99).

Table 4.9 is a summary table. Completed regression results are reported in Appendix Tables A4.11, A4.12 and A4.17. 
Table 4.10.

Projoven sixth public call effects on formal employment by level of completion. Heterogeneous treatment over time and across individual characteristics. Linear probability model - random effects estimates with sample selection correction.

\begin{tabular}{|c|c|c|c|c|c|c|c|c|c|}
\hline & $\begin{array}{l}\text { Effects } \\
\text { females } \\
\text { after } 6 \\
\text { months }\end{array}$ & $\begin{array}{l}\text { Add. } \\
\text { effects } \\
\text { females } \\
\text { after } 12 \\
\text { months }\end{array}$ & $\begin{array}{l}\text { Add. } \\
\text { effects } \\
\text { females } \\
\text { after } 18 \\
\text { months }\end{array}$ & $\begin{array}{l}\text { Effects } \\
\text { indivs. no } \\
\text { work } \\
\text { experience } \\
\text { after } 6 \\
\text { months } \\
{\left[\hat{\beta}_{7}\right]}\end{array}$ & $\begin{array}{l}\text { Add. } \\
\text { effects } \\
\text { indivs. no } \\
\text { work } \\
\text { experience } \\
\text { after } 12 \\
\text { months } \\
{\left[\hat{\beta}_{8}\right]}\end{array}$ & $\begin{array}{l}\text { Add. } \\
\text { effects } \\
\text { indivs. no } \\
\text { work } \\
\text { experience } \\
\text { after } 18 \\
\text { months } \\
{\left[\hat{\beta}_{9}\right]}\end{array}$ & $\begin{array}{l}\text { Effects } \\
\text { indivs. } \\
\text { lowest } \\
\text { quartile } \\
\text { after } 6 \\
\text { months } \\
{\left[\hat{\beta}_{10}\right]}\end{array}$ & $\begin{array}{l}\text { Add. } \\
\text { effects } \\
\text { indivs. } \\
\text { lowest } \\
\text { quartile } \\
\text { after } 12 \\
\text { months } \\
{\left[\hat{\beta}_{11}\right]}\end{array}$ & $\begin{array}{l}\text { Add. } \\
\text { effects } \\
\text { indivs. } \\
\text { lowest } \\
\text { quartile } \\
\text { after } 18 \\
\text { months } \\
{\left[\hat{\beta}_{12}\right]}\end{array}$ \\
\hline \multicolumn{10}{|c|}{ A. Effects of Projoven participation } \\
\hline [G2] vs. [G1] & $\begin{array}{l}-0.105 \\
(0.086)\end{array}$ & $\begin{array}{c}0.008 \\
(0.102)\end{array}$ & $\begin{array}{c}0.046 \\
(0.098)\end{array}$ & $\begin{array}{c}0.021 \\
(0.097)\end{array}$ & $\begin{array}{l}-0.090 \\
(0.107)\end{array}$ & $\begin{array}{c}0.089 \\
(0.102)\end{array}$ & $\begin{array}{c}0.031 \\
(0.103)\end{array}$ & $\begin{array}{c}0.003 \\
(0.108)\end{array}$ & $\begin{array}{c}0.003 \\
(0.106)\end{array}$ \\
\hline [G3] vs. [G1] & $\begin{array}{l}-0.099 \\
(0.087)\end{array}$ & $\begin{array}{c}0.111 \\
(0.097)\end{array}$ & $\begin{array}{c}0.068 \\
(0.086)\end{array}$ & $\begin{array}{l}-0.062 \\
(0.098)\end{array}$ & $\begin{array}{l}-0.190^{*} \\
(0.099)\end{array}$ & $\begin{array}{c}0.034 \\
(0.095)\end{array}$ & $\begin{array}{l}0.159^{*} \\
(0.088)\end{array}$ & $\begin{array}{l}-0.022 \\
(0.102)\end{array}$ & $\begin{array}{c}-0.08 \\
(0.078)\end{array}$ \\
\hline [G4] vs. [G1] & $\begin{array}{l}-0.059 \\
(0.047)\end{array}$ & $\begin{array}{r}0.024 \\
(0.052)\end{array}$ & $\begin{array}{l}-0.011 \\
(0.052)\end{array}$ & $\begin{array}{c}0.094 \\
(0.065)\end{array}$ & $\begin{array}{l}-0.091 \\
(0.063)\end{array}$ & $\begin{array}{l}-0.064 \\
(0.063)\end{array}$ & $\begin{array}{l}-0.042 \\
(0.065)\end{array}$ & $\begin{array}{c}0.059 \\
(0.063)\end{array}$ & $\begin{array}{c}0.020 \\
(0.066)\end{array}$ \\
\hline \multicolumn{10}{|c|}{ B. Effects of Projoven internship placement } \\
\hline [G3] vs. [G2] & $\begin{array}{l}-0.084 \\
(0.091)\end{array}$ & $\begin{array}{r}0.104 \\
(0.095)\end{array}$ & $\begin{array}{c}0.049 \\
(0.088)\end{array}$ & $\begin{array}{l}-0.059 \\
(0.102)\end{array}$ & $\begin{array}{l}-0.153 \\
(0.101)\end{array}$ & $\begin{array}{c}0.025 \\
(0.097)\end{array}$ & $\begin{array}{c}0.128 \\
(0.097)\end{array}$ & $\begin{array}{l}-0.064 \\
(0.103)\end{array}$ & $\begin{array}{l}-0.126 \\
(0.080)\end{array}$ \\
\hline [G4] vs. [G2] & $\begin{array}{l}-0.058 \\
(0.049)\end{array}$ & $\begin{array}{c}0.009 \\
(0.053)\end{array}$ & $\begin{array}{l}-0.026 \\
(0.052)\end{array}$ & $\begin{array}{l}0.118^{*} \\
(0.067)\end{array}$ & $\begin{array}{l}-0.099 \\
(0.063)\end{array}$ & $\begin{array}{l}-0.071 \\
(0.062)\end{array}$ & $\begin{array}{l}-0.058 \\
(0.071)\end{array}$ & $\begin{array}{c}0.053 \\
(0.065)\end{array}$ & $\begin{array}{l}-0.007 \\
(0.067)\end{array}$ \\
\hline \multicolumn{10}{|c|}{ C. Effects of Projoven internship completion } \\
\hline [G4] vs. [G3] & $\begin{array}{l}-0.092^{*} \\
(0.052)\end{array}$ & $\begin{array}{c}0.025 \\
(0.053)\end{array}$ & $\begin{array}{l}-0.033 \\
(0.053)\end{array}$ & $\begin{array}{c}0.085 \\
(0.074)\end{array}$ & $\begin{array}{l}-0.103 \\
(0.063)\end{array}$ & $\begin{array}{l}-0.078 \\
(0.061)\end{array}$ & $\begin{array}{c}0.009 \\
(0.076)\end{array}$ & $\begin{array}{c}0.046 \\
(0.063)\end{array}$ & $\begin{array}{c}0.002 \\
(0.066)\end{array}$ \\
\hline
\end{tabular}

[G1]: Control group (992 individuals).

[G2]: Dropout group with only classroom training and no internship placement (183 individuals).

[G3]: Dropout group with classroom training and internship placement (231 individuals).

[G4]: Treatment group with the full treatment (578 individuals).

Robust standard errors clustered by individuals in parentheses.

[ $\hat{\beta}_{4}$ ] represents the interactions with the "female" dummy 6 months after the training; with [ $\hat{\beta}_{5}$ ],

$\left[\hat{\beta}_{6}\right]$ additional effects in the following periods.

[ $\hat{\beta}_{7}$ ] represents the interactions with the "no work experience" dummy 6 months after the training; with [ $\hat{\beta}_{8}$ ], [ $\hat{\beta}_{9}$ ] additional effects in the following periods.

[ $\hat{\beta}_{10}$ ] represents the interactions with the "lowest quartile" dummy 6 months after the training; with [ $\hat{\beta}_{11}$ ], [ $\hat{\beta}_{12}$ ] additional effects in the following periods.

The time dimension of the panel consists of four time periods: Nov-99, May-01, Nov-01, and May-02. This represents baseline before Projoven, 6 months after Projoven, 12 months after Projoven and 18 months after Projoven, respectively. In all the models the base periods are Nov-99 and May-01. Two base periods are chosen, as the treatment variable takes the value zero for all individuals (treatment and controls) before the programme (Nov-99).

Table 4.10 is a summary table. Completed regression results are reported in Appendix Tables A4.13, A4.15 and A4.17. 
Table 4.11.

Projoven sixth public call effects on monthly wages by level of completion, conditional on being employed. Heterogeneous treatment over time and across individual characteristics. Random effects estimates with sample selection correction.

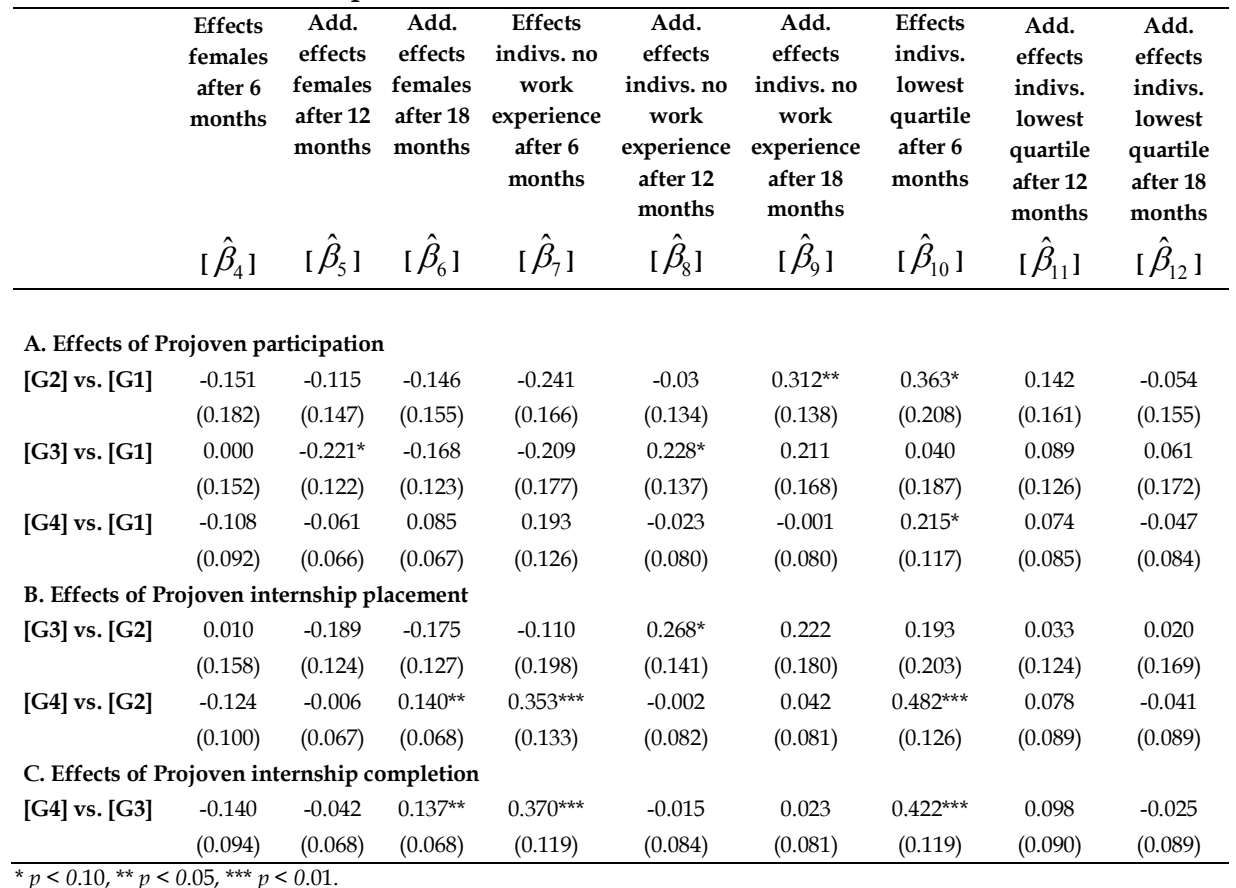

[G1]: Control group (992 individuals).

[G2]: Dropout group with only classroom training and no internship placement (183 individuals).

[G3]: Dropout group with classroom training and internship placement (231 individuals).

[G4]: Treatment group with the full treatment (578 individuals).

Robust standard errors clustered by individuals in parentheses.

$\left[\hat{\beta}_{4}\right.$ ] represents the interactions with the "female" dummy 6 months after the training; with $\left[\hat{\beta}_{5}\right],\left[\hat{\beta}_{6}\right]$ additional effects in the following periods.

[ $\hat{\beta}_{7}$ ] represents the interactions with the "no work experience" dummy 6 months after the training; with [ $\hat{\beta}_{8}$ ], [ $\hat{\beta}_{9}$ ] additional effects in the following periods.

[ $\hat{\beta}_{10}$ ] represents the interactions with the "lowest quartile" dummy 6 months after the training; with [ $\hat{\beta}_{11}$ ], [ $\hat{\beta}_{12}$ ] additional effects in the following periods.

The time dimension of the panel consists of four time periods: Nov-99, May-01, Nov-01, and May-02. This represents baseline before Projoven, 6 months after Projoven, 12 months after Projoven, and 18 months after Projoven, respectively. In all the models the base periods are Nov-99 and May-01. Two base periods are chosen, as the treatment variable takes the value zero for all individuals (treatment and controls) before the programme (Nov-99).

Table 4.11 is a summary table. Completed regression results are reported in Appendix Tables A4.14, A4.16 and A4.17. 


\subsection{Conclusions}

YJTPs seem to be more effective in Latin America than in Europe and the U.S. In terms of employment prospects and earnings these programmes yield higher returns for youths in Latin America, particularly for women. Although these differences may be explained by certain circumstances such as the existence of an informal labour market, lack of qualified human resources or the lack of social welfare programmes, still some issues have not been accounted for. Unobservables have not been dealt with directly. Most of the studies rely on purging time-invariant unobservables via difference-in-difference estimators with propensity score matching techniques. However, the presence of pre-programme earnings dips is evidence of some systematic differences between trainees and control group, which cast doubt on their comparability. In addition, the review of the studies accounting for trainees with partial instruction demonstrated that ignoring dropouts could yield misleading conclusions about the effectiveness of training programmes. Programmes seemed to be more effective conditioned on completion.

The analysis of Projoven's sixth public call, a typical YJTP in Latin America, sheds light on the importance of controlling for low completion rates, individual heterogeneity and the presence of unobservables in treatment effect estimations. This study addresses these issues and four general conclusions are reached.

First, Projoven is not as effective as originally thought, in terms of employment, compared to non-participation [G1]. Only in the short-term (six months post-training) and conditionally on internship completion [G4], is it possible to observe a positive effect (of $9 \%$ ) on overall employment. This effect is not permanent and decreases over time. The diminishing returns of the training over time could be due to economic circumstances. In 2001, real economic growth was only $0.2 \%$, which is low in comparison with the $3 \%$ growth in 2000 or the $5 \%$ average in the period 2002-2005. That is why these conclusions may not be generalized for other public calls. In addition, the programme produces no significant returns in terms of formal employment; however, internship completion is rewarded more than dropping out in this respect.

Second, Projoven seems to be an effective policy intervention in terms of monthly wages. The programme increases monthly wages of trainees by more than $30 \%$ at all levels of completion. However, the effects on wages, which are in line with estimations from the literature, cannot be fully attributed to training. Although the construction of a new control group reduced significantly the differences in wages between the control group and trainees prior to the programme, some systematic differences are still observed. The fact that the programme yields no returns on formal employment excludes the possibility of explaining wage increases via productivity enhancement or trainees having better jobs. Actually, it seems that trainees work more hours in the same type of precarious jobs they would be working in the absence of the programme. The auxiliary Tobit regressions of hours worked proved this to be the case. Nopo and Robles (2002) obtained a similar conclusion for the sixth public call. Nevertheless, these results may not be generalized to other public calls. Using 
polynomial matching methods in a pool of four public calls and without accounting for sample selection, Chong et al. (2008) found that, in the short- and medium-term, Projoven has significant effects on trainees' employment quality indicators such as labour contracts, health coverage, social security coverage and firm size.

Third, ignoring dropouts could lead to misleading conclusions about the effects of YJTPs. In the case of Projoven's sixth public call, it is observed that classroom instruction alone yields no returns to trainees, neither in terms of overall, nor in terms of formal employment or monthly wages. Nevertheless, once enrolled, the enrolee is definitively better off from completion of training. Under no circumstances are dropouts ([G2] and [G3]) better off with respect to employment prospects or wages. These results hold even when allowing for internship placement and completion to be endogenously determined.

Finally, the results suggest that the programme yields greater returns on overall and formal employment conditions for trainees with no work experience prior to training. In terms of monthly wages, the programme produces additional returns for individuals with no work experience and for those in the lowest household income per capita quartile prior to training, but conditioned on completion [G4]. In addition, these effects seemed to be constant over time. Contrary to previous findings, no additional effects for women are found. Perhaps the literature confounds the additional effects across individual characteristics with gender. Economically disadvantaged women are more likely to not have much work experience when they are young. However, these results must be taken as indicative, since the specification used in this study (random effects estimators) is more restricted.

To conclude, confounding the effects of unobservables, individual heterogeneity and low completion rates yields a different picture of Projoven's effects on trainee labour market outcomes. Decomposing programme effects by level of completion suggests that the programme is more effective, particularly with respect to wages and overall employment, conditioned on completion. Additionally, the results might imply a need to revise the targeting strategy and the official goals of the programme. In order to enhance training effects, the programme must encourage the participation of individuals with no work experience. In the low-skill job market, experience is regarded as more relevant than educational credentials. For youth with no work experience, attaining first-time employment is almost impossible in Peru. Thus, programmes that provide an internship (work experience) definitely impact their chances in the labour market. Given this, Projoven should consider strategies to make training more attractive and implement the right incentives for trainees to complete training. 


\section{Appendix}

Table A4.1.

Projoven sixth public call participation effects on overall employment. Heterogeneous effects over time. LPM-FE estimates.

\begin{tabular}{|c|c|c|c|c|c|c|}
\hline & \multicolumn{2}{|c|}{ [G2] vs. [G1] } & \multicolumn{2}{|c|}{ [G3] vs. [G1] } & \multicolumn{2}{|c|}{ [G4] vs. [G1] } \\
\hline & Coef. & $\begin{array}{l}\text { Std. } \\
\text { err. }\end{array}$ & Coef. & $\begin{array}{l}\text { Std. } \\
\text { err. }\end{array}$ & Coef. & $\begin{array}{l}\text { Std. } \\
\text { err. }\end{array}$ \\
\hline Projoven & 0.033 & $(0.059)$ & -0.006 & $(0.054)$ & $0.091^{* *}$ & $(0.044)$ \\
\hline Projoven [12 months] & -0.036 & $(0.051)$ & -0.068 & $(0.045)$ & $-0.105^{* * *}$ & $(0.036)$ \\
\hline Projoven [18 months] & -0.069 & $(0.056)$ & -0.018 & $(0.054)$ & $-0.125^{* * *}$ & $(0.043)$ \\
\hline Years schooling & -0.014 & $(0.044)$ & -0.028 & $(0.044)$ & -0.027 & $(0.041)$ \\
\hline Potential experience & -0.028 & $(0.035)$ & -0.027 & $(0.035)$ & -0.027 & $(0.035)$ \\
\hline Child & 0.013 & $(0.088)$ & -0.042 & $(0.088)$ & -0.059 & $(0.075)$ \\
\hline Child*Female & -0.042 & $(0.115)$ & -0.032 & $(0.116)$ & -0.011 & $(0.097)$ \\
\hline Married & -0.061 & $(0.045)$ & -0.047 & $(0.044)$ & -0.049 & $(0.039)$ \\
\hline Ln hh income per capita & $-0.013^{* *}$ & $(0.005)$ & $-0.014^{* * *}$ & $(0.005)$ & $-0.014^{* * *}$ & $(0.004)$ \\
\hline Previous job-training course & $-0.055^{*}$ & $(0.031)$ & $-0.067^{* *}$ & $(0.030)$ & -0.037 & $(0.025)$ \\
\hline Constant & 0.914 & $(0.575)$ & $1.078^{*}$ & $(0.574)$ & $1.068^{* *}$ & $(0.537)$ \\
\hline Time Dummies & \multicolumn{2}{|c|}{ yes } & \multicolumn{2}{|c|}{ yes } & \multicolumn{2}{|c|}{ yes } \\
\hline Number of observations & \multicolumn{2}{|c|}{4724} & \multicolumn{2}{|c|}{4827} & \multicolumn{2}{|c|}{6257} \\
\hline Number of individuals & \multicolumn{2}{|c|}{1186} & \multicolumn{2}{|c|}{1212} & \multicolumn{2}{|c|}{1570} \\
\hline F-test & \multicolumn{2}{|c|}{$F(12,681)=8.71$} & \multicolumn{2}{|c|}{$F(12,707)=10.65$} & \multicolumn{2}{|c|}{$\mathrm{F}(12,1065)=12.33$} \\
\hline R-squared & \multicolumn{2}{|c|}{0.071} & \multicolumn{2}{|c|}{0.0766} & \multicolumn{2}{|c|}{0.0632} \\
\hline $\operatorname{corr}\left(\eta_{i}, X_{i t} \alpha\right)$ & \multicolumn{2}{|c|}{-0.218} & \multicolumn{2}{|c|}{-0.2292} & \multicolumn{2}{|c|}{-0.2435} \\
\hline Robust Hausman test for FE & \multicolumn{2}{|c|}{$\chi_{(12)}^{2}=22.932$} & \multicolumn{2}{|c|}{$\chi_{(12)}^{2}=41.259$} & \multicolumn{2}{|c|}{$\chi_{(12)}^{2}=39.652$} \\
\hline$p$-value & \multicolumn{2}{|c|}{0.0283} & \multicolumn{2}{|c|}{0.0000} & \multicolumn{2}{|c|}{0.0001} \\
\hline
\end{tabular}

[G1]: Control group (992 individuals).

[G2]: Dropout group with only classroom training and no internship placement (183 individuals).

[G3]: Dropout group with classroom training and internship placement (231 individuals).

[G4]: Treatment group with the full treatment (578 individuals).

Robust standard errors clustered by individuals in parentheses.

The time dimension of the panel consists of four time periods: Nov-99, May-01, Nov-01, and May-02. This represents baseline before Projoven, 6 months after Projoven, 12 months after Projoven, and 18 months after Projoven, respectively. In all the models the base periods are Nov-99 and May-01. Two base periods are chosen, as the treatment variable takes the value zero for all individuals (treatment and controls) before the programme (Nov-99). 
Appendix

Table A4.2.

Projoven sixth public call internship placement effects on overall employment. Heterogeneous effects over time [only trainees sample]. LPM-FE estimates.

\begin{tabular}{|c|c|c|c|c|}
\hline & \multicolumn{2}{|c|}{ [G3] vs. [G2] } & \multicolumn{2}{|c|}{ [G4] vs. [G2] } \\
\hline & Coef. & $\begin{array}{l}\text { Std. } \\
\text { err. }\end{array}$ & Coef. & $\begin{array}{l}\text { Std. } \\
\text { err. }\end{array}$ \\
\hline Internship & -0.041 & $(0.062)$ & 0.055 & $(0.054)$ \\
\hline Internship [12 months] & -0.033 & $(0.056)$ & -0.063 & $(0.048)$ \\
\hline Internship [18 months] & 0.051 & $(0.057)$ & -0.049 & $(0.048)$ \\
\hline Years schooling & 0.060 & $(0.051)$ & 0.033 & $(0.049)$ \\
\hline Potential experience & 0.002 & $(0.047)$ & 0.009 & $(0.047)$ \\
\hline Child & 0.150 & $(0.100)$ & 0.042 & $(0.065)$ \\
\hline Child*Female & $-0.277^{*}$ & $(0.155)$ & -0.123 & $(0.092)$ \\
\hline Married & $-0.211^{\star * *}$ & $(0.066)$ & $-0.141^{\text {*** }}$ & $(0.051)$ \\
\hline Ln hh income per capita & $-0.016^{* *}$ & $(0.008)$ & $-0.015^{* * *}$ & $(0.004)$ \\
\hline Previous job-training course & $-0.129^{* * *}$ & $(0.037)$ & -0.040 & $(0.026)$ \\
\hline Constant & 0.086 & $(0.683)$ & 0.332 & $(0.665)$ \\
\hline Time Dummies & \multicolumn{2}{|c|}{ yes } & \multicolumn{2}{|c|}{ yes } \\
\hline Number of observations & \multicolumn{2}{|c|}{1653} & \multicolumn{2}{|c|}{3083} \\
\hline Number of individuals & \multicolumn{2}{|c|}{414} & \multicolumn{2}{|c|}{772} \\
\hline F-test & \multicolumn{2}{|c|}{$F(12,413)=9.60$} & \multicolumn{2}{|c|}{$\mathrm{F}(12,771)=9.91$} \\
\hline R-squared & \multicolumn{2}{|c|}{0.077} & \multicolumn{2}{|c|}{0.0451} \\
\hline $\operatorname{corr}\left(\eta_{i}, X_{i t} \alpha\right)$ & \multicolumn{2}{|c|}{-0.1813} & \multicolumn{2}{|c|}{-0.019} \\
\hline Robust Hausman test for FE & \multicolumn{2}{|c|}{$\chi_{(11)}^{2}=49.632$} & \multicolumn{2}{|c|}{$\chi_{(11)}^{2}=42.749$} \\
\hline$p$-value & \multicolumn{2}{|c|}{0.0000} & \multicolumn{2}{|c|}{0.0000} \\
\hline
\end{tabular}

${ }^{*} p<0.10,{ }^{* *} p<0.05$, *** $p<0.01$.

SSC stands for sample selection correction.

[G2]: Dropout group with only classroom training and no internship placement (183 individuals).

[G3]: Dropout group with classroom training and internship placement (231 individuals).

[G4]: Treatment group with the full treatment (578 individuals).

The time dimension of the panel consists of four time periods: Nov-99, May-01, Nov-01, and May-02. This represents baseline before Projoven, 6 months after Projoven, 12 months after Projoven, and 18 months after Projoven, respectively. In all the models, the base periods are Nov-99 and May-01. Two base periods are chosen, as the treatment variable takes the value zero for all individuals (treatment and controls) before the programme (Nov-99).

Robust standard errors clustered by individuals in parentheses. The standard errors should be interpreted as asymptotic lower bounds. 
Table A4.3.

Projoven sixth public call internship completion effects. Heterogeneous treatment over time [only trainees placed in internships sample] [G4] vs. [G3]. FE estimates [with sample selection correction - Wooldridge, 1995]

\begin{tabular}{|c|c|c|c|c|c|c|}
\hline & \multicolumn{2}{|c|}{$\begin{array}{c}\text { Dep. var. ov. } \\
\text { employment [LPM] }\end{array}$} & \multicolumn{2}{|c|}{$\begin{array}{c}\text { Dep. var. formal } \\
\text { employment [LPM } \\
\text { with SSC] }\end{array}$} & \multicolumn{2}{|c|}{$\begin{array}{c}\text { Dep. var. In monthly } \\
\text { wages [with SSC] }\end{array}$} \\
\hline & Coef. & Std. err. & Coef. & Std. err. & Coef. & Std. err. \\
\hline Internship Completion & $0.103^{*}$ & $(0.061)$ & $0.187^{*}$ & $(0.097)$ & $0.351^{* *}$ & $(0.139)$ \\
\hline Internship Completion * [12 months] & -0.014 & $(0.051)$ & -0.014 & $(0.077)$ & $-0.263^{* *}$ & $(0.110)$ \\
\hline Internship Completion * [18 months] & $-0.109^{*}$ & $(0.059)$ & -0.029 & $(0.071)$ & $-0.354^{* * *}$ & $(0.112)$ \\
\hline Years schooling & -0.031 & $(0.058)$ & -0.068 & $(0.102)$ & 0.22 & $(0.150)$ \\
\hline Potential experience & -0.035 & $(0.055)$ & -0.053 & $(0.096)$ & 0.217 & $(0.143)$ \\
\hline Child & -0.1 & $(0.066)$ & & & & \\
\hline Child*Female & -0.067 & $(0.088)$ & & & & \\
\hline Married & $-0.093^{*}$ & $(0.053)$ & & & & \\
\hline Ln hh income per capita & $-0.017^{* * *}$ & $(0.004)$ & & & & \\
\hline Previous job-training course & $-0.050^{*}$ & $(0.027)$ & 0.002 & $(0.035)$ & $-0.145^{\star \star *}$ & $(0.054)$ \\
\hline Commerce sector & & & -0.025 & $(0.043)$ & -0.079 & $(0.071)$ \\
\hline Manufacturing sector & & & $0.081^{* *}$ & $(0.041)$ & 0.01 & $(0.062)$ \\
\hline Micro enterprise & & & $-0.140^{* * *}$ & $(0.031)$ & $-0.443^{* * *}$ & $(0.051)$ \\
\hline Constant & 1.163 & $(0.776)$ & 1.506 & $(1.382)$ & 2.067 & $(2.054)$ \\
\hline Time Dummies & \multicolumn{2}{|c|}{ yes } & \multicolumn{2}{|c|}{ yes } & \multicolumn{2}{|c|}{ yes } \\
\hline SSC terms & \multicolumn{2}{|c|}{ no } & \multicolumn{2}{|c|}{ yes } & \multicolumn{2}{|c|}{ yes } \\
\hline Number of observations & \multicolumn{2}{|c|}{2827} & \multicolumn{2}{|c|}{1908} & \multicolumn{2}{|c|}{1772} \\
\hline Number of individuals & \multicolumn{2}{|c|}{708} & \multicolumn{2}{|c|}{679} & \multicolumn{2}{|c|}{646} \\
\hline Overall F-test & \multicolumn{2}{|c|}{$\mathrm{F}(12,2815)=10.27$} & \multicolumn{2}{|c|}{$\mathrm{F}(15,1888)=3.56$} & \multicolumn{2}{|c|}{$\mathrm{F}(15,1757)=27.70$} \\
\hline F-Test SSC terms & & & \multicolumn{2}{|c|}{$F(4,678)=1.50$} & \multicolumn{2}{|c|}{$\mathrm{F}(4,645)=15.06$} \\
\hline$p$-value & & & \multicolumn{2}{|c|}{0.2004} & \multicolumn{2}{|c|}{0.000} \\
\hline R-squared & \multicolumn{2}{|c|}{0.0512} & \multicolumn{2}{|c|}{0.0573} & \multicolumn{2}{|c|}{0.3755} \\
\hline $\operatorname{corr}\left(\eta_{i}, X_{i t} \alpha\right)$ & \multicolumn{2}{|c|}{-0.389} & \multicolumn{2}{|c|}{-0.3779} & \multicolumn{2}{|c|}{-0.4174} \\
\hline Robust Hausman test for FE & \multicolumn{2}{|c|}{$\chi_{(11)}^{2}=84.248$} & \multicolumn{2}{|c|}{$\chi_{(15)}^{2}=49.343$} & \multicolumn{2}{|c|}{$\chi_{(15)}^{2}=45.340$} \\
\hline$p$-value & \multicolumn{2}{|c|}{0.0000} & & & & \\
\hline
\end{tabular}

${ }^{*} p<0.10,{ }^{* *} p<0.05,{ }^{* * *} p<0.01$.

SSC stands for sample selection correction.

[G3]: Dropout group with classroom training and internship placement (231 individuals).

[G4]: Treatment group with the full treatment (578 individuals).

The time dimension of the panel consists of four time periods: Nov-99, May-01, Nov-01 and May-02. This represents baseline before Projoven, 6 months after Projoven, 12 months after Projoven, and 18 months after Projoven, respectively. In all the models, the base periods are Nov-99 and May-01. Two base periods are chosen, as the treatment variable takes the value zero for all individuals (treatment and controls) before the programme (Nov-99).

Robust standard errors clustered by individuals in parentheses. The standard errors should be interpreted as asymptotic lower bounds. 
Appendix

Table A4.4.

Projoven sixth public call participation effects on formal employment. Heterogeneous effects over time. LPM-FE estimates [corrected for sample selection - Wooldridge, 1995].

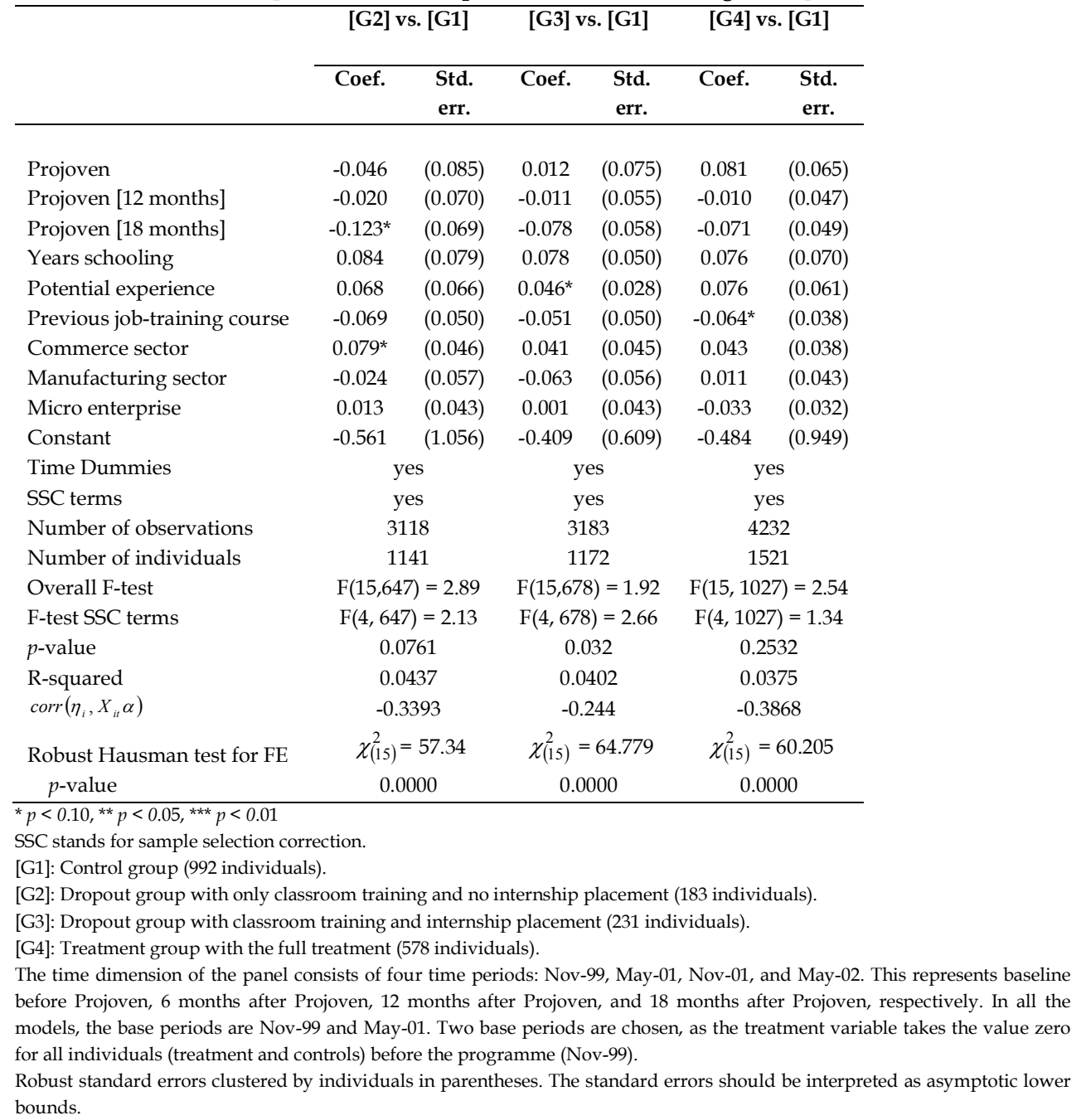


Table A4.5.

Projoven sixth public call internship effects on formal employment. Heterogeneous effects over time [only trainees sample]. LPM-FE estimates [corrected for sample selection - Wooldridge, 1995].

\begin{tabular}{|c|c|c|c|c|}
\hline & \multicolumn{2}{|c|}{ [G3] vs. [G2] } & \multicolumn{2}{|c|}{ [G4] vs. [G2] } \\
\hline & Coef. & $\begin{array}{l}\text { Std. } \\
\text { err. }\end{array}$ & Coef. & $\begin{array}{l}\text { Std. } \\
\text { err. }\end{array}$ \\
\hline Internship & 0.032 & $(0.094)$ & 0.092 & $(0.076)$ \\
\hline Internship [12 months] & 0.031 & $(0.077)$ & 0.048 & $(0.067)$ \\
\hline Internship [18 months] & 0.036 & $(0.074)$ & 0.067 & $(0.063)$ \\
\hline Years schooling & 0.083 & $(0.087)$ & 0.062 & $(0.079)$ \\
\hline Potential experience & 0.032 & $(0.082)$ & 0.072 & $(0.075)$ \\
\hline Previous job-training course & 0.048 & $(0.050)$ & -0.029 & $(0.034)$ \\
\hline Commerce sector & 0.046 & $(0.058)$ & 0.025 & $(0.042)$ \\
\hline Manufacturing sector & 0.059 & $(0.057)$ & $0.100^{* * *}$ & $(0.039)$ \\
\hline Micro enterprise & $-0.115^{* * *}$ & $(0.044)$ & $-0.121^{* * *}$ & $(0.030)$ \\
\hline Constant & -0.409 & $(1.201)$ & -0.289 & $(1.078)$ \\
\hline Time Dummies & \multicolumn{2}{|c|}{ yes } & \multicolumn{2}{|c|}{ yes } \\
\hline SSC terms & \multicolumn{2}{|c|}{ yes } & \multicolumn{2}{|c|}{ yes } \\
\hline Number of observations & \multicolumn{2}{|c|}{1047} & \multicolumn{2}{|c|}{2096} \\
\hline Number of individuals & \multicolumn{2}{|c|}{387} & \multicolumn{2}{|c|}{736} \\
\hline Overall F-test & \multicolumn{2}{|c|}{$F(15,386)=1.58$} & \multicolumn{2}{|c|}{$F(15,735)=3.49$} \\
\hline F-test SSC terms & \multicolumn{2}{|c|}{$F(4,386)=2.90$} & \multicolumn{2}{|c|}{$F(4,735)=2.09$} \\
\hline$p$-value & \multicolumn{2}{|c|}{0.022} & \multicolumn{2}{|c|}{0.0799} \\
\hline R-squared & \multicolumn{2}{|c|}{0.0438} & \multicolumn{2}{|c|}{0.0524} \\
\hline $\operatorname{corr}\left(\eta_{i}, X_{i t} \alpha\right)$ & \multicolumn{2}{|c|}{-0.132} & \multicolumn{2}{|c|}{-0.3913} \\
\hline Robust Hausman test for FE & \multicolumn{2}{|c|}{$\chi_{(15)}^{2}=27.007$} & \multicolumn{2}{|c|}{$\chi_{(15)}^{2}=49.701$} \\
\hline$p$-value & \multicolumn{2}{|c|}{0.0287} & \multicolumn{2}{|c|}{0.0000} \\
\hline
\end{tabular}

SSC stands for Sample selection correction.

[G2]: Dropout group with only classroom training and no internship placement (183 individuals).

[G3]: Dropout group with classroom training and internship placement (231 individuals).

[G4]: Treatment group with the full treatment (578 individuals).

The time dimension of the panel consists of four time periods: Nov-99, May-01, Nov-01, and May-02. This represents baseline before Projoven, 6 months after Projoven, 12 months after Projoven, and 18 months after Projoven, respectively. In all the models, the base periods are Nov-99 and May-01. Two base periods are chosen, as the treatment variable takes the value zero for all individuals (treatment and controls) before the programme (Nov-99).

Robust standard errors clustered by individuals in parentheses. The standard errors should be interpreted as asymptotic lower bounds. 
Appendix

Table A4.6.

Projoven sixth public call participation effects on monthly wages. Heterogeneous effects over time. FE estimates [with sample selection correction - Wooldridge, 1995]

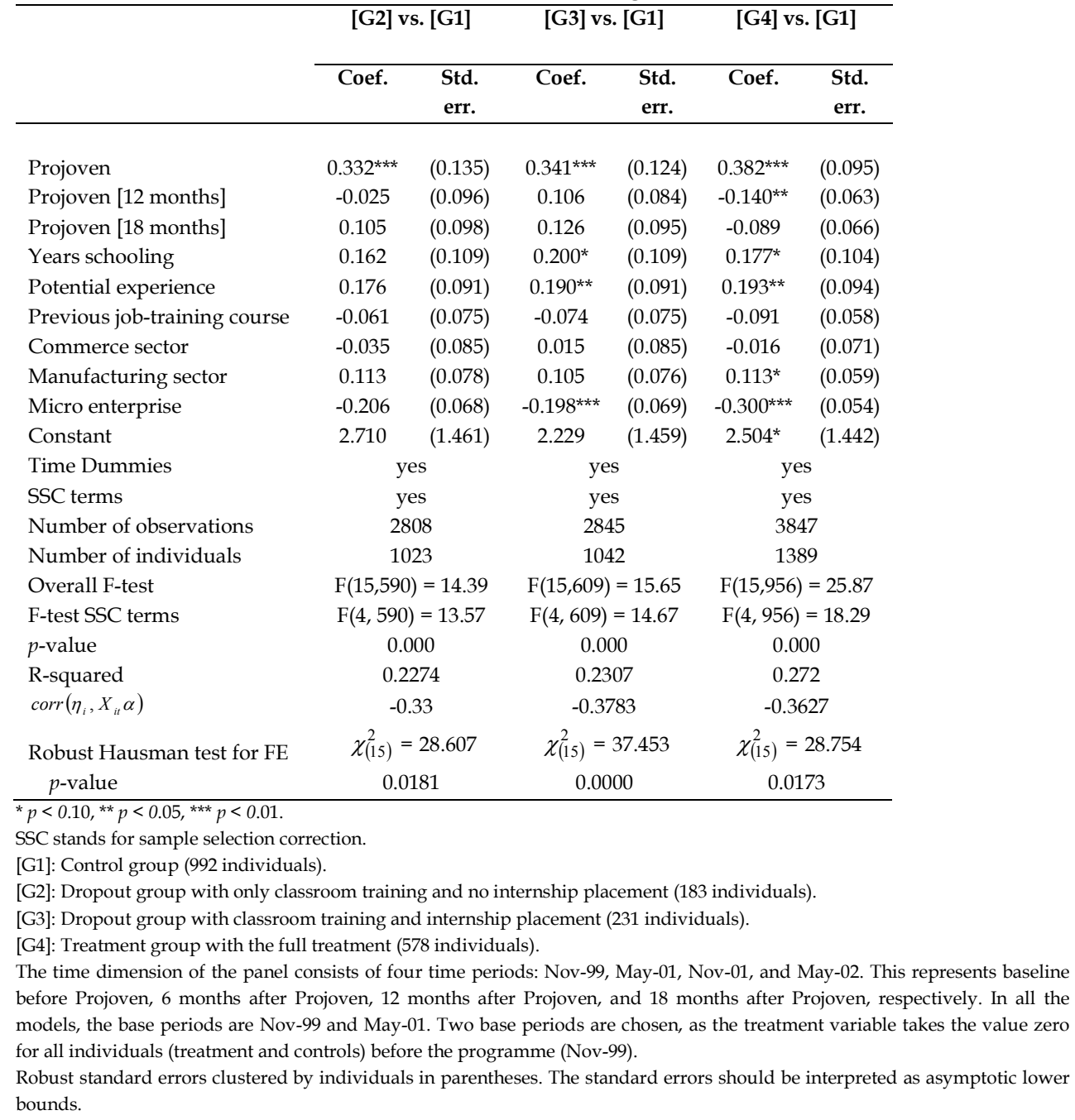


Table A4.7.

Projoven sixth public call internship placement effects on monthly wages. Heterogeneous treatment over time [only trainees sample]. FE estimates [with sample selection correction Wooldridge, 1995]

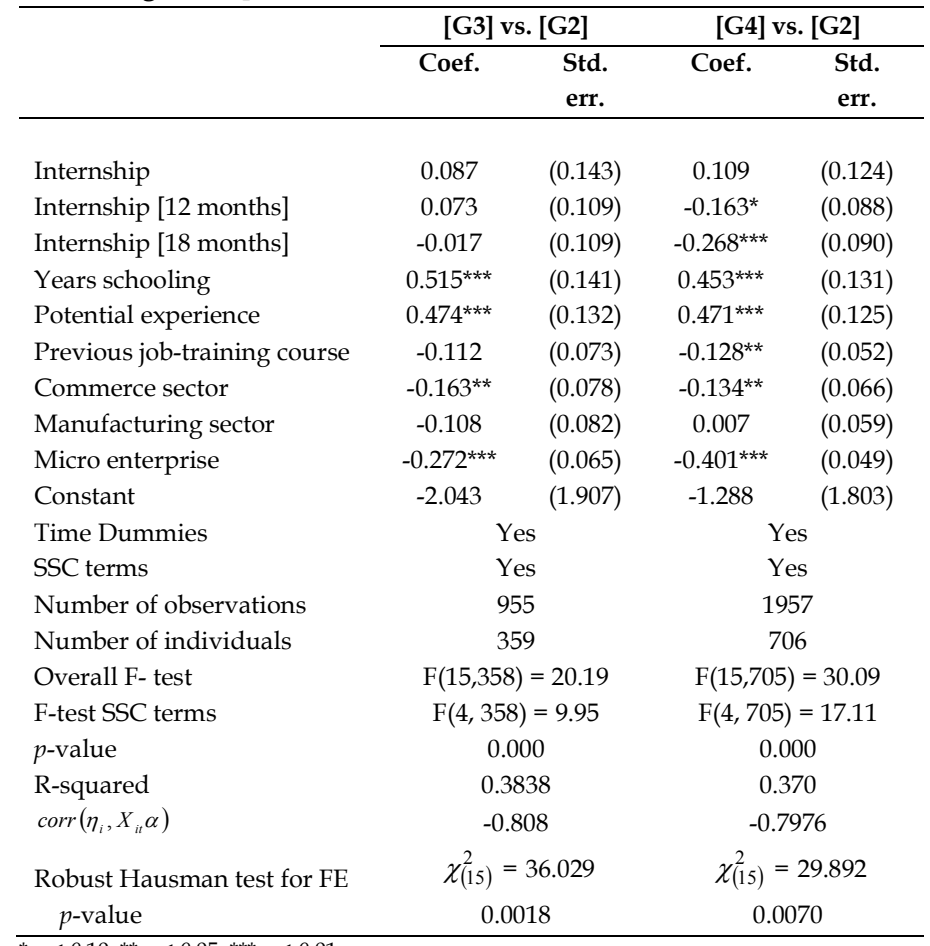

${ }^{*} p<0.10,{ }^{* *} p<0.05,{ }^{* * *} p<0.01$.

SSC stands for sample selection correction.

[G2]: Dropout group with only classroom training and no internship placement (183 individuals).

[G3]: Dropout group with classroom training and internship placement (231 individuals).

[G4]: Treatment group with the full treatment (578 individuals).

The time dimension of the panel consists of four time periods: Nov-99, May-01, Nov-01, and May-02. This represents baseline before Projoven, 6 months after Projoven, 12 months after Projoven, and 18 months after Projoven, respectively. In all the models, the base periods are Nov-99 and May-01. Two base periods are chosen, as the treatment variable takes the value zero for all individuals (treatment and controls) before the programme (Nov-99).

Robust standard errors clustered by individuals in parentheses. The standard errors should be interpreted as asymptotic lower bounds. 
Table A4.8.

Projoven sixth public call internship placement effects. Endogenous and heterogeneous treatment over time [only trainees sample] [G3] vs. [G2]. Pooled two-stage least squares with sample selection correction estimation.

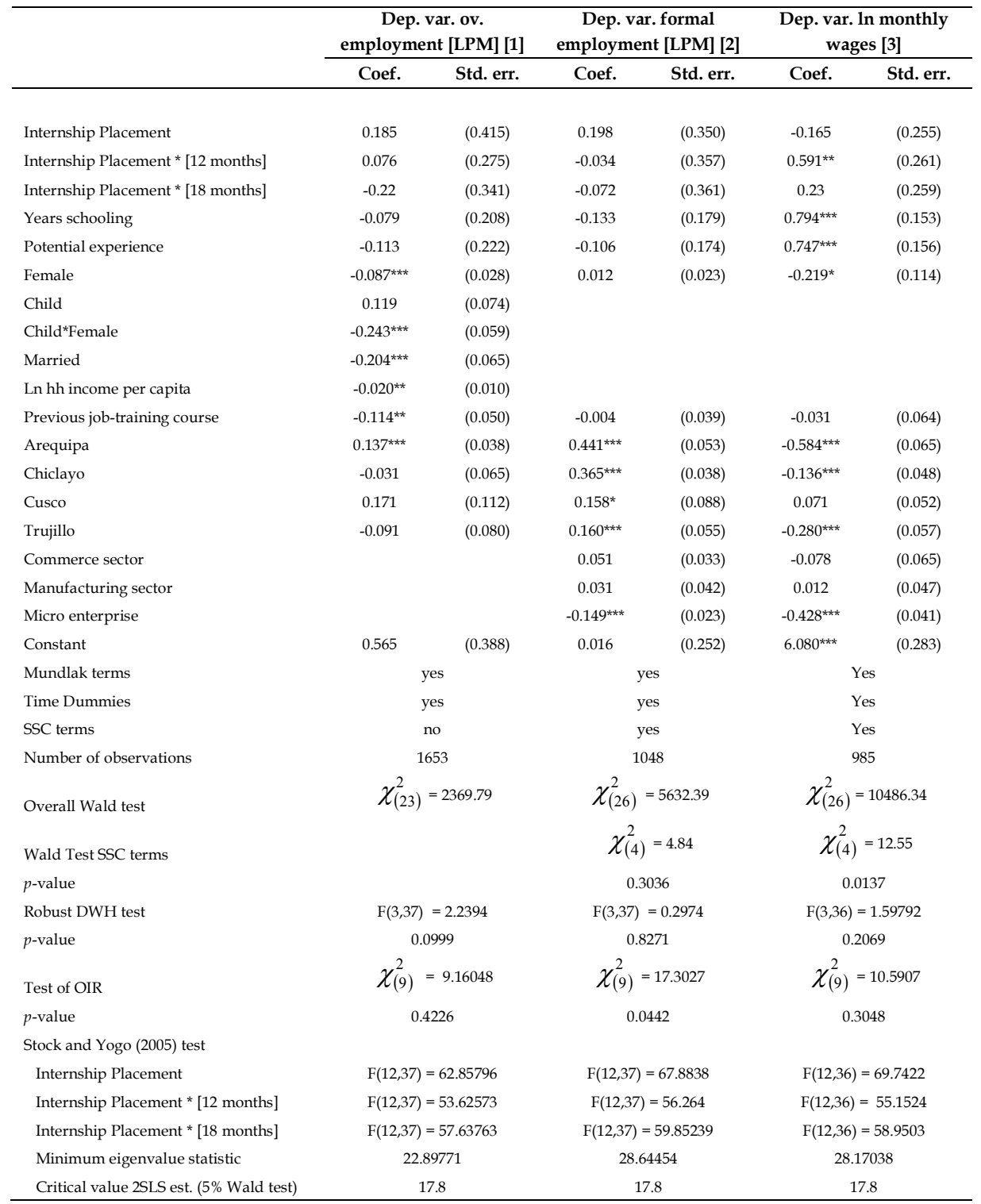

${ }^{*} p<0.10,{ }^{* *} p<0.05,{ }^{* * *} p<0.01$

SSC stands for sample selection correction; DWH for Durbin-Wu-Hausman test; and OIR for overidentifying restrictions test.

[G2]: Dropout group with only classroom training and no internship placement (183 individuals).

[G3]: Dropout group with classroom training and internship placement (231 individuals).

The time dimension of the panel consists of four time periods: Nov-99, May-01, Nov-01, and May-02. This represents baseline before Projoven, 6 months after Projoven, 12 months after Projoven, and 18 months after Projoven, respectively. In all the models, the base periods are Nov-99 and May-01. Two base periods are chosen, as the treatment variable takes the value zero for all individuals (treatment and controls) before the programme (Nov-99).

Robust standard errors clustered by individuals in parentheses. The standard errors should be interpreted as asymptotic lower bounds. 
Table A4.9.

Projoven sixth public call internship placement effects. Endogenous and heterogeneous treatment over time [only trainees sample] [G4] vs. [G2]. Pooled two-stage least squares with sample selection correction estimation.

\begin{tabular}{|c|c|c|c|c|c|c|}
\hline & \multicolumn{2}{|c|}{$\begin{array}{c}\text { Dep. var. ov. employment } \\
{[\mathrm{LPM}][1]}\end{array}$} & \multicolumn{2}{|c|}{$\begin{array}{c}\text { Dep. var. formal } \\
\text { employment [LPM] [2] }\end{array}$} & \multicolumn{2}{|c|}{$\begin{array}{l}\text { Dep. var. In monthly } \\
\text { wages [3] }\end{array}$} \\
\hline & Coef. & Std. err. & Coef. & Std. err. & Coef. & Std. err. \\
\hline Internship Placement & $0.215^{*}$ & $(0.115)$ & 0.485 & $(0.300)$ & 0.632 & $(1.076)$ \\
\hline Internship Placement * [12 months] & -0.112 & $(0.093)$ & -0.129 & $(0.237)$ & 0.034 & $(0.904)$ \\
\hline Internship Placement * [18 months] & -0.105 & $(0.172)$ & -0.151 & $(0.301)$ & -0.115 & $(0.931)$ \\
\hline Years schooling & -0.094 & $(0.101)$ & -0.138 & $(0.124)$ & 0.387 & $(0.393)$ \\
\hline Potential experience & -0.109 & $(0.099)$ & -0.135 & $(0.119)$ & 0.372 & $(0.408)$ \\
\hline Female & $-0.095^{* * *}$ & $(0.020)$ & 0.003 & $(0.026)$ & $-0.150^{\star \star *}$ & $(0.054)$ \\
\hline Child & 0.09 & $(0.065)$ & & & & \\
\hline Child*Female & $-0.234^{* * *}$ & $(0.045)$ & & & & \\
\hline Married & $-0.133^{* *}$ & $(0.057)$ & & & & \\
\hline Ln hh income per capita & $-0.014^{* * *}$ & $(0.005)$ & & & & \\
\hline Previous job-training course & -0.038 & $(0.024)$ & -0.023 & $(0.037)$ & 0.000 & $(0.068)$ \\
\hline Arequipa & $0.110^{* * *}$ & $(0.023)$ & $0.363^{* * *}$ & $(0.039)$ & $-0.627^{\star * *}$ & $(0.135)$ \\
\hline Chiclayo & -0.050 & $(0.040)$ & $0.317^{* * *}$ & $(0.039)$ & -0.054 & $(0.084)$ \\
\hline Cusco & $0.058^{\star *}$ & $(0.023)$ & $0.057^{* *}$ & $(0.027)$ & -0.035 & $(0.073)$ \\
\hline Trujillo & $-0.097^{* * *}$ & $(0.035)$ & $0.097^{* * *}$ & $(0.025)$ & $-0.162^{\star * *}$ & $(0.061)$ \\
\hline Commerce sector & & & 0.029 & $(0.033)$ & -0.045 & $(0.053)$ \\
\hline Manufacturing sector & & & 0.041 & $(0.030)$ & 0.041 & $(0.051)$ \\
\hline Micro enterprise & & & $-0.135^{* * *}$ & $(0.028)$ & $-0.523^{\star * *}$ & $(0.053)$ \\
\hline Constant & $0.595^{\star * *}$ & $(0.166)$ & -0.085 & $(0.198)$ & $5.806^{* * *}$ & $(0.603)$ \\
\hline Mundlak terms & \multicolumn{2}{|c|}{ yes } & \multicolumn{2}{|c|}{ yes } & \multicolumn{2}{|c|}{ yes } \\
\hline Time Dummies & \multicolumn{2}{|c|}{ yes } & \multicolumn{2}{|c|}{ yes } & \multicolumn{2}{|c|}{ yes } \\
\hline SSC terms & \multicolumn{2}{|c|}{ no } & \multicolumn{2}{|c|}{ yes } & \multicolumn{2}{|c|}{ yes } \\
\hline Number of observations & \multicolumn{2}{|c|}{3083} & \multicolumn{2}{|c|}{2097} & \multicolumn{2}{|c|}{2041} \\
\hline Overall Wald test & \multicolumn{2}{|c|}{$\chi_{(23)}^{2}=1521.12$} & \multicolumn{2}{|c|}{$\chi_{(26)}^{2}=2421.91$} & \multicolumn{2}{|c|}{$\chi_{(26)}^{2}=3336.43$} \\
\hline Wald Test SSC terms & & & \multicolumn{2}{|c|}{$\chi_{(4)}^{2}=3.62$} & \multicolumn{2}{|c|}{$\chi_{(4)}^{2}=8.93$} \\
\hline$p$-value & & & \multicolumn{2}{|c|}{0.4606} & \multicolumn{2}{|c|}{0.0629} \\
\hline Robust DWH test & \multicolumn{2}{|c|}{$F(3,39)=0.977693$} & \multicolumn{2}{|c|}{$\mathrm{F}(3,39)=0.846231$} & \multicolumn{2}{|c|}{$\mathrm{F}(3,39)=1.39239$} \\
\hline$p$-value & \multicolumn{2}{|c|}{0.4131} & \multicolumn{2}{|c|}{0.477} & & \\
\hline Test of OIR & $\chi_{(9)}^{2}$ & .81067 & $\chi_{(9)}^{2}$ & 26235 & $\chi_{(9)}^{2}$ & 3422 \\
\hline$p$-value & & & & & & \\
\hline Stock and Yogo (2005) test & & & & & & \\
\hline Internship Placement & $\mathrm{F}(12,3$ & 9.2555 & $\mathrm{~F}(12,39$ & 59.59 & $\mathrm{~F}(12,39)$ & 9.0079 \\
\hline Internship Placement * [12 months] & $\mathrm{F}(12,3$ & 1.535 & $\mathrm{~F}(12,39)$ & 1.6703 & $\mathrm{~F}(12,39$ & 3.7783 \\
\hline Internship Placement * [18 months] & $\mathrm{F}(12,3$ & 4.7269 & $\mathrm{~F}(12,39)$ & 7.7693 & $\mathrm{~F}(12,39$ & 1.8624 \\
\hline Minimum eigenvalue statistic & & & 23. & & 23 & \\
\hline Critical value 2 SLS est. (5\% wald test) & & & & & & \\
\hline
\end{tabular}

SSC stands for sample selection correction; DWH for Durbin-Wu-Hausman test; and OIR for overidentifying restrictions test.

[G2]: Dropout group with only classroom training and no internship placement (183 individuals).

[G4]: Treatment group with the full treatment (578 individuals).

The time dimension of the panel consists of four time periods: Nov-99, May-01, Nov-01, and May-02. This represents baseline before Projoven, 6 months after Projoven, 12 months after Projoven, and 18 months after Projoven, respectively. In all the models, the base periods are Nov-99 and May-01. Two base periods are chosen, as the treatment variable takes the value zero for all individuals (treatment and controls) before the programme (Nov-99).

Robust standard errors clustered by individuals in parentheses. The standard errors should be interpreted as asymptotic lower bounds. 
Table A4.10.

Projoven sixth public call internship completion effects. Heterogeneous treatment over time [only trainees placed in internships sample] [G4] vs. [G3]. Pooled two-stage least squares with sample selection correction estimation.

\begin{tabular}{|c|c|c|c|c|c|c|}
\hline & \multicolumn{2}{|c|}{$\begin{array}{c}\text { Dep. var. ov. employment } \\
\text { [LPM] [1] }\end{array}$} & \multicolumn{2}{|c|}{$\begin{array}{c}\text { Dep. var. formal } \\
\text { employment [LPM] [2] }\end{array}$} & \multicolumn{2}{|c|}{$\begin{array}{c}\text { Dep. var. In monthly } \\
\text { wages [3] }\end{array}$} \\
\hline & Coef. & $\begin{array}{l}\text { Std. } \\
\text { err. }\end{array}$ & Coef. & $\begin{array}{l}\text { Std. } \\
\text { err. }\end{array}$ & Coef. & $\begin{array}{l}\text { Std. } \\
\text { err. }\end{array}$ \\
\hline Internship Completion & 0.172 & $(0.136)$ & $0.327^{* *}$ & $(0.153)$ & 0.695 & $(0.543)$ \\
\hline Internship Completion * [12 months] & -0.111 & $(0.157)$ & 0.070 & $(0.150)$ & -0.497 & $(0.442)$ \\
\hline Internship Completion * [18 months] & 0.036 & $(0.137)$ & -0.142 & $(0.223)$ & -0.286 & $(0.496)$ \\
\hline Years schooling & -0.098 & $(0.129)$ & -0.087 & $(0.175)$ & -0.036 & $(0.543)$ \\
\hline Potential experience & -0.091 & $(0.122)$ & -0.091 & $(0.159)$ & -0.052 & $(0.514)$ \\
\hline Female & $-0.095^{* * *}$ & $(0.021)$ & -0.024 & $(0.022)$ & $-0.174^{\star \star *}$ & $(0.064)$ \\
\hline Child & -0.016 & $(0.051)$ & & & & \\
\hline Child*Female & $-0.234^{\star \star *}$ & $(0.045)$ & & & & \\
\hline Married & -0.087 & $(0.056)$ & & & & \\
\hline Ln hh income per capita & $-0.017^{\star * *}$ & $(0.004)$ & & & & \\
\hline Previous job-training course & -0.050 & $(0.033)$ & -0.031 & $(0.032)$ & -0.048 & $(0.056)$ \\
\hline Arequipa & $0.105^{* * *}$ & $(0.027)$ & $0.377^{\star * *}$ & $(0.037)$ & $-0.599^{* * *}$ & $(0.125)$ \\
\hline Chiclayo & -0.054 & $(0.038)$ & $0.358^{* * *}$ & $(0.043)$ & -0.096 & $(0.068)$ \\
\hline Cusco & 0.033 & $(0.030)$ & 0.045 & $(0.056)$ & -0.092 & $(0.098)$ \\
\hline Trujillo & $-0.101^{\text {*** }}$ & $(0.039)$ & 0.059 & $(0.041)$ & $-0.199^{*}$ & $(0.104)$ \\
\hline Commerce sector & & & 0.012 & $(0.032)$ & -0.002 & $(0.065)$ \\
\hline Manufacturing sector & & & 0.013 & $(0.037)$ & 0.065 & $(0.054)$ \\
\hline Micro enterprise & & & $-0.153^{* * *}$ & $(0.028)$ & $-0.554^{\star * *}$ & $(0.052)$ \\
\hline Constant & $0.672^{* * *}$ & $(0.166)$ & 0.166 & $(0.265)$ & $5.756^{* * *}$ & $(0.553)$ \\
\hline Mundlak terms & \multicolumn{2}{|c|}{ yes } & \multicolumn{2}{|c|}{ yes } & \multicolumn{2}{|c|}{ yes } \\
\hline Time Dummies & \multicolumn{2}{|c|}{ yes } & \multicolumn{2}{|c|}{ yes } & \multicolumn{2}{|c|}{ yes } \\
\hline SSC terms & \multicolumn{2}{|c|}{ no } & \multicolumn{2}{|c|}{ yes } & \multicolumn{2}{|c|}{ yes } \\
\hline Number of observations & \multicolumn{2}{|c|}{2827} & \multicolumn{2}{|c|}{1909} & \multicolumn{2}{|c|}{1849} \\
\hline Overall Wald test & \multicolumn{2}{|c|}{$\chi_{(23)}^{2}=1993.82$} & \multicolumn{2}{|c|}{$\chi_{(26)}^{2}=2411.81$} & \multicolumn{2}{|c|}{$\chi_{(26)}^{2}=2254.67$} \\
\hline Wald Test SSC terms & & & \multicolumn{2}{|c|}{$\chi_{(4)}^{2}=7.90$} & \multicolumn{2}{|c|}{$\chi_{(4)}^{2}=15.44$} \\
\hline$p$-value & & & \multicolumn{2}{|c|}{0.0952} & \multicolumn{2}{|c|}{0.0039} \\
\hline Robust DWH test & \multicolumn{2}{|c|}{$\mathrm{F}(3,38)=6.20241$} & \multicolumn{2}{|c|}{$\mathrm{F}(3,38)=1.91838$} & \multicolumn{2}{|c|}{$F(3,38)=1.12364$} \\
\hline$p$-value & \multicolumn{2}{|c|}{0.0016} & \multicolumn{2}{|c|}{0.143} & & \\
\hline Test of OIR & $\chi_{(9)}^{2}$ & 23207 & $\chi_{(9)}^{2}$ & 5149 & $\chi_{(9}^{2}$ & 0303 \\
\hline$p$-value & & & & & & \\
\hline Stock and Yogo (2005) test & & & & & & \\
\hline Internship Completion & $\mathrm{F}(12,3$ & 8.5661 & $\mathrm{~F}(12,38$ & .7998 & $\mathrm{~F}(12,3$ & .0554 \\
\hline Internship Completion * [12 months] & $\mathrm{F}(12,3$ & .7263 & $\mathrm{~F}(12,3$ & 8.858 & $\mathrm{~F}(12,3$ & 6.8677 \\
\hline Internship Completion * [18 months] & $\mathrm{F}(12,3$ & 9.6821 & $\mathrm{~F}(12,38$ & .5849 & $\mathrm{~F}(12,3$ & 2.0137 \\
\hline Minimum eigenvalue statistic & & & & & & \\
\hline Critical value 2 SLS est. (5\% Wald test) & & & & & & \\
\hline
\end{tabular}

SSC stands for sample selection correction; DWH for Durbin-Wu-Hausman test; and OIR for overidentifying restrictions test.

[G3]: Dropout group with classroom training and internship placement (231 individuals).

[G4]: Treatment group with the full treatment (578 individuals).

The time dimension of the panel consists of four time periods: Nov-99, May-01, Nov-01, and May-02. This represents baseline before Projoven, 6 months after Projoven, 12 months after Projoven, and 18 months after Projoven, respectively. In all the models, the base periods are Nov-99 and May-01. Two base periods are chosen, as the treatment variable takes the value zero for all individuals (treatment and controls) before the programme (Nov-99).

Robust standard errors clustered by individuals in parentheses.The standard errors should be interpreted as asymptotic lower bounds. 
Table A4.11.

Projoven sixth public call participation effects on overall employment. Heterogeneous effects over time and across individual characteristics. LPM-RE estimates

\begin{tabular}{|c|c|c|c|c|c|c|}
\hline & \multicolumn{2}{|c|}{ [G2] vs. [G1] } & \multicolumn{2}{|c|}{ [G3] vs. [G1] } & \multicolumn{2}{|c|}{ [G4] vs. [G1] } \\
\hline & Coef. & $\begin{array}{l}\text { Std. } \\
\text { err. }\end{array}$ & Coef. & $\begin{array}{l}\text { Std. } \\
\text { err. }\end{array}$ & Coef. & $\begin{array}{l}\text { Std. } \\
\text { err. }\end{array}$ \\
\hline Projoven*Female & -0.079 & $(0.067)$ & $-0.114^{*}$ & $(0.065)$ & $-0.069^{*}$ & $(0.039)$ \\
\hline Projoven*No work experience & $0.167^{* *}$ & $(0.068)$ & $0.148^{* *}$ & $(0.068)$ & $0.243^{* * *}$ & $(0.048)$ \\
\hline Projoven*Lowest quartile & -0.013 & $(0.077)$ & 0.012 & $(0.071)$ & 0.029 & $(0.052)$ \\
\hline Projoven*Female*[12 months $]$ & 0.084 & $(0.073)$ & 0.100 & $(0.067)$ & -0.013 & $(0.041)$ \\
\hline Projoven*No work experience*[12 months $]$ & -0.01 & $(0.079)$ & -0.074 & $(0.068)$ & -0.043 & $(0.047)$ \\
\hline Projoven*Lowest quartile*[12 months $]$ & -0.052 & $(0.083)$ & -0.026 & $(0.068)$ & 0.023 & $(0.052)$ \\
\hline Projoven*Female*[18 months] & 0.011 & $(0.077)$ & 0.084 & $(0.070)$ & 0.000 & $(0.046)$ \\
\hline Projoven*No work experience*[18 months $]$ & 0.003 & $(0.082)$ & 0.085 & $(0.076)$ & $0.093^{*}$ & $(0.050)$ \\
\hline Projoven*Lowest quartile*[18 months] & -0.01 & $(0.084)$ & -0.055 & $(0.080)$ & 0.007 & $(0.053)$ \\
\hline Female & $-0.050^{*}$ & $(0.029)$ & $-0.048^{*}$ & $(0.028)$ & $-0.046^{*}$ & $(0.026)$ \\
\hline No work experience & $-0.373^{* * *}$ & $(0.030)$ & $-0.374^{* * *}$ & $(0.030)$ & $-0.391^{* * *}$ & $(0.027)$ \\
\hline Lowest quartile & $-0.064^{*}$ & $(0.033)$ & $-0.055^{*}$ & $(0.033)$ & $-0.055^{*}$ & $(0.031)$ \\
\hline Constant & $0.181^{* * *}$ & $(0.021)$ & $0.177^{* * *}$ & $(0.021)$ & $0.165^{\star * *}$ & $(0.017)$ \\
\hline Time Dummies & \multicolumn{2}{|c|}{ Yes } & \multicolumn{2}{|c|}{ yes } & \multicolumn{2}{|c|}{ yes } \\
\hline Number of observations & \multicolumn{2}{|c|}{2571} & \multicolumn{2}{|c|}{2626} & \multicolumn{2}{|c|}{3434} \\
\hline Number of individuals & \multicolumn{2}{|c|}{645} & \multicolumn{2}{|c|}{659} & \multicolumn{2}{|c|}{861} \\
\hline Wald test & \multicolumn{2}{|c|}{$\chi_{(14)}^{2}=263.51$} & \multicolumn{2}{|c|}{$\chi_{(14)}^{2}=268.74$} & \multicolumn{2}{|c|}{$\chi_{(14)}^{2}=345.39$} \\
\hline R-squared & \multicolumn{2}{|c|}{0.3307} & \multicolumn{2}{|c|}{0.323} & \multicolumn{2}{|c|}{0.2901} \\
\hline
\end{tabular}

${ }^{*} p<0.10,{ }^{* *} p<0.05,{ }^{* * *} p<0.01$.

[G1]: Control group (992 individuals).

[G2]: Dropout group with only classroom training and no internship placement (183 individuals).

[G3]: Dropout group with classroom training and internship placement (231 individuals).

[G4]: Treatment group with the full treatment (578 individuals).

The time dimension of the panel consists of four time periods: Nov-99, May-01, Nov-01, and May-02. This represents baseline before Projoven, 6 months after Projoven, 12 months after Projoven, and 18 months after Projoven, respectively. In all the models the base periods are Nov-99 and May-01. Two base periods are chosen, as the treatment variable takes the value zero for all individuals (treatment and controls) before the programme (Nov-99).

Robust standard errors clustered by individuals in parentheses. 
Table A4.12.

Projoven sixth public call internship placement effects on overall employment. Heterogeneous effects over time and across individual characteristics [only trainees sample]. LPM-RE estimates.

\begin{tabular}{|c|c|c|c|c|}
\hline & \multicolumn{2}{|c|}{ [G3] vs. [G2] } & \multicolumn{2}{|c|}{ [G4] vs. [G2] } \\
\hline & Coef. & $\begin{array}{l}\text { Std. } \\
\text { err. }\end{array}$ & Coef. & $\begin{array}{l}\text { Std. } \\
\text { err. }\end{array}$ \\
\hline Internship*Female & -0.095 & $(0.065)$ & -0.049 & $(0.039)$ \\
\hline Internship* No work experience & 0.108 & $(0.068)$ & $0.241^{* * *}$ & $(0.048)$ \\
\hline Internship*Lowest quartile & 0.009 & $(0.069)$ & 0.014 & $(0.051)$ \\
\hline Internship ${ }^{*}$ Female ${ }^{*}[12$ months] & 0.102 & $(0.067)$ & 0.000 & $(0.042)$ \\
\hline Internship*No work experience*[12 months] & -0.067 & $(0.069)$ & -0.038 & $(0.048)$ \\
\hline Internship*Lowest quartile*[12 months] & -0.020 & $(0.068)$ & 0.027 & $(0.052)$ \\
\hline Internship ${ }^{*}$ Female $^{*}[18$ months $]$ & 0.106 & $(0.070)$ & 0.041 & $(0.045)$ \\
\hline Internship*No work experience* ${ }^{*} 18$ months $]$ & 0.105 & $(0.076)$ & $0.106^{* *}$ & $(0.050)$ \\
\hline Internship ${ }^{*}$ Lowest quartile*[18 months $]$ & -0.032 & $(0.079)$ & 0.018 & $(0.053)$ \\
\hline Female & -0.036 & $(0.032)$ & $-0.045^{*}$ & $(0.025)$ \\
\hline No work experience & $-0.315^{* * *}$ & $(0.034)$ & $-0.360^{* * *}$ & $(0.028)$ \\
\hline Lowest quartile & -0.029 & $(0.035)$ & -0.047 & $(0.029)$ \\
\hline Constant & $0.164^{\star * *}$ & $(0.024)$ & $0.145^{* * *}$ & $(0.017)$ \\
\hline Time Dummies & \multicolumn{2}{|c|}{ yes } & \multicolumn{2}{|c|}{ yes } \\
\hline Number of observations & \multicolumn{2}{|c|}{821} & \multicolumn{2}{|c|}{1629} \\
\hline Number of individuals & \multicolumn{2}{|c|}{206} & \multicolumn{2}{|c|}{408} \\
\hline Wald test & \multicolumn{2}{|c|}{$\chi_{(14)}^{2}=118.23$} & \multicolumn{2}{|c|}{$\chi_{(14)}^{2}=221.66$} \\
\hline R-squared & \multicolumn{2}{|c|}{0.2024} & \multicolumn{2}{|c|}{0.1729} \\
\hline
\end{tabular}

${ }^{*} p<0.10,{ }^{* *} p<0.05,{ }^{* * *} p<0.01$.

[G2]: Dropout group with only classroom training and no internship placement (183 individuals).

[G3]: Dropout group with classroom training and internship placement (231 individuals).

[G4]: Treatment group with the full treatment (578 individuals).

The time dimension of the panel consists of four time periods: Nov-99, May-01, Nov-01, and May-02. This represents baseline before Projoven, 6 months after Projoven, 12 months after Projoven, and 18 months after Projoven, respectively. In all the models, the base periods are Nov-99 and May-01. Two base periods are chosen, as the treatment variable takes the value zero for all individuals (treatment and controls) before the programme (Nov-99).

Robust standard errors clustered by individuals in parentheses. 
Table A4.13.

Projoven sixth public call participation effects on formal employment. Heterogeneous effects over time and across individual characteristics. LPM-RE estimates [with sample selection correction Wooldridge, 1995].

\begin{tabular}{|c|c|c|c|c|c|c|}
\hline & \multicolumn{2}{|c|}{ [G2] vs. [G1] } & \multicolumn{2}{|c|}{ [G3] vs. [G1] } & \multicolumn{2}{|c|}{ [G4] vs. [G1] } \\
\hline & Coef. & $\begin{array}{l}\text { Std. } \\
\text { err. }\end{array}$ & Coef. & $\begin{array}{l}\text { Std. } \\
\text { err. }\end{array}$ & Coef. & $\begin{array}{l}\text { Std. } \\
\text { err. }\end{array}$ \\
\hline Projoven*Female & -0.105 & $(0.086)$ & -0.099 & $(0.087)$ & -0.059 & $(0.047)$ \\
\hline Projoven*No work experience & 0.021 & $(0.097)$ & -0.062 & $(0.098)$ & 0.094 & $(0.065)$ \\
\hline Projoven*Lowest quartile & 0.031 & $(0.103)$ & $0.159^{*}$ & $(0.088)$ & -0.042 & $(0.065)$ \\
\hline Projoven ${ }^{*}$ Female ${ }^{*}[12$ months $]$ & 0.008 & $(0.102)$ & 0.111 & $(0.097)$ & 0.024 & $(0.052)$ \\
\hline Projoven*No work experience* ${ }^{*} 12$ months $]$ & -0.090 & $(0.107)$ & $-0.190^{*}$ & $(0.099)$ & -0.091 & $(0.063)$ \\
\hline Projoven*Lowest quartile*[12 months $]$ & 0.003 & $(0.108)$ & -0.022 & $(0.102)$ & 0.059 & $(0.063)$ \\
\hline Projoven*Female*[18 months $]$ & 0.046 & $(0.098)$ & 0.068 & $(0.086)$ & -0.011 & $(0.052)$ \\
\hline Projoven ${ }^{*}$ No work experience* $[18$ months $]$ & 0.089 & $(0.102)$ & 0.034 & $(0.095)$ & -0.064 & $(0.063)$ \\
\hline Projoven*Lowest quartile* $[18$ months $]$ & 0.003 & $(0.106)$ & -0.08 & $(0.078)$ & 0.02 & $(0.066)$ \\
\hline Female & $0.108^{* * *}$ & $(0.040)$ & $0.091^{* *}$ & $(0.040)$ & $0.114^{* * *}$ & $(0.035)$ \\
\hline No work experience & 0.069 & $(0.046)$ & 0.047 & $(0.044)$ & 0.048 & $(0.042)$ \\
\hline Lowest quartile & $0.105^{\star *}$ & $(0.042)$ & $0.072^{*}$ & $(0.041)$ & $0.085^{* *}$ & $(0.038)$ \\
\hline Constant & $-0.094^{* * *}$ & $(0.033)$ & $-0.064^{* *}$ & $(0.032)$ & $-0.086^{* * *}$ & $(0.025)$ \\
\hline Time Dummies & \multicolumn{2}{|c|}{ yes } & \multicolumn{2}{|c|}{ yes } & \multicolumn{2}{|c|}{ yes } \\
\hline Number of observations & \multicolumn{2}{|c|}{1538} & \multicolumn{2}{|c|}{1559} & \multicolumn{2}{|c|}{2110} \\
\hline Number of individuals & \multicolumn{2}{|c|}{614} & \multicolumn{2}{|c|}{633} & \multicolumn{2}{|c|}{828} \\
\hline Overall Wald test & \multicolumn{2}{|c|}{$\chi_{(14)}^{2}=37.86$} & \multicolumn{2}{|c|}{$\chi_{(14)}^{2}=34.22$} & \multicolumn{2}{|c|}{$\chi_{(14)}^{2}=40.54$} \\
\hline R-squared & \multicolumn{2}{|c|}{0.0644} & \multicolumn{2}{|c|}{0.0479} & \multicolumn{2}{|c|}{0.0495} \\
\hline
\end{tabular}

${ }^{*} p<0.10,{ }^{* *} p<0.05,{ }^{* * *} p<0.01$.

[G1]: Control group (992 individuals).

[G2]: Dropout group with only classroom training and no internship placement (183 individuals).

[G3]: Dropout group with classroom training and internship placement (231 individuals).

[G4]: Treatment group with the full treatment (578 individuals).

The time dimension of the panel consists of four time periods: Nov-99, May-01, Nov-01, and May-02. This represents baseline before Projoven, 6 months after Projoven, 12 months after Projoven, and 18 months after Projoven, respectively. In all the models the base periods are Nov- 99 and May-01. Two base periods are chosen, as the treatment variable takes the value zero for all individuals (treatment and controls) before the programme (Nov-99).

Robust standard errors clustered by individuals in parentheses. 
Table A4.14.

Projoven sixth public call participation effects on monthly wages. Heterogeneous effects over time and across individual characteristics. RE estimates [with sample selection correction - Wooldridge, 1995].

\begin{tabular}{|c|c|c|c|c|c|c|}
\hline & \multicolumn{2}{|c|}{ [G2] vs. [G1] } & \multicolumn{2}{|c|}{ [G3] vs. [G1] } & \multicolumn{2}{|c|}{ [G4] vs. [G1] } \\
\hline & Coef. & $\begin{array}{l}\text { Std. } \\
\text { err. }\end{array}$ & Coef. & $\begin{array}{l}\text { Std. } \\
\text { err. }\end{array}$ & Coef. & $\begin{array}{l}\text { Std. } \\
\text { err. }\end{array}$ \\
\hline Projoven*Female & -0.151 & $(0.182)$ & 0.000 & $(0.152)$ & -0.108 & $(0.092)$ \\
\hline Projoven*No work experience & -0.241 & $(0.166)$ & -0.209 & $(0.177)$ & 0.193 & $(0.126)$ \\
\hline Projoven*Lowest quartile & $0.363^{*}$ & $(0.208)$ & 0.040 & $(0.187)$ & $0.215^{*}$ & $(0.117)$ \\
\hline Projoven*Female*[12 months] & -0.115 & $(0.147)$ & $-0.221^{*}$ & $(0.122)$ & -0.061 & $(0.066)$ \\
\hline Projoven*No work experience*[12 months $]$ & -0.03 & $(0.134)$ & $0.228^{*}$ & $(0.137)$ & -0.023 & $(0.080)$ \\
\hline Projoven*Lowest quartile*[12 months] & 0.142 & $(0.161)$ & 0.089 & $(0.126)$ & 0.074 & $(0.085)$ \\
\hline Projoven*Female*[18 months $]$ & -0.146 & $(0.155)$ & -0.168 & $(0.123)$ & 0.085 & $(0.067)$ \\
\hline Projoven*No work experience* $[18$ months $]$ & $0.312^{* *}$ & $(0.138)$ & 0.211 & $(0.168)$ & -0.001 & $(0.080)$ \\
\hline Projoven*Lowest quartile*[18 months $]$ & -0.054 & $(0.155)$ & 0.061 & $(0.172)$ & -0.047 & $(0.084)$ \\
\hline Female & $-0.262^{* *}$ & $(0.125)$ & $-0.261^{* *}$ & $(0.125)$ & $-0.190^{*}$ & $(0.106)$ \\
\hline No work experience & $0.352^{* * *}$ & $(0.131)$ & $0.303^{* *}$ & $(0.131)$ & $0.245^{\star *}$ & $(0.118)$ \\
\hline Lowest quartile & 0.095 & $(0.131)$ & 0.132 & $(0.130)$ & -0.041 & $(0.116)$ \\
\hline Constant & 0.050 & $(0.078)$ & 0.061 & $(0.077)$ & 0.057 & $(0.061)$ \\
\hline Time Dummies & \multicolumn{2}{|c|}{ yes } & \multicolumn{2}{|c|}{ yes } & \multicolumn{2}{|c|}{ yes } \\
\hline Number of observations & \multicolumn{2}{|c|}{1303} & \multicolumn{2}{|c|}{1298} & \multicolumn{2}{|c|}{1814} \\
\hline Number of individuals & \multicolumn{2}{|c|}{528} & \multicolumn{2}{|c|}{536} & \multicolumn{2}{|c|}{732} \\
\hline Overall Wald test & \multicolumn{2}{|c|}{$\chi_{(14)}^{2}=40.78$} & \multicolumn{2}{|c|}{$\chi_{(14)}^{2}=20.25$} & \multicolumn{2}{|c|}{$\chi_{(14)}^{2}=35.99$} \\
\hline R-squared & \multicolumn{2}{|c|}{0.0366} & \multicolumn{2}{|c|}{0.0336} & \multicolumn{2}{|c|}{0.0141} \\
\hline \multicolumn{7}{|l|}{${ }^{*} p<0.10,{ }^{* *} p<0.05,{ }^{* * *} p<0.01$} \\
\hline \multicolumn{7}{|l|}{ [G1]: Control group (992 individuals). } \\
\hline \multicolumn{7}{|c|}{ [G2]: Dropout group with only classroom training and no internship placement (183 individuals). } \\
\hline \multicolumn{7}{|c|}{ [G3]: Dropout group with classroom training and internship placement (231 individuals). } \\
\hline \multicolumn{7}{|c|}{ [G4]: Treatment group with the full treatment (578 individuals). } \\
\hline \multicolumn{7}{|c|}{$\begin{array}{l}\text { The time dimension of the panel consists of four time periods: Nov- } 99 \text {, May- } 01, \text { Nov- } 01 \text {, and May- } 02 \text {. This represents baseline } \\
\text { before Projoven, } 6 \text { months after Projoven, } 12 \text { months after Projoven, and } 18 \text { months after Projoven, respectively. In all the } \\
\text { models, the base periods are Nov- } 99 \text { and May- } 01 \text {. Two base periods are chosen, as the treatment variable takes the value zero } \\
\text { for all individuals (treatment and controls) before the programme (Nov-99). }\end{array}$} \\
\hline
\end{tabular}


Table A4.15.

Projoven sixth public call internship effects on formal employment. Heterogeneous effects over time and across individual characteristics [only trainees sample]. LPM-RE estimates [with sample selection correction - Wooldridge, 1995].

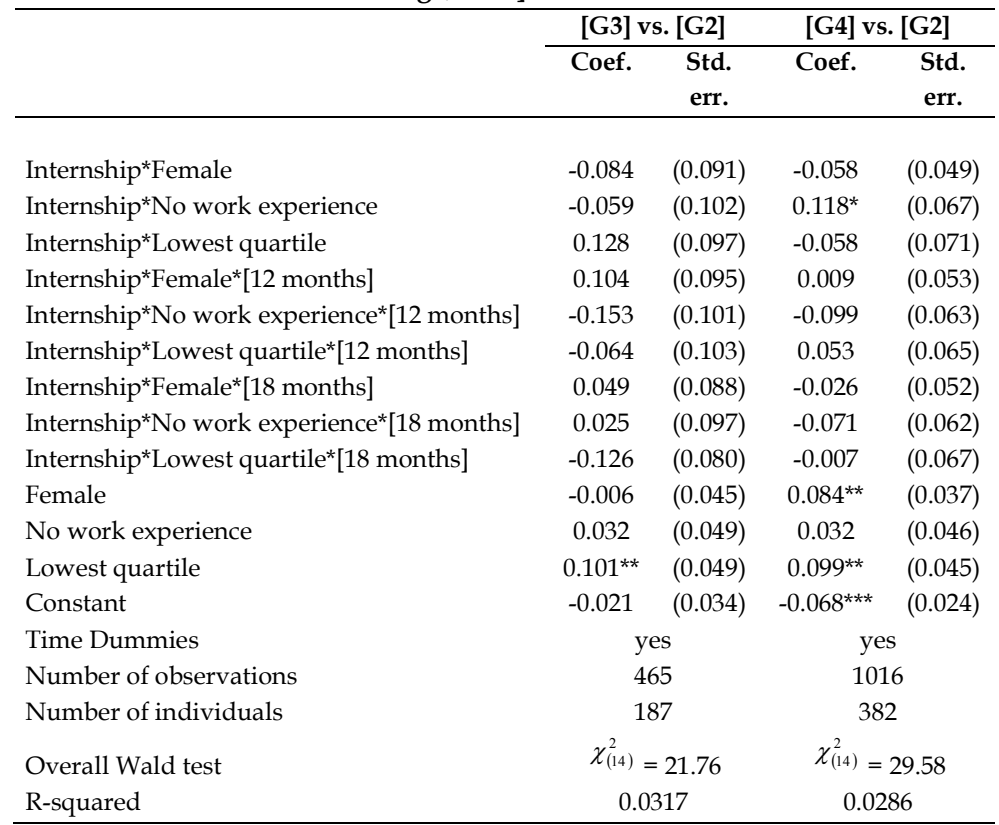

${ }^{*} p<0.10,{ }^{* *} p<0.05,{ }^{* * *} p<0.01$.

[G2]: Dropout group with only classroom training and no internship placement (183 individuals).

[G3]: Dropout group with classroom training and internship placement (231 individuals).

[G4]: Treatment group with the full treatment (578 individuals).

The time dimension of the panel consists of four time periods: Nov-99, May-01, Nov-01, and May-02. This represents baseline before Projoven, 6 months after Projoven, 12 months after Projoven, and 18 months after Projoven, respectively. In all the models, the base periods are Nov-99 and May-01. Two base periods are chosen, as the treatment variable takes the value zero for all individuals (treatment and controls) before the programme (Nov-99).

Robust standard errors clustered by individuals in parentheses. 
Table A4.16.

Projoven sixth public call internship placement effects on monthly wages. Heterogeneous treatment over time and across individual characteristics [only trainees sample]. RE estimates [with sample selection correction - Wooldridge, 1995].

\begin{tabular}{|c|c|c|c|c|}
\hline & \multicolumn{2}{|c|}{ [G3] vs. [G2] } & \multicolumn{2}{|c|}{ [G4] vs. [G2] } \\
\hline & Coef. & Std. err. & Coef. & Std. err. \\
\hline Internship*Female & 0.010 & $(0.158)$ & -0.124 & $(0.100)$ \\
\hline Internship*No work experience & -0.110 & $(0.198)$ & $0.353^{* * *}$ & $(0.133)$ \\
\hline Internship*Lowest quartile & 0.193 & $(0.203)$ & $0.482^{* * *}$ & $(0.126)$ \\
\hline Internship*Female*[12 months] & -0.189 & $(0.124)$ & -0.006 & $(0.067)$ \\
\hline Internship*No work experience*[12 months] & $0.268^{*}$ & $(0.141)$ & -0.002 & $(0.082)$ \\
\hline Internship*Lowest quartile*[12 months] & 0.033 & $(0.124)$ & 0.078 & $(0.089)$ \\
\hline Internship*Female*[18 months] & -0.175 & $(0.127)$ & $0.140^{* *}$ & $(0.068)$ \\
\hline Internship*No work experience* [18 months] & 0.222 & $(0.180)$ & 0.042 & $(0.081)$ \\
\hline Internship*Lowest quartile*[18 months] & 0.020 & $(0.169)$ & -0.041 & $(0.089)$ \\
\hline Female & $-0.477^{* * *}$ & $(0.140)$ & $-0.239 * *$ & $(0.107)$ \\
\hline No work experience & $0.365^{* *}$ & $(0.146)$ & 0.18 & $(0.130)$ \\
\hline Lowest quartile & -0.110 & $(0.158)$ & $-0.482^{* * *}$ & $(0.128)$ \\
\hline Constant & 0.150 & $(0.101)$ & $0.121^{*}$ & $(0.069)$ \\
\hline Time Dummies & \multicolumn{2}{|c|}{ yes } & \multicolumn{2}{|c|}{ yes } \\
\hline Number of observations & \multicolumn{2}{|c|}{405} & \multicolumn{2}{|c|}{921} \\
\hline Number of individuals & \multicolumn{2}{|c|}{166} & \multicolumn{2}{|c|}{362} \\
\hline Overall Wald test & \multicolumn{2}{|c|}{$\chi_{(14)}^{2}=37.33$} & \multicolumn{2}{|c|}{$\chi_{(14)}^{2}=72.25$} \\
\hline R-squared & \multicolumn{2}{|c|}{0.0548} & \multicolumn{2}{|c|}{0.0300} \\
\hline
\end{tabular}

${ }^{*} p<0.10,{ }^{* *} p<0.05,{ }^{* * *} p<0.01$.

[G2]: Dropout group with only classroom training and no internship placement (183 individuals).

[G3]: Dropout group with classroom training and internship placement (231 individuals).

[G4]: Treatment group with the full treatment (578 individuals).

The time dimension of the panel consists of four time periods: Nov-99, May-01, Nov-01, and May-02. This represents baseline before Projoven, 6 months after Projoven, 12 months after Projoven, and 18 months after Projoven, respectively. In all the models, the base periods are Nov-99 and May-01. Two base periods are chosen, as the treatment variable takes the value zero for all individuals (treatment and controls) before the programme (Nov-99).

Robust standard errors clustered by individuals in parentheses. 
Table A4.17.

Projoven sixth public call internship completion effects. Heterogeneous treatment over time [only trainees placed in internships sample] [G4] vs. [G3]. RE estimates [with sample selection correction].

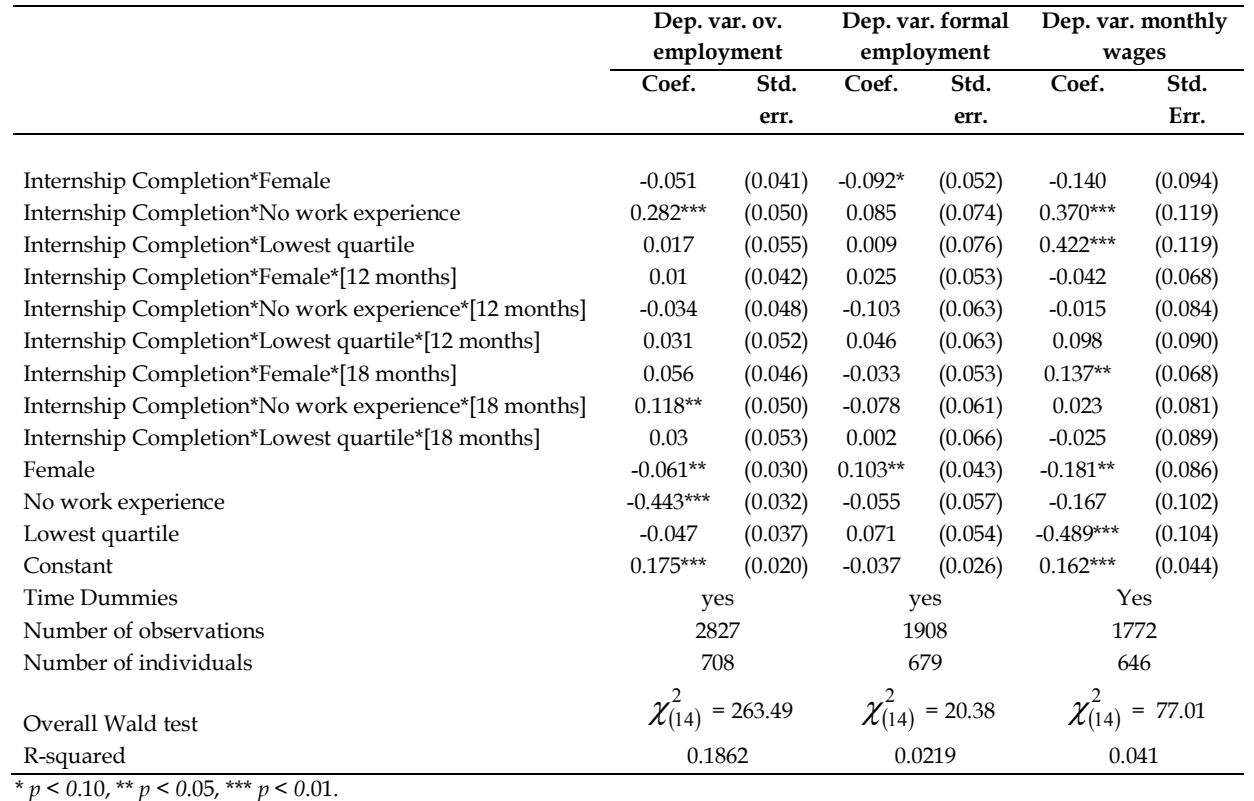

[G3]: Dropout group with classroom training and internship placement (231 individuals).

[G4]: Treatment group with the full treatment (578 individuals).

The time dimension of the panel consists of four time periods: Nov-99, May-01, Nov-01, and May-02. This represents baseline before Projoven, 6 months after Projoven, 12 months after Projoven, and 18 months after Projoven, respectively. In all the models, the base periods are Nov-99 and May-01. Two base periods are chosen, as the treatment variable takes the value zero for all individuals (treatment and controls) before the programme (Nov-99).

Robust standard errors clustered by individuals in parentheses. 
Table A4.18.

Projoven sixth public call effects on overall employment by level of completion. Heterogeneous treatment over time and endogenous treatment. Linear probability model - pooled two-stage least squares estimates [without Mundlak terms].

\begin{tabular}{ccc}
$\begin{array}{c}\text { Effects } \\
\text { after } \mathbf{6} \\
\text { months }\end{array}$ & $\begin{array}{c}\text { Additional } \\
\text { effects after } \\
\mathbf{1 2} \text { months }\end{array}$ & $\begin{array}{c}\text { Additional } \\
\text { effects after } \\
\mathbf{1 8} \text { months }\end{array}$ \\
$\hat{\beta}_{1}$ & $\left.\hat{\beta}_{2}\right]$ & $\left.\hat{\beta}_{3}\right]$ \\
\hline
\end{tabular}

A. Effects of Projoven internship placement

$\begin{array}{lccc}\text { [G3] vs. [G2] } & 0.227 & 0.048 & -0.257 \\ & (0.439) & (0.287) & (0.358) \\ \text { [G4] vs. [G2] } & 0.261^{* *} & -0.152 & -0.142 \\ & (0.118) & (0.101) & (0.177)\end{array}$

B. Effects of Projoven internship completion

$\begin{array}{llll}\text { [G4] vs. [G3] } & 0.225^{*} & -0.155 & -0.008 \\ & (0.136) & (0.157) & (0.139)\end{array}$

${ }^{*} p<0.10,{ }^{* *} p<0.05,{ }^{* * *} p<0.01$.

[G2]: Dropout group with only classroom training and no internship placement (183 individuals).

[G3]: Dropout group with classroom training and internship placement (231 individuals).

[G4]: Treatment group with the full treatment (578 individuals).

Robust standard errors clustered by individuals in parentheses.

Table A4.19.

Projoven sixth public call effects on overall employment by level of completion. Heterogeneous treatment over time and endogenous treatment. Linear probability model - pooled two-stage least squares estimates [using initial values of the time-varying regressors as Mundlak terms].

\begin{tabular}{ccc}
$\begin{array}{c}\text { Effects } \\
\text { after 6 } \\
\text { months }\end{array}$ & $\begin{array}{c}\text { Additional } \\
\text { effects after } \\
\mathbf{1 2} \text { months }\end{array}$ & $\begin{array}{c}\text { Additional } \\
\text { effects after } \\
\mathbf{1 8} \text { months }\end{array}$ \\
$\left.\hat{\beta}_{1}\right]$ & {$\left[\hat{\beta}_{2}\right]$} & $\left.\hat{\beta}_{3}\right]$ \\
\hline
\end{tabular}

A. Effects of Projoven internship placement

$\begin{array}{lccc}\text { [G3] vs. [G2] } & 0.237 & 0.046 & -0.257 \\ & (0.420) & (0.271) & (0.339) \\ \text { [G4] vs. [G2] } & 0.233^{* *} & -0.134 & -0.123 \\ & (0.117) & (0.097) & (0.175)\end{array}$

B. Effects of Projoven internship completion

$\begin{array}{lccc}\text { [G4] vs. [G3] } & 0.209 & -0.144 & 0.013 \\ & (0.133) & (0.147) & (0.134)\end{array}$

${ }^{*} p<0.10,{ }^{* *} p<0.05,{ }^{* * *} p<0.01$.

[G2]: Dropout group with only classroom training and no internship placement (183 individuals).

[G3]: Dropout group with classroom training and internship placement (231 individuals).

[G4]: Treatment group with the full treatment (578 individuals).

Robust standard errors clustered by individuals in parentheses. 
Table A4.20.

Projoven sixth public call effects on formal employment by level of completion. Heterogeneous treatment over time and endogenous treatment. Linear probability model - pooled two-stage least squares estimates with sample selection correction (Semykina and Wooldridge, 2006) [without Mundlak terms].

\begin{tabular}{ccc}
\hline $\begin{array}{c}\text { Effects after } \\
6 \text { months }\end{array}$ & $\begin{array}{c}\text { Additional } \\
\text { effects after } \\
12 \text { months }\end{array}$ & $\begin{array}{c}\text { Additional } \\
\text { effects after } \\
18 \text { months }\end{array}$ \\
$\left.\hat{\beta}_{1}\right]$ & $\hat{\beta}_{2}$ & $\left.\hat{\beta}_{3}\right]$ \\
\hline
\end{tabular}

A. Effects of Projoven internship placement

$\begin{array}{lccc}\text { [G3] vs. [G2] } & 0.185 & -0.018 & -0.050 \\ & (0.349) & (0.353) & (0.350) \\ \text { [G4] vs. [G2] } & 0.368 & -0.078 & -0.050 \\ & (0.292) & (0.278) & (0.313)\end{array}$

B. Effects of Projoven internship completion

\begin{tabular}{lccc} 
[G4] vs. [G3] & $0.277^{*}$ & 0.126 & -0.101 \\
& $(0.164)$ & $(0.174)$ & $(0.220)$ \\
\hline
\end{tabular}

${ }^{*} p<0.10,{ }^{* *} p<0.05,{ }^{* * *} p<0.01$.

[G1]: Control group (992 individuals).

[G2]: Dropout group with only classroom training and no internship placement (183 individuals).

[G3]: Dropout group with classroom training and internship placement (231 individuals).

[G4]: Treatment group with the full treatment (578 individuals).

Robust standard errors clustered by individuals in parentheses.

Table A4.21.

Projoven sixth public call effects on formal employment by level of completion. Heterogeneous treatment over time and endogenous treatment. Linear probability model - Two-stage least squares estimates with sample selection correction (Semykina and Wooldridge, 2006) [using initial values of the time-varying regressors as Mundlak terms].

\begin{tabular}{ccc}
$\begin{array}{c}\text { Effects } \\
\text { after 6 } \\
\text { months }\end{array}$ & $\begin{array}{c}\text { Additional } \\
\text { effects after } \\
12 \text { months }\end{array}$ & $\begin{array}{c}\text { Additional } \\
\text { effects after } \\
18 \text { months }\end{array}$ \\
{$\left[\hat{\beta}_{1}\right]$} & $\hat{\beta}_{2}$ & $\left.\hat{\beta}_{3}\right]$ \\
\hline
\end{tabular}

A. Effects of Projoven internship placement
[G3] vs. [G2]
0.195
$-0.037$
$-0.069$
$(0.344)$
$(0.357)$
$(0.358)$
[G4] vs. [G2]
0.273
$-0.002$
0.022
$(0.281)$
$(0.263)$
(0.296)

B. Effects of Projoven internship completion

\begin{tabular}{lccc} 
[G4] vs. [G3] & $0.308^{*}$ & 0.095 & -0.133 \\
& $(0.159)$ & $(0.143)$ & $(0.217)$ \\
\hline
\end{tabular}

${ }^{*} p<0.10,{ }^{* *} p<0.05,{ }^{* * *} p<0.01$.

[G1]: Control group (992 individuals).

[G2]: Dropout group with only classroom training and no internship placement (183 individuals).

[G3]: Dropout group with classroom training and internship placement (231 individuals).

[G4]: Treatment group with the full treatment (578 individuals).

Robust standard errors clustered by individuals in parentheses. 
Table A4.22.

Projoven sixth public call effects on monthly wages by level of completion. Heterogeneous treatment over time and endogenous treatment. Two-stage least squares estimates with sample selection correction (Semykina and Wooldridge, 2006) [without Mundlak terms].

\begin{tabular}{|c|c|c|}
\hline $\begin{array}{c}\text { Effects } \\
\text { after } 6 \\
\text { months } \\
{ }_{[} \hat{\beta}_{1]}\end{array}$ & $\begin{array}{c}\begin{array}{c}\text { Additional } \\
\text { effects after } \\
12 \text { months } \\
\hat{\beta}_{2}\end{array}\end{array}$ & $\begin{array}{l}\text { Addi } \\
\text { effect } \\
18 \mathrm{~m}\end{array}$ \\
\hline
\end{tabular}

A. Effects of Projoven internship placement

$\begin{array}{lccc}\text { [G3] vs. [G2] } & -0.011 & 0.473^{*} & 0.108 \\ & (0.229) & (0.242) & (0.249) \\ \text { [G4] vs. [G2] } & 0.952 & -0.177 & -0.364 \\ & (0.916) & (0.813) & (0.815)\end{array}$

B. Effects of Projoven internship completion

\begin{tabular}{lccc} 
[G4] vs. [G3] & 0.744 & -0.546 & -0.301 \\
& $(0.517)$ & $(0.427)$ & $(0.496)$ \\
\hline
\end{tabular}

${ }^{*} p<0.10,{ }^{* *} p<0.05,{ }^{* * *} p<0.01$.

[G1]: Control group (992 individuals).

[G2]: Dropout group with only classroom training and no internship placement (183 individuals).

[G3]: Dropout group with classroom training and internship placement (231 individuals).

[G4]: Treatment group with the full treatment (578 individuals).

Robust standard errors clustered by individuals in parentheses.

Table A4.23.

Projoven sixth public call effects on monthly wages by level of completion. Heterogeneous treatment over time and endogenous treatment. Two-stage least squares estimates with sample selection correction (Semykina and Wooldridge, 2006) [using initial values of the time-varying regressors as Mundlak terms].

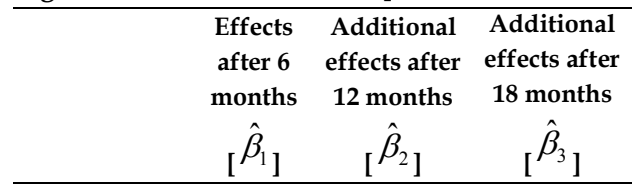
A. Effects of Projoven internship placement

$\begin{array}{lccc}\text { [G3] vs. [G2] } & -0.045 & 0.543^{* *} & 0.184 \\ & (0.241) & (0.248) & (0.251) \\ \text { [G4] vs. [G2] } & 0.917 & -0.132 & -0.323 \\ & (0.925) & (0.803) & (0.823)\end{array}$

B. Effects of Projoven internship completion

$\begin{array}{lccc}\text { [G4] vs. [G3] } & 0.815 & -0.592 & -0.357 \\ & (0.532) & (0.427) & (0.499)\end{array}$

${ }^{*} p<0.10,{ }^{* *} p<0.05,{ }^{* * *} p<0.01$.

[G1]: Control group (992 individuals).

[G2]: Dropout group with only classroom training and no internship placement (183 individuals).

[G3]: Dropout group with classroom training and internship placement (231 individuals).

[G4]: Treatment group with the full treatment (578 individuals).

Robust standard errors clustered by individuals in parentheses. 
Chapter 4. Evaluation of Projoven Effectiveness 


\section{Chapter 5}

\section{Determinants of dropout behaviour in Projoven}

\subsection{Introduction ${ }^{1}$}

A general conclusion of the evaluation literature, and confirmed also for Projoven case in Chapter 4, is that youth job training programmes (YJTP) are more effective when completed. Yet, YJTPs suffer from substantial dropout problems. Low completion rates can be seen as evidence of YJTPs not targeting the right individuals, YJTPs not considering particular regional/context features, and/or limitations of the programme's characteristics. First, some individual characteristics can enhance training returns. Consequently, some youths, who may find that they do not benefit sufficiently from the training to compensate for their opportunity costs, will not make the necessary effort to complete the programme. Second, economic circumstances or regional context modify trainees' opportunity costs of undertaking training and the availability of internship opportunities. Third, training characteristics (students per course, workload, teacher experience, presence of a written contract in the internship, etc.) can modify individual expectations about the returns of the training. Youths can drop out during the training if they realise that the programme is not going to yield the returns they hoped.

The aim of this chapter is to find out the factors affecting trainees' dropout behaviour in Projoven. This chapter tests whether individual characteristics, regional features or training characteristics influence trainees' dropout decisions in Projoven by using a probit model with sample selection. This model takes into account the fact that the dropout decision is only observed for those trainees who are placed in internships. In addition, a multinomial probit model is estimated in order to allow the effects of the explanatory variables to vary across two different exit routes (in comparison with training completion): i) dropping out of training to take on another job and ii) dropping out of training into unemployment or inactivity.

This chapter's estimations show no evidence of selection into an internship. It seems that training providers' (ECAP) characteristics influence the likelihood of placing trainees in internships. In addition, the results suggest that trainees' dropout decisions follow a

${ }^{1}$ This chapter is based on de Crombrugghe, D., H. Espinoza and H. Heijke (2010) “Determinants of dropout behaviour in a job training programme for disadvantaged youths". Working Paper ROA-RM-2010/8, Research Centre for Education and the Labour Market (ROA), Maastricht. 
Chapter 5. Determinants of Dropout Behaviour in Projoven

rational pattern. Trainees stay in the programme as long as they perceive evidence that it is worthwhile to do so. First, individuals with certain characteristics (such as males with work experience) that indicate higher training returns are less likely to drop out into unemployment, but more likely to drop out for another job. This is only distinguishable in the multinomial probit model. Second, in both models (probit with sample selection and multinomial probit), it is found that in cities where fewer job opportunities are available (in comparison with Lima), trainees are also less likely to drop out. Finally, when the training conditions indicate chances of being hired on a permanent basis or the training firm is committed to the training activities (presence of a written contract), trainees are also less likely to drop out, regardless of the exit route.

This chapter proceeds as follows: Section 5.2 presents a discussion of the dropout behaviour in YJTPs. Section 5.3 presents the empirical framework to evaluate dropout determinants at Projoven. Section 5.4 describes Projoven's dataset. Section 5.5 displays the results of the estimations. Finally, Section 5.6 draws some conclusions.

\subsection{YJTP Dropout Behaviour}

To understand the nature of the dropout phenomenon, it is necessary to assess its extent, to comprehend how the dropout decision is made, and to find out its determinants. This section discusses these considerations.

\subsubsection{Dropout extent}

The dropout phenomenon is widespread in YJTPs. In Table 5.1 it is observed that, with the exception of the Argentinean Proyecto Joven, which has a completion rate of $90 \%$, YJTPs in Latin America (Peru, Uruguay, Chile, Panama and the Dominican Republic) experience completion rates below $77 \%$. Low completion rates are not just a Latin American phenomenon. Table 5.1 also displays some figures about YJTP performance in Germany and the United States, where the completion rates are lower than in some Latin American programmes.

All Latin American YJTPs share the two-step sequence design of classroom instruction and on-the-job internship. In most cases, the policy planner finances job training centres to provide the training and to ensure that a quota of trainees is placed in firms for onthe-job training experience. Interestingly, the YJTPs listed in Table 5.1 present high completion rates (higher than 90\%) for the first phase of the training in comparison with the second phase of the training. This phenomenon can be explained by the twofold institutional arrangements. First, job training centres are bound by contract to ensure 
that a certain share of trainees participate in the on-the-job training experience after the classroom training phase. In Latin American countries, this percentage is $70 \%$, on average. However, in such cases as in Uruguay, training centres must only comply with a $45 \%$ quota. This can explain why Projoven-Uruguay has the lowest completion rate among the examples compiled.

Second, another institutionally related explanation of the dropout phenomenon is the time gap between the two instructive phases. Santiago Consultores Asociados (1999) points out for the Chilean case that the transition from classroom instruction to the onthe-job training internship is not immediate. In many cases, weeks of delay discourage trainees from showing up. Such situations are also observed in Projoven-Peru.

Table 5.1.

Youth job training programmes and completion rates.

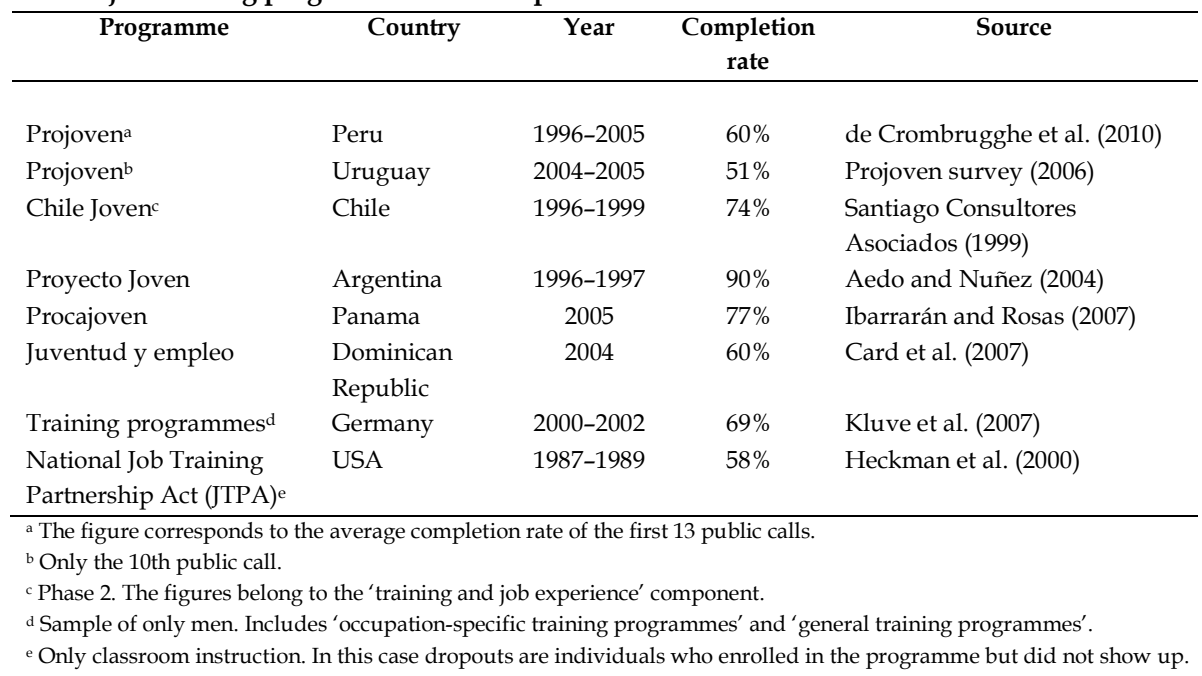

\subsubsection{Dropout decision and its determinants}

In publicly funded YJTPs for economically disadvantaged individuals, all trainees are assumed to be able to graduate. In Projoven, for instance, training completion is not conditional on further tests or examinations. Trainees obtain a certificate of participation if they attend the courses and if they are present for the internship. This makes it difficult to extrapolate the results of the substantial literature on individuals' dropout decisions in post-secondary education. ${ }^{2}$ In the case of post-secondary education,

${ }^{2}$ See Stratton et al. (2006) for a review of the conceptual and empirical work of this literature. 
completion (obtaining a degree/certificate) depends not only on attendance but on the capacity of the individuals to complete knowledge and skills assessments. This study borrows two elements from this literature which may apply to the analysis of dropout behaviour in YJTPs: i) the presence of uncertainty about training returns and ii) the existence of job opportunities.

First, uncertainty about the returns of YJTPs can lead individuals to modify their optimal length of training, even after enrolment. To be able to complete the programme, the trainee must believe that it is worth doing so. As such the expectancy about the returns of the training should be larger than the returns of the alternative activity. It is unlikely that trainees know beforehand the returns of the training. The only way the youth can definitively determine whether the training is appropriate for him or her is by enrolling. It should be noted that well-known vocational training schools, which increase expectancy of high returns, rarely participate in Projoven. According to Projoven records, less than $5 \%$ of the trainees receive instruction in well-known vocational training schools. In Peru, as in other developing countries, no ranking of vocational training institutions exists. In addition, even if it existed, it is very unlikely that individuals at the bottom of the income distribution would be aware of it. Second, urgent job offers or individual shocks can also lead to a dropout decision. Youths can embark in training activities while waiting for a job offer.

A consequence of the trainees' uncertainty about training returns and future job offers is that before undertaking training, potential trainees ignore whether they are capable of completing the training or if it is worth doing so. It is assumed that an individual's decision to drop out is a consequence of a cost-benefit assessment made under uncertainty. In general, individuals remain in the programme as long as they feel it increases their chances to succeed in the labour market (Schochet, 1998; Heckman and Smith, 1999). In this fashion, the likelihood of completing the training (or of dropping out) depends on individual opportunity costs and the expected outcomes of the training. The factors that affect trainees' opportunity costs and expected training outcomes can be classified into three categories: i) changes in labour market conditions, ii) the demographic characteristics of the individuals and iii) programme content.

First, regarding changes in labour market conditions, Di Pietro (2004) and Peraita and Pastor (2000) argue that a shock that diminishes the unemployment rate of the region of residence encourages individuals to drop out of high school. When unemployment is low, more job offers may be available. In the case of YJTPs, job offers can increase trainees' opportunity costs of staying in training. Studies such as that of the Santiago Consultores Asociados (1999) for the Chilean case, Aedo and Nuñez (2004) for the Argentinean case, and Waller (2008) for the German case, find that getting a job is the most common reason for dropping out of training. Market conditions also affect firms' 
training efforts (internship availability). On the one hand, recessions can increase firms' training efforts. The increased competition for sales in slack markets can induce business strategies that require more training. On the other hand, in a prolonged recession, expectations change and uncertainty increases. In these circumstances, the benefits of training are much more doubtful and the costs of training can only be reduced (Felstead and Green, 1996).

Second, individual characteristics, such as having children, having participated in training programmes before and/or having experienced unemployment influence dropout decisions by increasing the likelihood of leaving the programme (Waller, 2008). Impact evaluation literature offers plenty of examples that certain individual characteristics enhance training returns. For instance, women and individuals with no work experience benefit the most from YJTPs in Latin America (Betcherman et al., 2004; Chapter 4). These characteristics can make it worthwhile for some trainees to complete the training, but not for others.

Finally, programme characteristics, mainly the courses and the quality of internships, can also affect dropout decisions. Hanushek et al. (2006) find this to be the case for primary school students in developing country settings. High-quality training modifies trainees' expectations about training returns. The training quality information is fully gathered by the trainee only once enrolled. Consequently, individuals modify their expected training outcomes during the training, which can lead them to drop out.

These factors, which affect the opportunity costs and expected returns of undertaking training in the context of Projoven, are taken into account in the estimation of the dropout decision determinants.

\subsection{Empirical Framework}

This section presents two models to estimate the likelihood of dropping out of a Projoven internship. The choice of the models is based on the distribution of trainees by participation level. In Figure 5.1, it is observed that almost all the trainees in the sample completed the Projoven classroom phase. However, not all trainees were placed in internships. Of the trainees who started the programme, $2.2 \%$ dropped out during the first month of classroom instruction, $20 \%$ were not placed in internships by their ECAPs, $21.7 \%$ dropped out of the training during the first two months of the internship, and $57 \%$ completed the programme. This phenomenon of few dropouts in the classroom phase occurs in virtually all the Latin American programmes as previously mentioned. Perhaps, in addition to the time gap between phases and the quota of internships, in the 
Chapter 5. Determinants of Dropout Behaviour in Projoven

case of Projoven it may also have to do with the way training providers are financially compensated by the programme. ECAPs are financially compensated by Projoven when trainees complete at least the classroom phase. This can encourage ECAPs to monitor closely that trainees attend the classroom training.

The first model, a probit model with sample selection correction (van de Ven and van Praag, 1981), tests and corrects for the possibility of selection into internship. If trainees placed in internships are not a random sample of all trainees, the parameters estimating the propensity to drop out can be biased. It could be the case that trainees with certain characteristics are more likely to be placed in internships.

The second model, a multinomial probit, distinguishes between different exit routes. Trainees can quit the programme because of a job offer or because of another reason that leads them to unemployment or inactivity. The second model tests whether the trainees who leave the programme for a job are different from those who leave the programme and end up unemployed or inactive.

\section{Figure 5.1.}

Distribution of trainees by participation level. Projoven sixth public call.

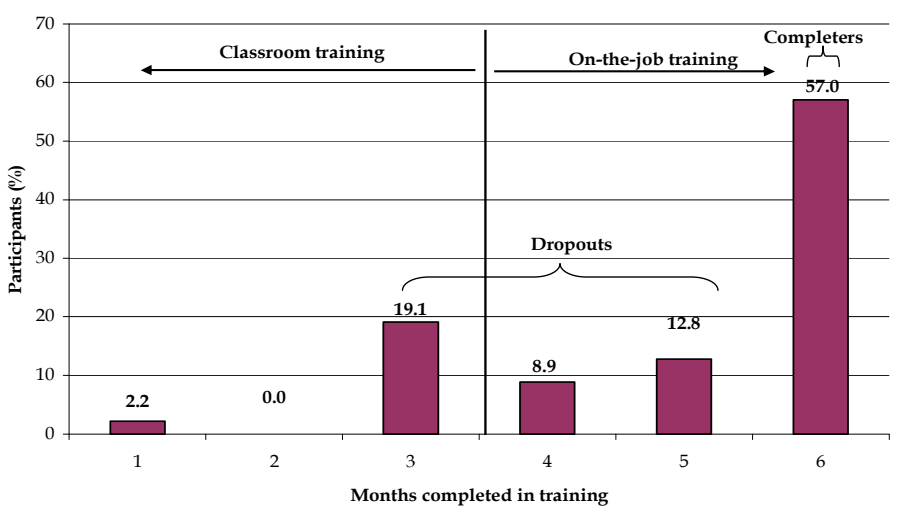

Source: Projoven. Further elaboration by the author.

\subsubsection{Model 1: Probability of dropping out of a Projoven internship (probit model} with sample selection)

One can only observe the decision to drop out from a Projoven internship for those trainees placed in internships. To account for selection into internship, this study 
proposes a probit model with sample selection. The dependent variable follows a process such as the one of Figure 5.2.

\section{Figure 5.2.}

Dropping out of a Projoven internship process.

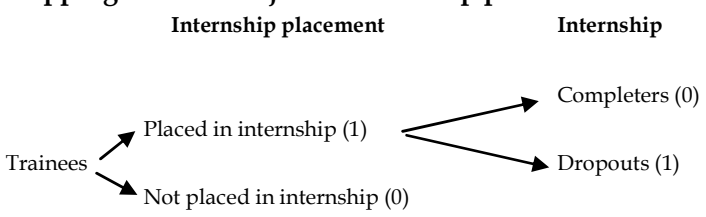

This empirical strategy assumes that an individual $(i)$ decides to drop out based on the expected utility for doing so $\left(U_{i}^{*}\right)$. When a trainee drops out, the individual's expected utility is specified as follows:

[Eq. 5.1] $U_{i}^{*}=X_{i}^{\prime} \beta_{1}+v_{i 1}$

with $\beta_{1}$ a vector of unknown parameters and $v_{i 1}$ an unobservable stochastic error distributed standard normally. Here, $X_{i}$ includes covariates such as individual characteristics (age, household size, sex, marital status, parental status, household income, years of schooling, previous training courses and work experience), city of residence, and characteristics of the internship (written contract in the internship). Implicitly, this specification assumes away a potential endogeneity of the contract variable. All trainees are supposed to be given a written contract during the internship, but this contract is not offered to all. Unobservables can affect both the likelihood of dropping out and the likelihood of being given a written contract. Unfortunately, the dataset lacks additional explanatory variables (to serve as instruments) to test for potential endogeneity. The limitation of the study in this respect is acknowledged by the author.

Utilities are obviously unobservable in contrast to the decision to drop out or stay in the programme which is observed. Formally, consider a variable $D_{i}$, where $D_{i}=1$ when the trainee drops out, and $D_{i}=0$ otherwise. Then, $D_{i}=0$ if $U_{i}^{*} \leq 0$ and $D_{i}=1$ if $U_{i}^{*}>0$. The probability of dropping out of the internship is modelled as

[Eq. 5.2] $\operatorname{Pr}\left[D_{i}=1\right]=\operatorname{Pr}\left[U_{i}^{*}>0\right]=\operatorname{Pr}\left[X_{i}^{\prime} \beta_{1}+v_{i 1}>0\right]$. 
Chapter 5. Determinants of Dropout Behaviour in Projoven

It should be recalled that the likelihood of dropping out of a Projoven internship is only observed for those trainees who were placed in internships. Let $H_{i}$, a dichotomous variable, denote the indicator of selection into an internship when $H_{i}=1$. Thus, the probability that $D_{i}$ is observed is given by

[Eq. 5.3] $\operatorname{Pr}\left[H_{i}=1\right]=\operatorname{Pr}\left[Z_{i}^{\prime} \beta_{2}+v_{i 2}>0\right]$,

where $\beta_{2}$ is a vector of unknown parameters, $v_{i 2}$ is an unobservable stochastic error distributed standard normally, and $Z_{i}$ is a vector containing almost all the variables included in $X_{i}$ except for the variable 'contract', which is only observed during the internship. Note that $Z_{i}$ also contains ECAP characteristics such as number of students per course, course workload, share of teachers with more than five years of experience, whether or not the trainee followed a production-oriented course, and dummy variables about the type of ECAP. These variables are excluded from the response equation because they are intrinsically related to the first phase of the training (classroom instruction). The second phase of the training (internship) is carried out in a training firm different from the ECAP. Therefore, the factors that affect the trainees' decision to drop out of the internship must be related to individual characteristics and internshiprelated variables rather than ECAP course-related variables. In addition, ECAP course features may reflect the ability to find internships. ${ }^{3}$

To estimate the likelihood of dropping out of a Projoven internship conditional on being placed in a training firm (internship), it is assumed that $\left(v_{i 1}, v_{i 2}\right)$ are bivariate normal for all $i$, with

[Eq. 5.4] $v_{i 1} \sim N(0,1)$,

[Eq. 5.5] $v_{i 2} \sim N(0,1)$,

[Eq. 5.6] $\operatorname{corr}\left(v_{i 1}, v_{i 2}\right)=\rho$.

If $\rho \neq 0$, estimates of [Eq. 5.2] will be biased unless we account for the selection. Eventually, the usual tests for independence of the structural equations will be performed to assess the robustness of the estimations.

\footnotetext{
${ }^{3}$ The (in) exclusion of type of ECAP in the response equation does not modify the estimates of the other coefficients in the regression.
} 


\subsubsection{Model 2: Probability of dropping out of a Projoven internship, given}

different exit routes (multinomial probit model)

In the data of Projoven's sixth public call, it is possible to identify three exit routes from a Projoven internship: i) completion, ii) dropping out of training for a job and iii) dropping out of training into unemployment or inactivity. The exit routes are represented by the categorical scalar $d_{i}$, which values representing completers (1), dropouts to a job (2) and dropouts to unemployment (3) (See Figure 5.3).

\section{Figure 5. 3.}

Projoven internship exit routes.

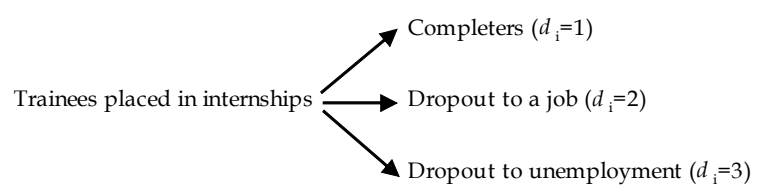

The previous section implicitly assumes that the effects of the explanatory variables are homogeneous across exit routes. This study aims to estimate whether the effect of the explanatory variables included in the dropout model differ, given that $d_{i}=m$, where $m=1,2$, or 3 . The multinomial probit approach is used, since it is assumed that all trainees face the same choice set once they are placed in internships. Hence, the utility of choosing the exit route $m=1,2,3$ is specified as

[Eq. 5.7] $U_{i m}^{*}=X_{i}^{\prime} \alpha_{m}+\xi_{i m}$,

where $X_{i}$ is defined as in the previous model. Associated with $X_{i}$ are the three vectors of regression coefficients $\alpha_{1}, \alpha_{2}$ and $\alpha_{3}$. The error terms $\xi_{i 1}, \xi_{i 2}$ and $\xi_{i 3}$ are assumed independent and standard normal. Trainee $i$ will choose the alternative $k$ in which the trainee's level of utility $U_{i k}^{*}>U_{i l}^{*}$ for all $l \neq k$. For $l \neq k$, let

$$
\left[\begin{array}{l}
\text { [Eq. 5.8] } \begin{array}{rl}
v_{i m} & =U_{i l}^{*}-U_{i k}^{*} \\
& =X_{i}^{\prime}\left(\alpha_{l}-\alpha_{k}\right)+\xi_{i l}-\xi_{i k} \\
& =X_{i}^{\prime} \gamma_{m}+\varepsilon_{i m},
\end{array}
\end{array}\right.
$$


where $m=l$ if $l<k$ and $m=l-1$ if $l>k$, so that $m=1,2$. Notice that $\varepsilon_{i}=\left(\varepsilon_{i 1}, \varepsilon_{i 2}\right) \sim$ $\operatorname{MVN}(0, \Sigma)$, where $\Sigma=\left(\begin{array}{ll}2 & 1 \\ 1 & 2\end{array}\right)$. The probability that the alternative $k$ is chosen is

[Eq. 5.9] $P_{i k}=\operatorname{Pr}\left(d_{i}=k \mid X_{i}\right)=\operatorname{Pr}\left(v_{i 1} \leq 0, v_{i 2} \leq 0\right)$

$$
=\operatorname{Pr}\left(\varepsilon_{i 1} \leq-X_{i}^{\prime} \gamma_{1}, \varepsilon_{i 2} \leq-X_{i}^{\prime} \gamma_{2}\right) \text {. }
$$

This probability (on which the likelihood function is based) involves a two-dimensional integral that is difficult to compute. Because of the exchangeable correlation structure of $\Sigma$, Dunnett's (1989) reduction of the multidimensional integral to a single dimension is utilised. Gaussian quadrature is used to approximate this integral. ${ }^{4}$ For purposes of identification, $d_{i}=1$ (training completion) is the base category $\left(\alpha_{1}=0\right)$. Therefore, the remaining set of coefficients $\alpha_{2}, \alpha_{3}$ will measure the differences relative to the completer's group.

\subsection{Data}

For the purposes of this chapter only the baseline survey of Projoven's sixth public call is used as a source of information about trainees' individual characteristics. Additionally, Projoven administrative records provide information about ECAP's characteristics. The dataset of Projoven's sixth public call consists of 1,014 individuals. From the sample, trainees who dropped out during the first month of classroom training have been excluded. As a consequence, the sample comprises 992 trainees.

Since Projoven has a fixed length of participation, this study distinguishes two types of individuals: those who complete the training and those who do not. Among those who do not complete the training, three categories are identified: involuntary ending (not placed in internships), dropping out of on-the-job training for a job, and dropping out of on-the-job training into unemployment or inactivity. Projoven administrative records do not include the reason for dropping out (job offer or unemployment).

The reason for dropping out was inferred from matching labour market conditions and dropout timing. Thus, individuals who were working during the month in which they dropped out or a month later are considered to have dropped out for a job; otherwise they are regarded as having dropped out into unemployment or inactivity.

\footnotetext{
${ }^{4}$ The Stata canned command mprobit is used to estimate the multinomial probit model.
} 
The reason for dropping out was inferred from matching labour market conditions and dropout timing. Thus, individuals who were working during the month in which they dropped out or a month later are considered to have dropped out for a job; otherwise they are regarded as having dropped out into unemployment or inactivity.

Table 5.2 displays the summary statistics. It is observed that trainees, both completers and dropouts, are similar in eligibility-related variables such as age, household income per capita and years of schooling. Table 5.2 also shows that the differences between completers and dropouts regarding household size, gender, marital status, number of children and participation in another training course are not statistically significant. In addition, a higher share of individuals without working experience is observed among dropouts in comparison with the completers.

Regarding the city of residence, the proportion of dropouts, in comparison with completers, is higher in Lima than in the rest of the cities; however, one must note that Lima has a higher share of trainees. A more detailed picture of dropout rates per city is given in Table 5.3. Table 5.3 shows that Arequipa, Cusco and Trujillo have better performance in terms of completion relative to Lima and Chiclayo. In terms of dropout exit routes, involuntary dropouts are, in statistical terms, as important as those who drop out for a job. Only $8 \%$ of the trainees drop out into unemployment or inactivity. Nevertheless, this proportion increases up to $17 \%$ in Chiclayo, where the involuntary dropout rate is also the highest $(41 \%)$, double the total's average $(18.5 \%)$.

With respect to ECAP characteristics, significant differences regarding students per course, course workload and cost per student per hour are observed. ECAP effectiveness is lower for trainees who drop out involuntarily. The ECAPs of completers have lower numbers of courses than the ECAPs of dropouts. The share of teachers with more than five years of experience is higher in the ECAPs of dropouts. Completers represent a higher share than dropouts in alternative indicators of training quality such as the share of trainees with a written contract in the internship. This indicator is also evidence of the low enforcement power of the programme. Firms must hire trainees under training contracts and pay them the minimum wage. Only the Projoven branch offices of Lima and Chiclayo collected this information directly from the trainees. ${ }^{5}$

\footnotetext{
${ }^{5}$ The inclusion of the written contract variable does not affect the coefficient estimation of the rest of the variables. As contract information is not available in Arequipa, Cusco, and Trujillo, this variable is coded as zero for trainees in those cities. Alternative models were run excluding this variable, and the coefficients' signs and significance were not altered. When running the model only for Chiclayo and Lima, the same conclusions apply.
} 


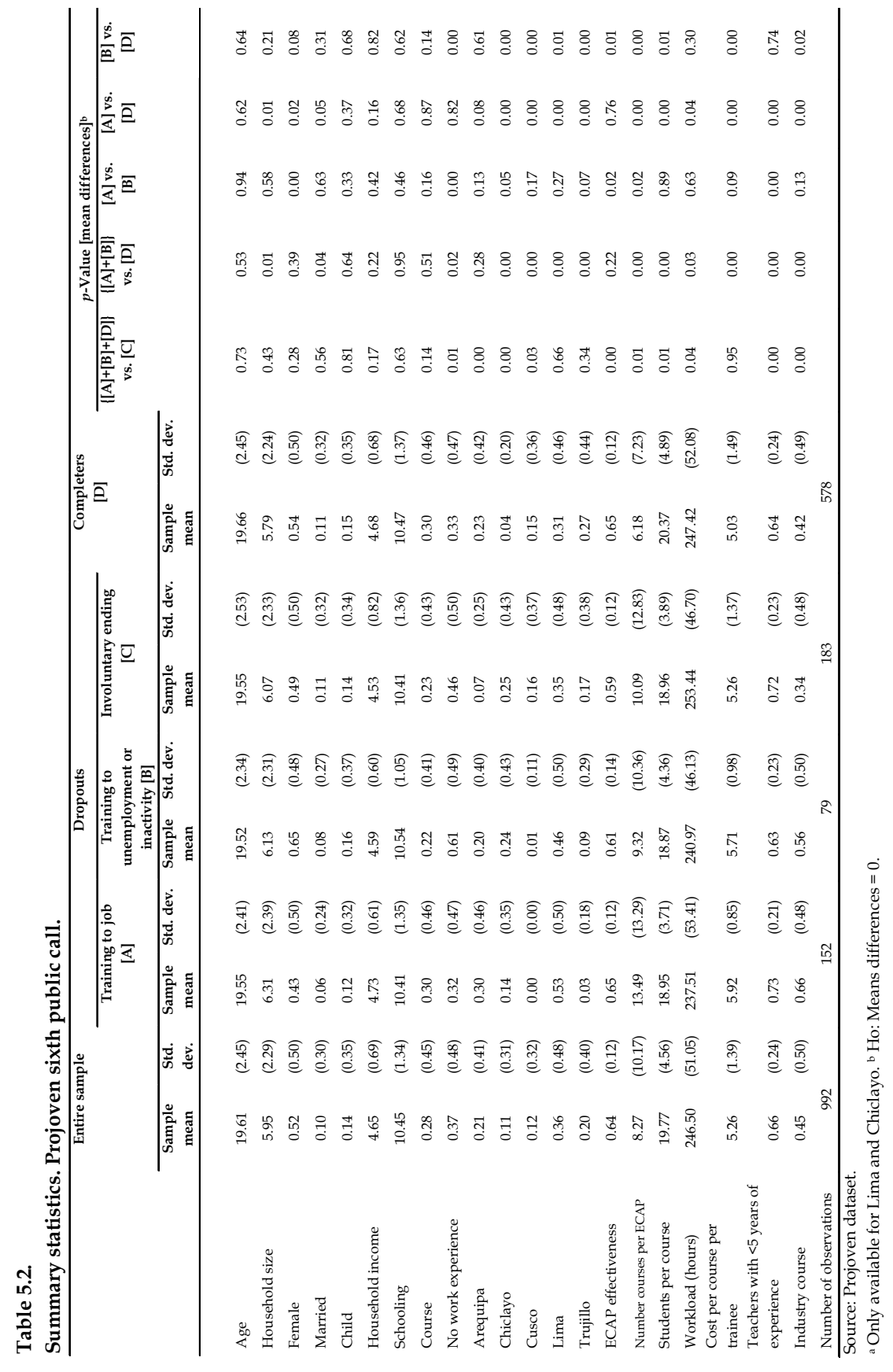




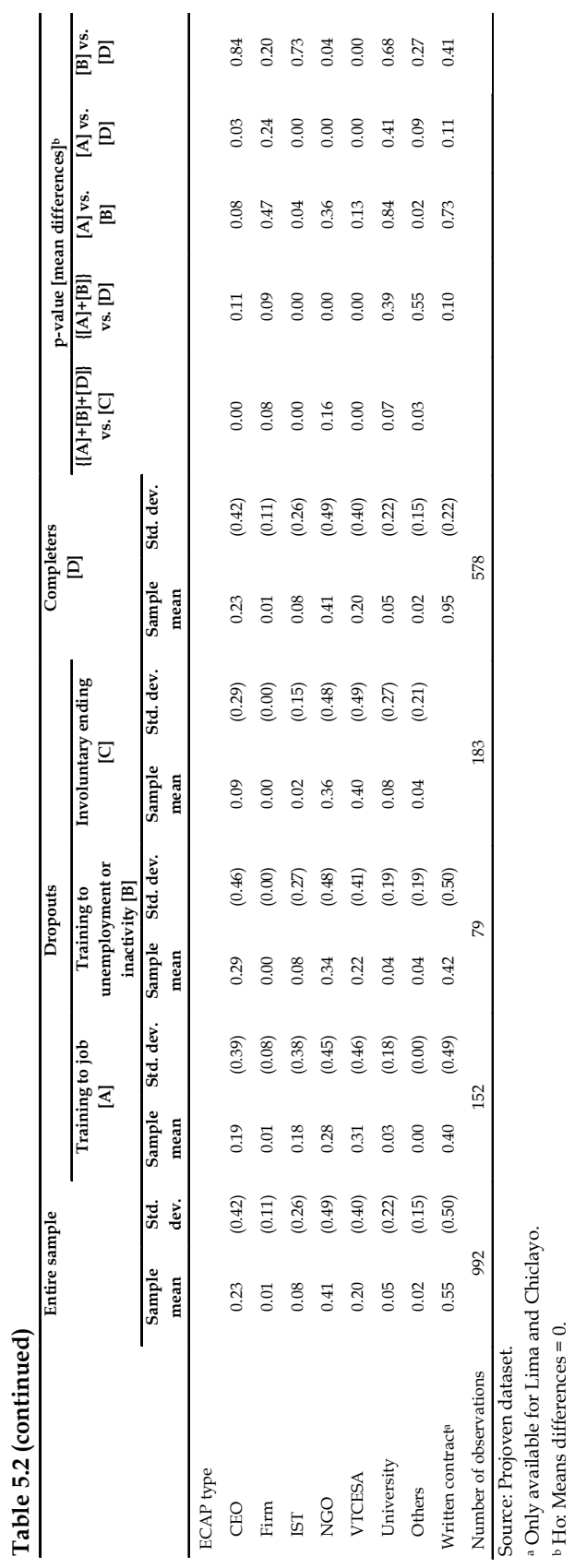


Chapter 5. Determinants of Dropout Behaviour in Projoven

Table 5.3.

Trainee completion level by city. Projoven sixth public call.

\begin{tabular}{lcccccc}
\hline & Arequipa & Chiclayo & Cusco & Lima & Trujillo & Total \\
\hline $\begin{array}{l}\text { Completers } \\
\begin{array}{l}\text { Dropouts } \\
\quad \text { To a job }\end{array}\end{array}$ & 64.4 & 22.7 & 73.5 & 49.9 & 77.9 & $\mathbf{5 8 . 3}$ \\
$\quad \begin{array}{l}\text { To unemployment or } \\
\text { inactivity }\end{array} \quad$ Involuntary & 22.0 & 19.1 & 0.0 & 22.4 & 2.5 & $\mathbf{1 5 . 3}$ \\
$\quad$ & 7.8 & 17.3 & 0.9 & 10.0 & 3.5 & $\mathbf{8 . 0}$ \\
$\quad$ Total & 5.9 & 40.9 & 25.6 & 17.7 & 16.1 & $\mathbf{1 8 . 5}$ \\
\hline Source: Projoven dataset. & $\mathbf{1 0 0}$ & $\mathbf{1 0 0}$ & $\mathbf{1 0 0}$ & $\mathbf{1 0 0}$ & $\mathbf{1 0 0}$ & $\mathbf{1 0 0}$ \\
\hline
\end{tabular}

Source: Projoven dataset.

With respect to the types of courses, it is observed that dropouts (for a job or into unemployment or inactivity) represent a higher share in industry-oriented courses, whereas completers and involuntary dropouts represent a higher share in service-oriented courses. Regarding the type of training centres, Table 5.3 shows that completers represent a higher share than dropouts in centres for vocational training (CEOs), firms and non-governmental organizations (NGOs), whereas dropouts have a greater presence in institutes for tertiary technical education (ISTs), universities and vocational training centres sponsored by economic-sector associations of firms (VTCESA) and others.

\subsection{Results}

This section shows the results of the estimation of the probability of dropping out of a Projoven internship. Two models are presented: a probit model with sample selection (Model 1) and a multinomial probit model (Model 2). For Model 1, the results of the two parts of the model are presented: the probability of a Projoven internship placement (selection equation) and the probability of dropping out of a Projoven internship (response equation). For Model 2, the probability of dropping out of a Projoven internship given different exit routes is estimated.

\subsubsection{Model 1 - selection equation: Probability of a Projoven internship placement}

Table 5.4 displays the selection model indicating the likelihood of a trainee being placed in an internship. The results suggest that there are no discrimination practices in trainee placement in internships, at least based on observables. Variables such as age, household size, gender, having children, income, schooling, previous work experience and previous participation in a training course are not significant in the model.

The insignificant coefficient of individual-related variables may indicate that it is the capacity of the ECAP that determines internship placements. In fact, in the selection model, ECAP- 
related variables explain the trainees' likelihood of being placed in an internship. Higher costs per student increase the likelihood that a trainee is placed in an internship. Finding internships involves more costs than only providing classroom training. ECAPs that invest more per trainee are apparently more successful at finding internships. In addition, ECAPs that teach more courses face more difficulties finding internships for their trainees. In our estimates, a larger number of students per course increases the likelihood of being placed in an internship. Usually, it is thought that the lower the number of students in a class, the better the instruction. The course selection criteria, which mix low-quality courses and efficient ones, may be more important in this case. Since the programme rewards low-cost proposals, ECAPs try to offer as many courses as possible. Nevertheless, more efficient ECAPs can compensate for these costs by placing more students in each course. The marginal cost of placing an additional student may be reduced, given economies of scale.

The model also indicates that studying industry-oriented courses, relative to service-oriented ones, increases the probability of a trainee being placed in an internship. Perhaps these courses are relatively more in demand in the labour market. Other variables, although not statistically significant, provide an interesting explanation of internship placement. A higher share of instructors with more than five years of experience increases the likelihood of being placed in an internship. Perhaps old instructors have more contacts in the labour market. Additionally, an ECAP's effectiveness (share of trainees per ECAP working six months after the training) seems to work as a credential or indicator of reputation for the ECAP, given the positive sign of the coefficient.

It is not possible to draw any particular conclusions about the type of training centre. The NGO, CEO, VTCESA and University dummy coefficients are positive and statistically significant. This could imply that these types of training centres are most likely to place trainees in internships (relative to firms and IST). However, low-quality ECAPs outnumber high-quality ECAPs in Projoven, even within the seven categories considered in Table 5.2 (Chacaltana et al., 2003; Chong and Galdo, 2006).

Regarding the city dummies, only Arequipa is significant. It seems that ECAPs in Arequipa are more successful in placing trainees in internships (relative to Lima). It may be easier for ECAPs to place trainees in a booming environment. For instance, in 2000, the year of reference, the growth rate of the gross domestic product of Arequipa was relatively higher than Lima's (3.5\% versus $2.4 \%$, respectively). More internship vacancies may be available under those circumstances.

Summing up, there is no evidence of discrimination in trainees' placement into an internship. It seems that the ECAPs' features rather than trainee characteristics influence the likelihood of placement in internships. ${ }^{6}$ In addition, regional characteristics (represented by city dummies) also play a role. The environment where the training is carried out affects the ECAPs' capacity to place trainees in internships.

\footnotetext{
${ }^{6}$ This model estimates robust clustered standard errors to account for intra-ECAP correlation.
} 
Chapter 5. Determinants of Dropout Behaviour in Projoven

Table 5.4.

Probability of a Projoven internship placement. Model 1, probit estimates of the selection equation (dependent variable: internship placement $=1$ ).

\begin{tabular}{|c|c|c|}
\hline & Coef. & Std. err. \\
\hline Age & 0.005 & $(0.023)$ \\
\hline Household size & -0.017 & $(0.023)$ \\
\hline Female & 0.140 & $(0.117)$ \\
\hline Married & -0.386 & $(0.240)$ \\
\hline Child & 0.083 & $(0.095)$ \\
\hline Child * Female & -0.039 & $(0.092)$ \\
\hline Household income & 0.054 & $(0.065)$ \\
\hline Schooling & 0.021 & $(0.038)$ \\
\hline Course & 0.067 & $(0.118)$ \\
\hline No work experience & -0.035 & $(0.109)$ \\
\hline Arequipa & $0.654^{* * *}$ & $(0.235)$ \\
\hline Chiclayo & -0.350 & $(0.233)$ \\
\hline Cusco & -0.309 & $(0.230)$ \\
\hline Trujillo & 0.299 & $(0.220)$ \\
\hline ECAP effectiveness & 0.777 & $(0.556)$ \\
\hline Number of courses per ECAP & $-0.015^{* *}$ & $(0.006)$ \\
\hline Students per course & $0.034^{* * *}$ & $(0.013)$ \\
\hline Workload (hours) & 0.002 & $(0.001)$ \\
\hline Cost per course per trainee & $0.098^{* *}$ & $(0.048)$ \\
\hline $\begin{array}{l}\text { Teachers with }<5 \text { years of } \\
\text { experience }\end{array}$ & 0.357 & $(0.294)$ \\
\hline Industry course & $0.319^{* *}$ & $(0.139)$ \\
\hline CEO & $0.928^{* * *}$ & $(0.183)$ \\
\hline NGO & $0.448^{\star * *}$ & $(0.144)$ \\
\hline VTCESA & $0.578^{* *}$ & $(0.293)$ \\
\hline University & 0.075 & $(0.168)$ \\
\hline Constant & $-2.445^{\star *}$ & $(1.031)$ \\
\hline Number of observations & \multicolumn{2}{|c|}{992} \\
\hline Log-likelihood ratio & \multicolumn{2}{|c|}{$\chi_{(25)}^{2}=135.59$} \\
\hline Log pseudo-likelihood & \multicolumn{2}{|c|}{-406.49156} \\
\hline Pseudo-R2 & \multicolumn{2}{|c|}{0.1429} \\
\hline
\end{tabular}

\subsubsection{Model 1 - response equation: Probability of dropping out of a Projoven internship}

Table 5.5 displays the maximum likelihood estimations of the probit model with probit sample selection correction [A], an independent probit model [B], a linear probability model (LPM) with probit sample selection correction [C], and a linear probability model with logit 
sample selection correction [D].7 The last three models were included as a matter of comparison. In almost all the cases, the parameters coincide in sign; nonetheless, small differences are presented in some of the coefficients' magnitude. The coefficients of models $[B],[C]$ and [D] resemble those of model [A]. In interpreting and discussing the estimated marginal effects, this section will further concentrate on model [A].

A positive correlation $(\hat{\rho})$ indicates the overrepresentation of trainees, with unobserved characteristics making them more likely to be placed in an internship. This study finds that there is indeed a positive correlation $(\hat{\rho}=0.300)$ between the selection equation (likelihood of internship placement) and the response equation (dropout likelihood); however, it is not significant. From this, it is concluded that there is no clear evidence of sample selection. Similarly, models [C] and [D] provide little evidence of systematic sample selection.

In the response equation, it is noted that demographic variables such as age, female, years of schooling, children, marital status and household income are not statistically significant. Dropouts and completers are similar in these variables, since they determine whether individuals are eligible or self-selected into the programme. Similar results in this respect are found in Waller (2008). Interestingly, although not statistically significant, prior experience with training courses diminishes the likelihood of dropping out of a Projoven internship. Trainees who have followed vocational training courses in the past may be more trainable for training firms. In addition, trainees with prior vocational experience may have relatively higher marginal returns, making the option to quit less attractive.

It seems that trainees in larger households are more likely to drop out. Trainees in larger households may be more constrained by financial resources. It is argued that the poor have a higher discount rate and are, therefore, short-run focused in their decision making. Although completing training can provide higher returns in the long term, economically disadvantaged trainees feel tempted to drop out if a job opportunity presents itself, even if it is not a good one. Salaries are paid at the end of the month during the internship. Alternative jobs in the informal sector are usually paid daily, but not necessarily with higher compensations.

The model suggests that regional differences, relative to Lima, negatively affect trainees' dropout decisions. Poverty rates in urban areas are higher for Arequipa, Chiclayo, Cusco, and Trujillo than for Lima (39\%, 50\%, 54\%, 38\%, and 34\%, respectively, for the reference year 2000). The opportunity costs of trainees outside Lima seem to be lower, diminishing the likelihood of trainees dropping out.

\footnotetext{
${ }^{7}$ Lee (1983) suggests a technique to use a logit regression in the two-step Heckman procedure for sample selection correction. This method estimates the selection equation using a logit model. Then, it uses the individual probabilities predicted by the model. Using the inverse cumulative distribution function of the normal distribution, these individual probabilities are translated into the form they would have had had they been computed on the basis of a probit model. Finally, these quasi-probit scores are used to compute the inverse Mills ratio the same way as when using a probit selection model.
} 
Chapter 5. Determinants of Dropout Behaviour in Projoven

Table 5.5.

Probability of dropping out of a Projoven internship. Model 1, estimates of the response equation (dependent variable dropping out of internship $=1$ ).

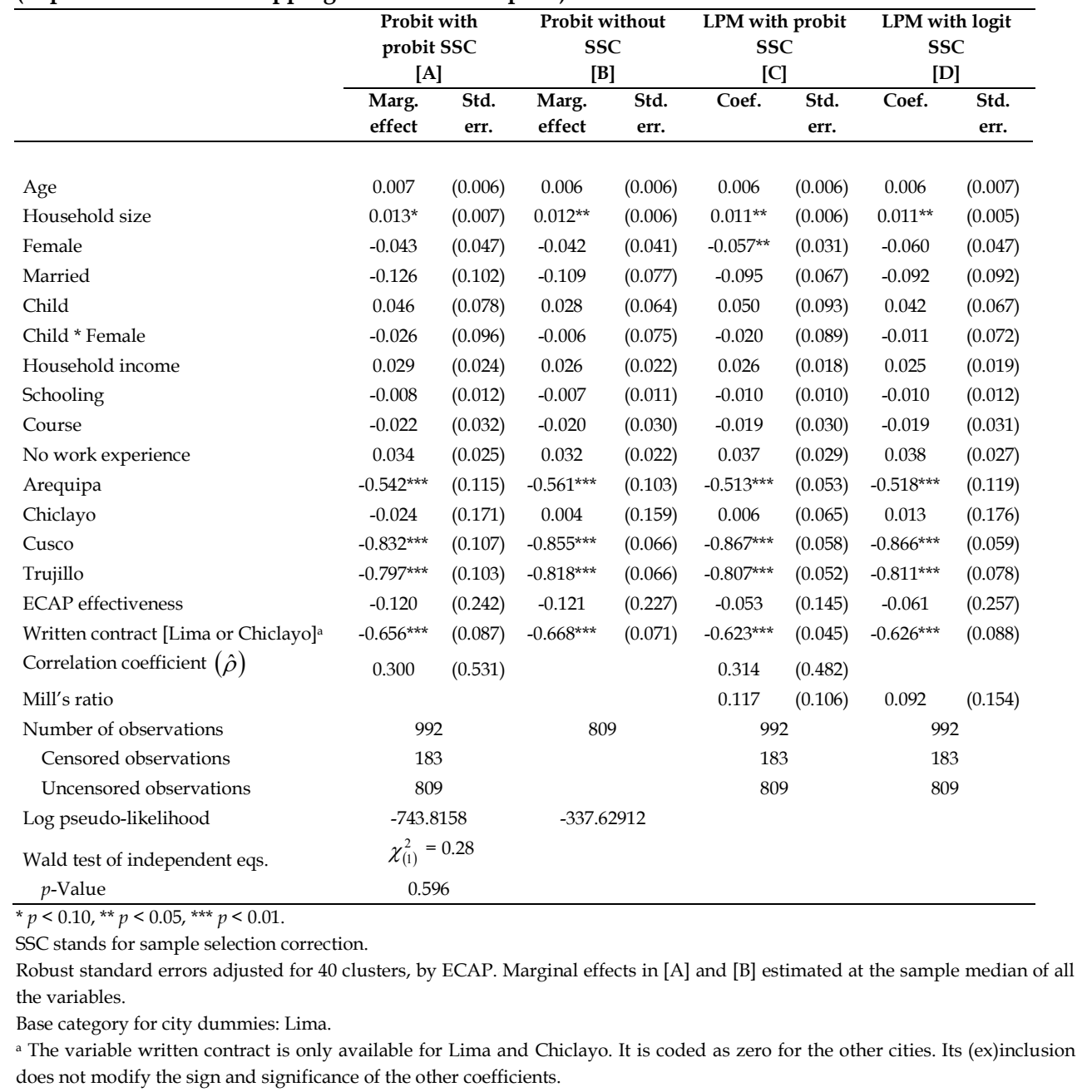

A crucial variable affecting the likelihood of dropping out is the presence of a written contract in the internship. Trainees with written contracts are less likely to drop out. Since it is possible that firms hire trainees after the three-month internship, the presence of a contract may encourages trainees to stay and complete the training. The absence of a written contract could be evidence of precarious working conditions. In the Peruvian labour market (formal or informal), working with no contract implies no social security coverage, long hours and an unsafe work environment (Chacaltana, 2006). Santiago Consultores Asociados (1999) for the Chilean case and Aedo and Nuñez (2004) for the Argentinean case surveyed dropouts on their reasons for quitting. Most of the dropouts argued that they worked under precarious 
conditions and in some cases the internship content was not related to the classroom instruction.

Finally, in Table 5.5 it is also noted that, although not statistically significant, the effectiveness of the training reduces the likelihood of dropping out. The fact that ECAPs are successful, in terms of their graduates finding work, encourages trainees to continue and complete the training.

\subsubsection{Model 2: Probability of dropping out of a Projoven internship through different exit routes}

The estimates of the multinomial probit model are displayed in Table 5.6. Contrary to the previous specification, this model allows the explanatory variable effects to differ by exit route. This specification accounts for two different exit routes: i) dropping out of a Projoven internship for a job and ii) dropping out of a Projoven internship into unemployment or inactivity. These are compared relative to programme completion (base category). This model disregards the selection process, since the hypothesis of sample selection was rejected in the previous section under different specifications.

In the component of the model concerning dropping out for a job, we observe that trainees with no work experience are less likely to drop out. Perhaps for these trainees the internship, as a working experience, is more valuable. In the market for low-skilled jobs, experience is valued the most. In this case, training can serve as a screening device to identify the productivity of unskilled youths. This result may also be related to the returns of the programme. In Chapter 4 it is observed that trainees with no work experience have higher returns from their training. Thus, trainees would not drop out for a job when the returns from doing so are lower. In addition, trainees with no work experience may not receive many job offers. Females are also less likely to drop out for a job. This could be related to the expected effects of the programme. Authors such as Betcherman et al. (2004) and Ibarrarán and Rosas (2007) find that YJTPs in Latin America yield higher returns, in terms of wages and employment, for women. Interestingly, although not statistically significant, female parents are less likely to drop out for a job. This seems to be an effect of the extra stipends for individuals in that category. As in the probit model, trainees in larger household are more likely to drop out for a job.

In the component of the model concerning dropping out into unemployment, it seems that trainees lacking work experience are more likely to drop out. Individuals with no work experience are less employable. Consequently, when they drop out, they usually find themselves unemployed. Waller (2008) finds a similar effect. This may also be the case for women, particularly those with children (although the latter is not a significant factor). The group of individuals who drop out of YJTPs into unemployment includes trainees who exclude themselves from the training due to random shocks, such as disease or a relative's death (Santiago Consultores Asociados, 1999; Aedo and Nuñez, 2004). Unfortunately, those 
distinguish exit routes. Similarly, the effect of household size is found to be positive and significant in Model 1 and in the drop out for a job component of Model 2, and negative and insignificant in the dropout into unemployment component of Model 2. Perhaps, Model 1 comprises the average effect of the two components of Model 2. This shows how important it is to distinguish between exit routes. It seems that trainees who drop out for a job are different from those who drop out into unemployment. Nevertheless, Model 1 is important to show that there is no evidence of selection into internship placement. In addition, precarious working conditions in the internship (no written contract) discourage trainees from continuing with the training, irrespective of the model or exit route. Both Model 1 and Model 2 address how crucial regional differences are in modifying trainees' expectations and opportunity costs to continue training.

\subsection{Conclusions}

Some studies suggest that YJTPs are more effective when completed (Mealli et al., 1996; Chacaltana et al., 2003; Chong and Galdo, 2003) or the longer the trainee is exposed to the training (Kluve et al., 2007; Flores-Lagunes et al., 2007). If training is effective conditional on completion, it is crucial to find out the reasons why trainees drop out. This chapter analyses the determinants of trainees' dropout decisions in the Peruvian YJTP Projoven. In this study, it is tested whether dropout is due to i) trainee characteristics, ii) regional context differences, or iii) training characteristics. Four general conclusions are reached.

First, the effects of individual characteristics vary across exit routes. When only one exit route is considered, only being a member of a larger household seems to be relevant. However, when more exit routes are considered, it is found that trainees who drop out for a job are different from those who drop out into unemployment. Males and individuals with work experience are more likely to drop out for a job, whereas they are significantly less likely to drop out into unemployment or inactivity. These results confirm two previous findings: i) In many YJTPs in Latin America, female trainees benefit the most from training (Betcherman et al., 2004); and ii) In the case of Projoven, trainees who do not have work experience benefit the most from training completion (Chapter 4). Thus, females and trainees with no work experience are most likely to be unemployed if they are not in the programme. The programme's effects could be enhanced if more women and individuals with no work experience were interested; however, some measures (incentives) must be implemented by the programme so that these individuals do not drop out.

Second, regional differences play an important role in explaining dropout behaviour. In both models, the comparison of small cities with Lima suggests that where fewer opportunities are available for youths, the dropout likelihood decreases. It seems that Projoven is seen as an alternative when jobs are unavailable.

Third, classroom instruction characteristics and internship conditions are crucial in explaining dropout behaviour. In the selection equation of Model 1, it is observed that an 
ECAP's capacity determines trainee placement in internships. This could be why the hypothesis of selection into internship is rejected. In addition, working with no written contract (i.e., under precarious conditions) discourages trainees from completing the programme despite the exit routes. Consequently, training content and its quality affect the dropout likelihood. This is an important result, since training content and quality affect not only the dropout likelihood, but also the labour market outcomes of the trainees.

Finally, the results suggest that trainees' dropout decisions follow a rational pattern. Trainees stay in the programme as long as they perceive evidence that it is worth doing so. First, since women and individuals with no work experience are most likely to benefit from the course, they are also less likely to drop out. Second, in cities where fewer job opportunities are available (in comparison with Lima), trainees are also less likely to drop out. Finally, when the training conditions indicate chances of being hired on a permanent basis or the training firm is committed to the training activities (having a written contract), trainees are also less likely to drop out.

Finding out what drives trainees to complete or drop out of YJTPs is important because it helps policy planners enhance the outcomes of their programmes. A more rigorous process of selecting training providers and more effective enforcement mechanisms are necessary to rule out internships that offer precarious conditions (in terms of the lack of contracts) and to ensure high-quality training courses, including internship placements. Hence, YJTPs such as Projoven could achieve better results in terms of completion rates and training outcomes. 


\section{Chapter 6}

\section{Conclusions}

\subsection{Summary of Findings}

\subsubsection{Projoven's Institutional Framework}

The review of Projoven's institutional framework revealed that its impact evaluation should take into account that i) not all trainees are placed in internships; ii) not all trainees complete the internships; and iii) distinguishing different categories of employment and individual heterogeneity could shed more light on Projoven's effectiveness assessment.

First, since a quarter of the trainees are not placed in internships, Projoven's impact evaluation should distinguish between the effects of the different phases of the programme. In principle, all trainees are entitled to follow the internship phase after the classroom phase. The only condition is attendance. Although more than $95 \%$ of the trainees complete the classroom phase, training providers fail to place a quarter of trainees in internships. This failure could be the result of the programme's course selection and the low threshold for internship placement set by Projoven. Projoven's course selection is based on an algorithm which assigns higher scores to proposals for low cost courses. In addition, training providers must comply with the requirement to place at least $60 \%$ of the trainees in internships. To present low cost course proposals, training providers may supply low quality training or not offer internship placements for all the trainees. Considering that not all trainees are placed in internships is important since the effects of the programme only materialise conditionally on the completion of the two training phases.

Second, since $30 \%$ of the trainees placed in internships drop out, Projoven's treatment effects evaluation should account for the presence of trainees with partial treatment. In the case of Projoven, the monitoring system fails to prevent training providers from supplying internships under precarious conditions, which may discourage trainees from staying in the programme. Projoven's treatment effects evaluation should account for trainees' dropout behaviour since different levels of training completion could bias the estimates of the effects of the programme. Not completing the programme could imply that trainees did not acquire all the skills they need in order to increase their labour market prospects.

Third, because of the presence of an informal labour market, Projoven's treatment effect evaluation should consider different categories of employment, including formal and informal, as well as individual heterogeneity (e.g., work experience). Half of the trainees are working before enroling in the programme. Given the lack of proper welfare programmes 
and driven by their urgent needs, economically disadvantaged youths may drop out of school early and search for jobs in the informal labour market (under precarious conditions). Thus, by observing only overall employment, the programme might overlook its effects on employment quality. Formal employment could be a better indicator of training programme effectiveness. In addition, differentiating Projoven's effects based on work experience could be more informative. Amalgamating the effects of trainees with different levels of work experience could lead to a misleading assessment of the programme's effectiveness. For instance, trainees with prior work experience could experience lower returns if the training merely teaches skills they already possess.

\subsubsection{Projoven Evaluation Data}

To evaluate Projoven's effects in terms of both overall and formal employment and also in terms of monthly wages, this study used Projoven's sixth public call dataset. The analysis of this data provides evidence of the presence of a pre-programme earnings dip for the trainees which may cast some doubts on their comparability with the control group. To avoid potential bias in Projoven's treatment effects estimations, a new control group was created using propensity score matching with replacement. After this procedure, systematic differences were significantly reduced. In addition, a Rosenbaum's sensitivity analysis suggests that the effects of Projoven in terms of employment are not especially sensitive to the presence of unobservables (hidden bias). Nevertheless, in terms of wages, some differences still persist. The test of systematic differences rejected the hypothesis of no systematic differences in terms of previous wages between the trainees and the control group. Therefore, estimations of Projoven's effects on trainees' wages must be considered cautiously.

\subsubsection{Projoven's Treatment Effect Evaluation}

The literature review of YJTP's treatment effects suggests that these programmes are relatively more effective in Latin America than in Europe or the U.S. In terms of employment prospects and earnings, these programmes have yielded higher returns for youths in Latin America, particularly for women. Regarding methods of estimation, in most of the Latin American studies, the presence of unobservables has not been dealt with directly. Most of the studies rely on the assumption that time-invariant unobservables are purged from the treatment effect estimations via difference-in-difference with propensity score matching techniques. However, the presence of pre-programme earnings dips provides evidence of some systematic differences between trainees and the control group, which casts doubt on their comparability. Additionally, the review of the studies accounting for trainees with partial treatment demonstrated that ignoring dropout rates could yield misleading conclusions about the effectiveness of training programmes. In general, YJTPs seemed to be more effective based on completion level or length of exposure to the training. 
Based on the discussion of the institutional analysis and the literature review, this thesis has developed an empirical strategy to evaluate the effectiveness of Projoven's sixth public call. Four groups are compared pair-wise: the control group, the dropout group with only classroom instruction, the dropout group with classroom instruction and internship placement, and the group completing the full programme. By doing so, the bias introduced by the different levels of training completion has been reduced. In addition, by using fixed effects and random effects estimators, it accounted for time-invariant unobservables and heterogeneity of trainees' characteristics (gender, poverty status and work experience), respectively. The estimations also accounted for selection effects and the potential endogeneity of training completion. To do so, pooled two-stage least squares methods with sample selection correction were used. In all the cases the estimations allow the treatment effects to vary over time by six, twelve and eighteen months after the programme. Controlling for sample selection allows the estimated effects on formal employment and wages to not be influenced by the fact that Projoven increases trainees' likelihood of being employed.

Decomposing the programme's effects by level of completion suggests that the programme is more effective conditionally upon completion. It is found that in terms of overall employment, the programme yields returns only in the short term (six months after the end of the programme) and conditionally on internship completion. In terms of formal employment, no significant effects were found. The programme seems to increase trainees' wages, but these effects diminish over time. The programme's positive effects on monthly wages and null effects on formal employment suggest that trainees are working more hours in the same type of precarious jobs that they would be working in the absence of the programme. In addition, when differentiating the programme's effects based on individual characteristics, it seems that Projoven yields additional returns, which are constant over time, for individuals with no work experience prior to enrolment.

\subsubsection{Determinants of Trainees' Decision to Drop Out}

The estimates of Projoven's treatment effects begs the question of why trainees drop out if it is apparently worth the effort to complete the training. To investigate the determinants of trainees' dropout behaviour, this study developed two empirical models. While the first one, a probit model with a sample selection correction, accounts for selection into internship, the second one, a multinomial model, accounts for two different exit-routes (dropping out for another job or going into unemployment/inactivity). These models test whether trainees' characteristics, regional differences and/or training characteristics affect their dropout behaviour. The results of the models suggest no evidence of selection into internship as having influence on the dropout rate, and that trainees stay in the programme as long as they perceive that it is worthwhile continuing the training. Three general conclusions are reached based on the analysis of trainees' dropout behaviour. First, since women and individuals with no work experience are most likely to benefit from the training, they are also less likely to drop out. This is related to the fact that trainees who are male and have prior work 
experience are less likely to drop out into unemployment, but are more likely to drop out for another job. Second, in cities where fewer job opportunities are available (in comparison with Lima), trainees are also less likely to drop out. Finally, under the presence of a written contract, which indicates more favourable working conditions, trainees are less likely to drop out. These results confirm two previous findings: i) in many YJTPs in Latin America, female trainees benefit the most from training (Betcherman et al., 2004); and ii) in the case of Projoven, trainees who do not have work experience benefit the most from training completion (Chapter 4).

\subsection{Contribution to Training Evaluation Research}

This thesis first contributes to the treatment effects research by explicitly examining the impact of the presence of trainees with partial instruction in YJTPs. In general, existing studies of training programmes for disadvantaged youths have difficulties accounting simultaneously for unobservables, potential endogeneity of training completion, trainees' heterogeneity and institutional arrangements. Several studies that do not account for the presence of trainees with partial treatment in Latin America found that training programmes are effective policy interventions, in terms of employment and wages, particularly for young women (Betcherman et al., 2004; Ibarrarán and Rosas, 2008). However, these studies cannot identify if both training components, classroom instruction and internship, are necessary to yield these returns or whether the presence of unobservables is driving those results. This study shows that integrating institutional arrangements, individual heterogeneity of trainees and trainees' dropout behaviour is crucial to understand and estimate the effects of skill development policies for disadvantaged youths. Projoven is, indeed, an effective policy intervention but conditionally on completion of both training phases and with diminishing returns over time. In addition, the programme yields additional returns for those trainees without work experience prior to the training and not for women. Perhaps previous evaluations, by neglecting trainees' work experience, confound the effects of work experience and gender.

Second, this study contributes to the empirical evaluation research which measures the effects of training programmes for disadvantaged youths. The approach here consists of comparing pair-wise four groups of youths (the control group, the dropout group with only classroom training, the dropout group with classroom training and internship placement, and the group completing the full programme) to avoid potential bias generated by completion levels. In addition, the use of fixed effects accounts for the presence of unobservables; and complemented with random effects allows the effects of the programme to vary, not only over time, but across individuals characteristics (gender, poverty status and work experience).

Third, this thesis contributes to the existing evaluation research by focusing on the determinants of trainees' dropout behaviour accounting for potential selection into 
internships and allowing the effects of the determinants to vary depending on the exit route (to another job or into unemployment). The few empirical studies that evaluated training programmes accounting for partial treatment did not develop further on why trainees drop out even though they concluded it is not worth doing so (e.g., Mealli et al., 1996; Heckman et al., 1998; Heckman et al., 2000; Lee and Lee, 2003; Flores-Lagunes et al., 2007). Only Waller (2008) studies the occurrence of dropouts in training programmes; however she only focuses on demographic characteristics of the trainees and does not account for different exit routes. Trainees who drop out for another job can have a different profile than those who drop out into unemployment. By accounting for potential selection into internship and different exit routes, this study suggests that individual characteristics, regional features and characteristics of the training affect trainees' dropout behaviour. Additionally, it argues that trainees who are male and have prior work experience are less likely to drop out into unemployment, but more likely to drop out for another job. This is crucial as to allow policy makers to enhance the benefits of training by taking into account these factors.

Both empirical structures - i) Projoven's effectiveness evaluation and ii) the analysis of the factors affecting trainees' dropout behaviour - complement each other in order to shed more light in studying the dropout phenomenon in training programmes. Whereas the first one evaluates the consequences of dropping out, in terms of employment condition and wages gains, the second one provides a profile of trainees who are most likely to drop out. The analysis of the factors affecting trainees' dropout behaviour complements Projoven's effectiveness evaluation by going beyond the consequences of dropping out. It gives some explanation as to why trainees drop out.

Although trainees' decision to drop out is obviously affected by the expectation of potential employment and income gains, both empirical structures are treated separately. The reason is that whereas in the evaluation of Projoven's effectiveness the internship placement is the treatment factor (which is allowed to be endogeneous and/or exogenous), in the analysis of dropout determinants internship placement is an element of sample selection. In addition, the endogenous treatment of internship (or the exogenous as well) does not allow differentiating trainees by exit route (another job or unemployment) because the exit routes are also the outcome to evaluate.

\subsection{Policy Implications}

The conclusions of this study imply that training could be an effective policy intervention to improve labour market prospects for economically disadvantaged youths. However, to enhance training potential it should be taken into account that the programme works differently for different people; that not all the trainees receive the same doses of treatment; and that precarious treatment conditions could lead them to drop out of the programme. As the behaviour of trainees, training providers and training firms are affected by the set of rules and incentives under which the programme is carried out, the analysis of the 
institutional framework must be also be taken into consideration when evaluating Projoven's effectiveness.

The perception that YJTPs are more effective in developing countries than in developed countries remains valid. However, a different angle has been added. Projoven indeed increases the employment prospects and monthly wages of its trainees, but only for those who manage to complete the training. The analysis of the programme's effects, accounting for levels of completion, warns training practitioners about why the trainees drop out although it is apparently not worthwhile to do so. This thesis found that trainees stay in training as long as they perceive it increases their chances in the labour market. Consequently, the quality of the classroom instruction and the conditions in which the internships are carried out are crucial. In this respect, the institutional arrangements of the programme play an important role. The monitoring system fails to prevent training providers from placing trainees in precarious internships. In addition, by preferring low unit cost training providers, the programme may compromise the quality of the training. Under these circumstances, certain trainees may not be placed in internships or may feel encouraged to drop out, diminishing Projoven's capacity to enhance labour market prospects of its participants.

Another important finding of this thesis is related to the individual heterogeneity. The estimation of Projoven's effects suggests that the programme yields additional returns, in terms of employment and monthly wages, for those trainees with no work experience. It was also found that, in the absence of the programme, trainees with no work experience are more likely to be unemployed. It seems that trainees with no prior work experience are the type of youths who are most in need of the programme and that they profit most from it as well. Consequently, the programme may increase its returns by targeting disadvantaged youths without work experience and accompanying this with measures to motivate these youths to stay in the programme. YJTPs are important to help disadvantaged youths to find their first job, which may be almost impossible otherwise in a developing country setting.

This thesis has shown that policy measures targeting disadvantaged youths need to combine an appropriate and integrated mix of occupational skills and internships and that an adequate supply of employment opportunities and a more developed market for vocational education is needed. Evidence presented in this study suggests that YJTPs in developing countries may improve labour market outcomes among disadvantaged youths. Nevertheless, if no internship opportunities are available, or the internships are carried out in precarious conditions, YJTPs such as Projoven may be ineffective. Consequently, these services need to be carried out in such a way that the institutional arrangements generate the right incentives to enhance their effectiveness: i) incentives for trainees to take up and complete the training; ii) incentives for training providers to offer high-quality courses and to find internship places for all participants; and iii) incentives for training firms to include training as an investment policy and offer proper conditions (written contracts). Encouraging shorter, more flexible training if trainees do not complete the programme is useless as well if graduates from YJTPs remain insufficiently prepared for the jobs available in the labour market. Eventually, YJTPs 
should be complemented with an integral reform of the market for vocational training. If training providers are not regulated, it would be expected that trainees continue dropping out and internships are not proper.

\subsection{Future Research}

The analysis conducted in this study exposes open questions and identifies the scope for further research, particularly in the empirical field. If data regarding other Projoven public calls and more detailed information matching trainees with firm characteristics were available, other directions for future research could be suggested. For instance, the link between business cycles, training providers' quality indicators and trainees' outcomes in a developing country context should be analyzed in more depth. This is a field of research for which empirical evidence is restricted to a few developed countries. Business cycles are likely to affect simultaneously trainees', training providers' and training firms' decisions to take up or to provide training. In addition, YJTPs could be more (or less) effective depending on which phase of the business cycle the programme is carried out. Contrary to other findings, Projoven's effects are found to diminish over time in this study, which coincides with the lower economic growth observed during 2001, post-training period of the sixth public call of the programme. Consequently, if data from other waves (public calls) of the programme were available, accounting for business cycle effects could modify the current view about YJTPs' effectiveness in developing countries.

Another direction for future research, if more detailed data matching trainees with firm characteristics were available, would be to control for training firms' effects in treatment effects estimations. Some firms provide better internship conditions and, therefore, are more likely to yield higher employment and income gains. In this study, the presence of a written contract in an internship is used as an indicator of internship conditions. Therefore, it would be interesting to evaluate also the effect of the regulation of internship contracts and whether this influences the decision of the training firm to provide proper internships. In a developing country context, transaction costs (contract regulation) play an important role in training provision as these could make training provisions relatively more expensive.

Lastly, a promising line of further research would be in terms of empirical methods. In this thesis, the estimation of the determinants of trainees' dropout behaviour endogeneity was assumed away. The presence of unobservables affecting dropout behaviour simultaneously with the explanatory variables (having a contract, for instance) could not be tested in this study. Another issue to consider is the sample selection in the multinomial probit model for trainees' dropout behaviour given different exit-routes. Although single-exit route models provided no evidence of sample selection, this thesis did not test selectivity in the multinomial model setting. Therefore, developing an empirical procedure for multinomial models with selectivity which accounts for potential endogeneity would be of interest. 
Chapter 6. Conclusions 


\section{Bibliography}

Abadie, A., and G. Imbens, 2002. Simple and Bias-Corrected Matching Estimators for Average Treatment Effects. NBER Technical Working Paper No. 283.

Acemoglu, D., and J. S. Pishke, 1999. The structure of wages and investment in general training. Journal of Political Economy, 107 (3), 539-572.

Aedo, C., and S. Nuñez, 2001. The impact of training policies in Latin America and the Caribbean: The case of Programa Joven. Working Paper Series Instituto Latinoamericano de Doctrina y Estudios (ILADES)/Georgetown University.

Aedo, C., and M. Pizarro, 2004. Rentabilidad Económica del Programa de Capacitación Laboral de Jóvenes Chile Joven. INACAP and Mideplan, Santiago de Chile.

Alcázar, L., J. R. Lopez-Cáliz, and E. Wachtenheim, 2003. Las pérdidas en el camino, fugas en el gasto público: transferencias municipales, vaso de leche y sector educación. Instituto Apoyo, Lima.

Alzúa, M. L., and P. Brassiolo, 2006. The Impact of Training Policies in Argentina: An Evaluation of Proyecto Joven. Working Paper OVE/WP-15/06, Inter-American Development Bank, Office of Evaluation and Oversight.

Angelucci, M., and O. Attanasio, 2006. Estimating ATT effects with non-experimental data and low compliance. IZA Discussion Paper 2368.

Arulampalam, W., A. L. Booth, and P. Elias, 1997. Work-related training and earnings growth for young men in Britain. Research in Labor Economics, 16, 119-147.

Ashenfelter, O., 1978. Estimating the effect of training programs on earnings. Review of Economics and Statistics 60 (1), 47-57.

Attanasio, O., A. Kugler, and C. Meghir, 2008. Training disadvantaged youth in Latin America: evidence from a randomized trial. NBER Working Paper 13931.

Becker, G. S., 1964. Human capital: A theoretical and empirical analysis with special reference to education. National Bureau of Economic Research, New York.

Betcherman, G., K. Olivas, and A. Dar, 2004. Impacts of active labour market programs: New evidence from evaluations with particular attention to developing and transition countries. World Bank Social Protection Discussion Paper 0402.

Booth, A. L., and D. J. Snower, 1996. Introduction: does the free market produce enough skills?. In A. L. Booth and D. J. Snower (eds.) Acquiring skills: market failures, their symptoms and policy responses. Cambridge University Press, Cambridge.

Burga, C., 2003. Re-evaluando Projoven: propensity score matching y una evaluacion paramétrica. CIES, Lima. 


\section{Bibliography}

Card, D., P. Ibarraran, F. Regalia, D. Rosas, and Y. Soares, 2007. The labor market impacts of youth training in the Dominican Republic: Evidence from a randomized evaluation. NBER Working Paper 12883.

Calderón-Madrid, A., 2006. Revisiting the Employability Effects of Training Programs for the Unemployed in Developing Countries. IADB Research Network Working Paper R-522.

Cameron, A. C.; and P. K. Trivedi, 2005. Microeconometrics. Cambridge University Press, Cambridge.

Chacaltana, J., 2006. Empleo para los Jóvenes. Centro de Estudios para el Desarrollo (CEDEP) Comisión Económica para América Latina (CEPAL) - Cooperación Técnica Alemana (GTZ), Lima.

Chacaltana, J., and D. Sulmont, 2004. Políticas activas en el mercado laboral peruano: el potencial de la capacitación y los servicios de empleo. In García, Chacaltana, Sulmont, Sierra, Sato y Jaramillo (2004), Políticas de empleo en el Perú. CIES, Lima.

Chacaltana, J., G. Guerrero, H. Espinoza, and O. Pain, 2003. ¿Qué funciona y qué no funciona en Projoven?: Una evaluación de los procesos de capacitación y medición de impacto. Inter American Development Bank Report.

Chong, A., and J. Galdo, 2006. Does the quality of training programs matter? Evidence from bidding processes data. IZA Discussion Paper 2202.

Chong, A., J. Galdo and J. Saavedra, 2008. Informality and productivity in the labor market in Peru. Journal of Economic Policy Reform 11 (4), 229-245.

de Crombrugghe, D., H. Espinoza, and H. Heijke, 2010. Job training programmes with low completion rate: The case of Projoven-Peru. Working Paper ROA-RM-2010/4, Research Centre for Education and the Labour Market (ROA), Maastricht.

de Crombrugghe, D., H. Espinoza, and H. Heijke, 2010. Dropout behaviour in youth job training programmes: The case of Projoven-Peru. Working Paper ROA-RM-2010/8, Research Centre for Education and the Labour Market (ROA), Maastricht.

Dehejia, R., and S. Wahba, 1999. Causal effects in non-experimental studies: reevaluating the evaluation of training programs. Journal of the American Statistical Association 94 (448), 10531062.

Delajara, M., S. Freije, and I. Soloaga, 2006. An Evaluation of Training for the Unemployed in Mexico. Working Paper OVE/WP-09/06, Inter-American Development Bank, Office of Evaluation and Oversight.

Di Pietro, G., 2004. The determinants of university dropout in Italy: A bivariate probability model with sample selection. Applied Economics Letters 11 (3), 187-191.

Díaz, J. J., M. Jaramillo, 2006. An evaluation of the Peruvian youth labor training program Projoven. Inter-American Development Bank Working Paper. 
Dunnett, C. W., 1989. Algorithm AS 251: Multivariate normal probability integrals with product correlation structure. Journal of the Royal Statistical Society, Series C 38, 564-579.

The Economic Commission for Latin America - ECLAC, 2008. Social panorama of Latin America. ECLAC, Santiago de Chile.

Egger, P., and N. García, 2000. Apertura económica y empleo: los países andinos de los noventa. OIT, Lima.

Felstead, A., and F. Green, 1996. Training implications of regulation compliance and business cycles. In A. L. Booth and D. J. Snower (eds.), Acquiring Skills: Market Failures, Their Symptoms and Policy Responses. Cambridge University Press, Cambridge.

Flores-Lagunes, A., A. Gonzalez, and T. C. Neumann, 2007. Estimating the effects of length of exposure to a training program: The case of Job Corps. IZA Discussion Paper 2846.

Friedlander, D., and P. K. Robins, 1995. Evaluating program evaluations: new evidence on commonly used non experimental methods. The American Economic Review 85 (4), 923-937.

Friedlander, D., D. H. Greenberg, and P. K. Robins, 1997. Evaluating government training programs for the economically disadvantaged. Journal of Economic Literature 35 (4), 1809-1855.

Galdo, J., 1998. La evaluación de proyectos de inversión social: impacto del programa de capacitación laboral juvenil Projoven. Boletín de Economía Laboral 9, 11-30.

Hanushek, E. A., V. Lavy, and K. Hitomi, 2006. Do students care about school quality? Determinants of dropout behaviour in developing countries. NBER Working Paper 12737.

Harhoff, D., and T. J. Kane, 1997. Is the German apprenticeship system a panacea for the U.S. labor market. Journal of Population Economics, 10 (2), 171-196.

Heckman, J., R. LaLonde, and J. Smith, 1999. The economics and econometrics of active labor market programs. In Ashenfelter, O., and D. Card, Handbook of Labor Economics, Vol. IV, 18652073.

Heckman, J. J., N. Hohmann, J. Smith, and M. Khoo, 2000. Substitution and dropout bias in social experiments: A study of an influential social experiment. Quarterly Journal of Economics 115 (2), 651-694.

Heckman, J. J., and J. A. Smith, 1999. The pre-program earnings dip and the determinants of participation in a social program: Implications for simple program evaluation strategies. NBER Working Paper 6983.

Heckman, J. J., J. A. Smith, and C. Taber, 1998. Accounting for dropouts in evaluation of social programs. Review of Economics and Statistics 80 (1), 1-14.

Heckman, J. J., and V. J. Hotz, 1989. Choosing among non-experimental methods for estimating the impact of social programs: the case of manpower training. NBER Research Working Paper 2861. 


\section{Bibliography}

Heckman, J. J., and R. Robb, 1989. Alternative methods for evaluating the impact of interventions: an overview. In Barnett, W. A., Gallant, A. R. (Eds.), New approaches to modelling, specification selection and econometric inference. Cambridge University Press, Cambridge.

Heckman, J. J., and J. A. Smith, 1997. Experimental and non-experimental evaluation. In Schmid G., J. O'Reilly, and K. Schömann (Eds.), International handbook of labour market policy and evaluation. Edward Elgar Publishing Inc., Massachusetts.

Hirano, K., and G. Imbens, 2004. The Propensity Score with Continuous Treatments. In Gelman, A., and X.-L. Meng (eds.), Applied Bayesian Modeling and Causal Inference from Incomplete-Data Perspectives. John Wiley and Sons, West Sussex.

Ibarrarán, P., and D. Rosas, 2007. Impact evaluation of a labour training program in Panama. Inter-American Development Bank Working Paper.

Ibarrarán, P., and D. Rosas, 2008. Evaluating the impact of job training programs in Latin America: Evidence from IDB funded operations. Inter-American Development Bank Working Paper.

Inter American Development Bank - IADB, 2001. Competitiveness: the business of growth. IADB, Washington.

Kluve, J., H. Schneider, A. Uhlendorff, and Z. Zhao, 2007. Evaluating continuous training programs using the generalized propensity score. IZA Discussion Paper 3255.

LaLonde, R., 1986. Evaluating the econometric evaluations of training programs. American Economic Review 76 (4), 604-620.

Lee, L.-F., 1983. Generalized econometric models with selectivity. Econometrica 51 (2), 507512.

Lee, M.-J., 2005. Micro-econometrics for policy, program, and treatment effects. Oxford University Press, Oxford.

Lee, M.-J., and S.-J. Lee, 2003. Analyzing effects of job-training programs suffering dropouts with an optimal multiple matching. Working Paper Singapore Management University.

Leuven, E., and H. Oosterbeek, 2006. An alternative approach to estimate the wage returns to private-sector training. Mimeo.

Mealli, F., S. Pudney, and J. Thomas, 1996. Training duration and post-training outcome: A duration-limited competing risks model. Economic Journal 106 (435), 422-433.

Mohrenweiser, J. and U. Backes-Gellner, 2008. Apprenticeship training - What for? Investment in human capita or substitution of cheap labour. Leading House Working Paper No. 17, Universität Zürich.

Mundlak, Y., 1978. On the pooling of time series and cross section data. Econometrica 46 (1), 69-85. 
Nopo, H., and J. Saavedra, 2003. Evaluación de impacto de mediano plazo de Projoven. GRADE, Lima.

Ñopo, H., M. Robles, and J. Saavedra, 2002. Una medición del impacto del programa de capacitación laboral juvenil Projoven. GRADE, Lima.

Nopo, H., M. Robles, and J. Saavedra, 2007. Occupational training to reduce gender segregation: The impact of Projoven. Inter-American Development Bank, Working paper 623.

O'Toole, D. M., L. S. Stratton, and J. N. Wetzel, 2006. Are the factors affecting dropout behavior related to initial enrollment intensity for college undergraduates? IZA Discussion Paper 1951.

Peraita, C., and M. Pastor, 2000. The primary school dropout in Spain: The influence of family background and labour market condition. Education Economics 8 (2), 157-168.

Projoven, 2000. Principales resultados de la evaluación de impacto: primera y segunda convocatoria. Ministerio de Trabajo y Promoción del Empleo, Lima.

Projoven, 2002. Informe sobre los procesos del área de focalización según sede regional: 9na Convocatoria. Ministerio de Trabajo y Promoción del Empleo, Lima.

Projoven, 2004. Evaluación de impacto de la octava convocatoria. Ministerio de Trabajo y Promoción del Empleo, Lima.

Projoven, 2005. Primera evaluación de impacto décima convocatoria. Ministerio de Trabajo y Promoción del Empleo, Lima.

Rosenbaum, P. R., 1995. Observational studies. Springer-Verlag, New York.

Rosenbaum, P. R. and D. B. Rubin, 1985. Constructing a control group using multivariate matched sampling methods that incorporate the propensity score. The American Statistician 39 (1), 33-39.

Saavedra, J., 2003. Labor markets during the 1990's. In Kuczinski, P. P., and J. Williamson, After the Washington consensus: restarting growth and reform in Latin America. Institute for International Economics, Washington D.C.

Saavedra, J., and J. Chacaltana, 2001. Exclusión y oportunidad: jóvenes urbanos y su inserción en el mercado de trabajo y en el mercado de capacitación. Grupo de Análisis para el Desarrollo GRADE, Lima.

Santiago Consultores Asociados, 1999. Evaluación ex post Chile Joven Fase II. Santiago Consultores Asociados, Santiago de Chile.

Schaffer, M.E., and S. Stillman, 2010. Xtoverid: Stata module to calculate tests of overidentifying restrictions after xtreg, xtivreg, xtivreg2 and xthtaylor http://ideas.repec.org/c/boc/bocode/s456779.html. 


\section{Bibliography}

Schmid, G., J. O'Reilly, and K. Schömann, 1996. Theory and Methodology of labour market policy and evaluation: and introduction. In: G. Schmid, J. O'Reilly and K. Schömann (eds.), International Handbook of Labour Market Policy and Evaluation. Edward Elgar Publishing Limited, The United Kingdom.

Schochet, P. Z., 1998. National Job Corps study: Eligible applicants' perspectives on Job Corps outreach and admissions. Report, Mathematica Policy Research, Princeton, NJ.

Semykina, A., and J. M. Wooldridge, 2006. Estimating panel data models in presence of endogeneity and selection: theory and application. Discussion paper, Department of Economics, Michigan State University, East Lansing, MI.

Smits, W., 2005. The quality of apprenticeship training. Conflicting interest of firms and apprentices. Research Centre for Education and the Labour Market (ROA), Maastricht.

Tokman, V. E., and D. Martínez (Eds.), 1999. Inseguridad laboral y competitividad: modalidades de contratación. Oficina Internacional del Trabajo, Lima.

van de Ven, W. P. M. M., and B. M. S. van Praag, 1981. The demand of deductibles in private health insurance: A probit model with sample selection. Journal of Econometrics 17 (2), 229252.

Velazco, J., 2004. Estado del Arte de la Protección Social para Trabajadores Informales en el Perú. Consorcio de Investigación Económica y Social - CIES, Lima.

Waller, M., 2008. Further training for the unemployed - What can we learn about dropouts from administrative data? FDZ Report 4/2008, The Research Data Centre (FDZ) of the German Federal Employment Agency (BA).

Wooldridge, J. M., 1995. Selection corrections for panel data models under conditional mean independence assumptions. Journal of Econometrics 68 (1), 115-132.

Wooldridge, J. M., 2002. Econometric Analysis of Cross Section and Panel Data. MIT Press, Cambridge, MA. 


\section{Summary in Dutch}

Latijns-Amerikaanse landen hebben te maken met grote barrières voor het verbeteren van de werkgelegenheidsperspectieven voor jongere werknemers, in het bijzonder die uit minder bevoorrechte milieus. Het groeiende aantal jonge mensen in tijdelijke, onzekere en slecht betaalde banen vraagt om hervormingen door beleidsmakers. Als beleidsmaatregel gericht op economisch achtergestelde jongeren zijn in Latijns-Amerika jeugdtrainingsprogramma's (YTPs - Youth Job-Training Programmes) geïntroduceerd. Het doel van deze programma's is om de arbeidsmarktperspectieven van deze jongeren te verbeteren door ze te voorzien van de basisvaardigheden die nodig zijn voor een baan evenals een aantal vakofberoepsspecifieke vaardigheden. Deze trainingsprogramma's worden uitgevoerd in Latijns Amerika sinds de beginjaren 90. Onder deze landen bevinden zich Venezuela (1993), Argentinië (1994), Paraguay (1994), Peru (1996), de Dominicaanse Republiek (1999), Colombia (2000), Panama (2002) en Haïti (2005). YJTPs zijn gebaseerd op een duaal systeem van scholing en een beroepsgerichte stage. De jongeren volgen een markt-georiënteerde benadering waarbij overheden de trainingsactiviteiten uitbesteden aan private partijen. De Latijns-Amerikaanse overheden financieren de trainingsaanbieders om de jongeren te trainen op hun eigen locaties en hen vervolgens van een stageplek te voorzien. De overheid beperkt haar rol tot het selecteren van de beste offertes van de private organisaties door middel van publieke inschrijvingen en het controleren van de kwaliteit van de aangeboden trainingen.

De Latijns-Amerikaanse YJTPs zijn uitgebreid geëvalueerd en de algemene conclusie is dat de trainingsprogramma's effectieve beleidsinterventies zijn. Er wordt aangevoerd dat deze programma's de kansen op werk voor jongeren vergroot, evenals hun potentiële inkomsten, in het bijzonder voor jonge vrouwen. De aanwezigheid van jongeren die het programma niet afronden, omdat zij geen stageplek krijgen toegewezen of omdat zij vrijwillig met het programma stoppen, wordt in de meeste evaluaties veronachtzaamd. Dit is cruciaal, want het is kenmerkend voor vrijwel alle trainingsprogramma's dat een belangrijk deel van de deelnemers de training niet afmaakt ('partial treatment'). Als er rekening wordt gehouden met het verschijnseldat een laag aantal deelnemers de training afrondt, kunnen de oorzaken en implicaties hiervan de huidige kijk op de effectiviteit van de YTPs in twijfel doen trekken. . Het zou bovendien informatie kunnen opleveren over het vergroten van de effectiviteit van deze programma's.

Het lage aantal dat het programma voltooit, levert aanwijzingen op dat i) aanbieders niet alle trainees van een stageplek voorzien; ii) stages gelopen worden onder slechte voorwaarden; iii) het programma voor sommige typen personen beter werkt dan voor anderen. Om de effectiviteit van het programma te kunnen bepalen en te begrijpen is het daarom belangrijk de effecten van de verschillende fases van het programma te onderscheiden, rekening te houden met de institutionele regelingen van de training (reglementen, stimuleringsmaatregelen en handhavingmechanismen) en de individuele 
heterogeniteit (individuele kenmerken). Als stages bovendien onder slechte omstandigheden worden gelopen, kunnen deelnemers afvallen voor betere mogelijkheden. Deze aspecten zijn genegeerd in eerdere evaluaties. Daarom blijft de relatie tussen het voltooien van de training, de heterogeniteit van de deelnemers en de institutionele regelingen van de training aan de ene kant en de kansen op de arbeidsmarkt aan de andere kant, dubbelzinnig. Dit proefschrift beoogt dit gat in de 'treatment effects' literatuur op te vullen.

Dit proefschrift evalueert in het bijzonder de effectiviteit van het Peruaanse YJTP Projoven in termen van zowel totale werkgelegenheid als formele werkgelegenheid en in termen van maandlonen. De casus die is gekozen voor deze studie is representatief voor soortelijke trainingsmaatregelen in Latijns-Amerika en heeft een gemiddeld aantal uitvallers. Projoven is een doorlopend trainingsprogramma dat is gestart in 1996 en dat minstens een keer per jaar wordt uitgevoerd in opeenvolgende golven of 'public calls' (publieke aanbestedingen). In de dertien jaar dat het operatief is, heeft het zo'n 60.000 personen getraind. Het programma wordt gerund door het Peruaanse ministerie van arbeid. Projoven financiert de trainingscursussen voor jongeren, maar de service wordt geleverd door trainingsinstituten die concurreren om de financiering te bemachtigen voor hun opleidingsaanbod. Het officiële doel van het programma is het faciliteren van de toegang tot de formele arbeidsmarkt voor economisch achtergestelde jongeren (16-24 jaar oud) door ze te voorzien van een basis training in laagopgeleide beroepen. De Projoven training is gebaseerd op twee opeenvolgende fasen: i) drie maanden scholing, die bijna alle deelnemers afronden, gevolgd door ii) drie maanden beroepsgerichte stage die aan de meerderheid, maar niet aan alle deelnemers wordt aangeboden.

Dit proefschrift integreert de analyse van het institutionele kader, de individuele heterogeniteit en het gedrag van de uitvallers tot een evaluatie van de effectiviteit van Projoven. Hiervoor wordt een driestappen benadering gevolgd. Hoofdstuk 2 geeft als eerste stap achtergrondinformatie over het programma en het bediscussieert het institutionele kader. Deze discussie levert een aantal elementen op waar rekening mee gehouden zou moeten worden in de evaluatie van het trainingsprogramma. Hoofdstuk 3 en 4 zijn als tweede stap gewijd aan de evaluatie van de 'treatment' effecten van Projoven. Hoofdstuk 3 beschrijft en bespreekt Projovens dataset en de $6^{\text {de }}$ 'public call', waarvoor gedetailleerde data beschikbaar zijn. In hoofdstuk 4 wordt een methodologie voorgesteld en toegepast om Projoven te evalueren. Deze methodologie houdt rekening met de niet-experimentele aard van de data, de heterogeniteit van de individuen, de selectie voor werk en de aanwezigheid van deelnemers met een 'partial treatment'. De evaluatie is uitgevoerd in termen van zowel totale als formele werkgelegenheid en in termen van maandlonen. Als derde stap identificeert en bediscussieert hoofdstuk 5 de factoren die het gedrag van de deelnemers die het programma afbreken, beïnvloeden. Onderzocht wordt of individuele eigenschappen, regionale kenmerken of trainingskenmerken de beslissing van de deelnemers om de training te stoppen, beïnvloedt. Tot slot wordt in hoofdstuk 6 een aantal algemene conclusies getrokken. 
Hoofdstuk 2 bestudeert tot op welke hoogte er rekening zou moeten worden gehouden met de institutionele regelingen in de evaluatie van de effectiviteit van het programma in de context waarin het programma wordt uitgevoerd. Naar aanleiding van een uiteenzetting hoe Projoven behoort te werken en hoe het daadwerkelijk werkt, stelt dit hoofdstuk drie elementen voor waarmee rekening moet worden gehouden wanneer de effectiviteit van een training als Projoven wordt geëvalueerd. Als eerste moet worden gerealiseerd dat niet alle leerlingen een stageplek toegewezen krijgen wanneer ze de scholing hebben afgerond. Daarom moet er bij het meten van Projovens impact een onderscheid worden gemaakt tussen de effecten van de twee fases van het programma. Ten tweede moet er bij het meten van Projoven's impact rekening worden gehouden met de aanwezigheid van deelnemers met een gedeeltelijke training, omdat $30 \%$ van de deelnemers de praktijkstage voortijdig afbreekt. Ten derde moet niet uit het oog worden verloren dat zowel de deelnemers als hun arbeidsmogelijkheden heterogeen zijn. Het feit dat de helft van de deelnemers voorafgaand aan het programma werkzaam is, hoogst waarschijnlijk in de informele sector, heeft gevolgen voor de berekening van het trainingseffect in termen van werkgelegenheidsindicatoren en individuele heterogeniteit. Het evalueren van de totale werkkansen kan de werkelijke potentie van het programma over het hoofd zien, omdat minder bevoorrechte jongeren regelmatig te werk gesteld zijn in riskante, slecht betaalde banen zonder sociale rechten (de informele arbeidsmarkt). Als er rekening wordt gehouden met de aanwezigheid van de informele arbeidsmarkt, zou het bepalen van de formele werkgelegenheidscondities van deelnemers additioneleaanwijzingen kunnen opleveren van Projoven's effect in termen van werkgelegenheid. Bovendien zou het programma de deelnemers verschillend kunnen beïnvloeden, afhankelijk van hun werkervaring. De trainingsopbrengsten zouden bijvoorbeeld relatief lager kunnen uitvallen voor jongeren met werkervaring, omdat zij al over een aantal vaardigheden beschikken.

Hoofdstuk 3 beschrijft Projovens dataset van de $6^{\text {de }}$ 'public call' . Deze dataset combineert niet alleen demografische informatie van de deelnemers en een officiële controlegroep, maar ook administratieve gegevens over de mate waarin men de training voltooid heeft. Hij omvat een vastlegging van de uitgangssituatie en drie na-interviews: zes, twaalf en achttien maanden na afloop van de training. Dit hoofdstuk zet uiteen hoe een nieuwe controlegroep werd gecreëerd door middel van 'propensity score matching with replacement'. Doel is om het probleem aan te pakken van de terugval in verdiensten die voorafgaand aan de training bij de deelnemers optreedt maar niet wordt waargenomen bij de officiële controle groep en die een aanwijzing kan vormen voor . systematische verschillen tussen beide groepen, wat hun vergelijkbaarheid ondermijnt. De nieuwe controlegroep is een deelsteekproef van de individuen in de officiële controlegroep. De toetsen die uitgevoerd zijn bij deze nieuwe controlegroep geven aan dat de geschatte trainingsseffecten in termen van werkkansen vrij zijn van bias, terwijl deze in termen van maandlonen kunnen zijn overschat.

Hoofdstuk 4 behandelt de effectiviteit van Projovens 6de 'public call in termen van zowel totale als formele werkgelegenheid en in termen van maandlonen. Er wordt rekening gehouden met de aanwezigheid van deelnemers die de training slechts gedeeltelijk ondergaan door gebruik te maken van 'fixed effect' methodes met correctie voor 
steekproefselectie. De correctie voor steekproefselectie zorgt ervoor dat de geschatte effecten opde formele werkgelegenheid en de lonen niet worden beïnvloed door het feit dat Projoven de waarschijnlijkheid van het vinden van werk zou kunnen vergroten. Er worden vier groepen paarsgewijs vergeleken: de controlegroep, de afvallers die alleen de scholingsfase hebben doorlopen, de afvallers met scholing en een onvolledige praktijkstage en de groep die het complete programma van scholing en praktijkstage heeft afgerond. De schattingen houden ook rekening met de potentiele endogeniteit van de afronding van de training door gebruik te maken van gepoolde 'two stages least squares' methoden met correctie voor steekproefselectie.

Splitsing van de effecten van het trainingsprogramma naar de mate van afronding levert aanwijzingen op dat het progamma effectiever is op voorwaarde dat men deze geheel afrond. Er wordt gevonden dat in termen van totale werkgelegenheid het programma alleen een gunstig effect heeft op de korte termijn (zes maanden na afloop van het programma) en op voorwaarde van voltooïng van de praktijkstage. In termen van formele werkgelegenheid werden geen significante resultaten gevonden. Het programma lijkt de lonen van de trainees te verhogen, maar dit effect neemt in de loop van de tijd af. De positieve effecten van het programma op de maandlonen en het ontbreken van een effect op de formele werkgelegenheid duidt er op dat de trainees meer uren zijn gaan werken in hetzelfde type onzekere banen als waarin zij werkzaam zouden zijn zonder het trainingsprogramma. Als verder de programma-effecten worden gedifferentieerd naar de individuele kenmerken van de deelnemers lijkt Projoven voor individuen die voor hun deelname geen werkervaring hadden extra opbrengsten te hebben die constant blijven in de loop van de tijd Er moet worden opgemerkt dat de algemeen-evenwichtseffecten van Projoven op de Peruaanse arbeidsmarkt te verwaarlozen zijn gegeven het beperkte bereik van Projoven.

De schatting van de effecten van de deelname aan Projoven roept de vraag op waarom er deelnemers afvallen wanneer het duidelijk de moeite waard is om de training af te ronden. Om de determinanten van het gedrag van de afvallers te onderzoeken, worden in hoofdstuk 5 twee empirisch modellen ontwikkeld. Het eerste model, een probit model met correctie voor steekproefselectie, verklaart waarom deelnemers wel of niet voor een stageplek worden geselecteerd, terwijl het tweede model, een multinomiaal model, de twee verschillende uitvalsroutes (uitval vanwege een andere baan of uitval leidend tot werkloosheid/inactiviteit) verklaart. Deze modellen toetsen of de kenmerken van de deelnemers, de regionale verschillen en/of de kenmerken van de training het gedrag dat leidt tot uitval beïnvloeden. De resultaten van de modellen duiden op de afwezigheid van een invloed van de selectie voor de praktijkstage op het aantal afvallers en dat de deelnemers het programma blijven volgen zolang zij het de moeite waard vinden de training te blijven volgen. Er kunnen drie algemene conclusies worden getrokken op basis van de analyse van het gedrag van de deelnemers die uitvallen. Allereerst is het minder waarschijnlijk dat vrouwen en personen zonder werkervaring het programma afbreken, aangezien zij hoogst waarschijnlijk het meest profiteren van de training. Dit is gerelateerd aan het feit dat mannelijke deelnemers met werkervaring voorafgaand aan het programma, waarschijnlijk minder snel uitvallen en werkloos worden, dan dat zij het programma 
verlaten vanwege een andere baan. Ten tweede is het ook minder waarschijnlijk dat deelnemers afvallen in steden waar minder banen beschikbaar zijn (in vergelijking met Lima). Tenslotte is het minder waarschijnlijk dat deelnemers afvallen wanneer zij een geschreven contract hebben, wat betere werkomstandigheden veronderstelt.

Hoofdstuk 6 beschrijft tot slot de conclusies van de studie. De conclusies van deze studie duiden erop dat de training een effectieve beleidsinterventie zou kunnen voor het verbeteren van de arbeidsmarkt perspectieven van financieel achtergestelde jongeren. Om het potentieel van de training te vergroten moet er echter wel rekening mee worden gehouden dat het programma anders werkt voor verschillende typen personen, dat niet alle deelnemers de training in dezelfde mate afronden en dat onzekere trainingsomstandigheden kunnen leiden tot het afbreken van deelname aan het programma. Bovendien moet bij een evaluatie van de effectiviteit van Projoven een analyse van het institutionele kader in beschouwing worden genomen, omdat het gedrag van deelnemers, aanbieders van trainingen en stagebedrijven wordt beïnvloed door de regelingen en stimuleringsmaatregelen die voor het programma gelden.

Dit proefschrift laat zien dat beleidsmaatregelen gericht op economisch achtergestelde jongeren een geschikte en geïntegreerde mix van het leren van beroepsvaardigheden en een stage moet zijn en dat een adequaat aanbod van werkgelegenheidsmogelijkheden en een beter ontwikkelde markt voor scholing nodig zijn. De in deze studie geleverde aanwijzingen laten zien dat YJTPs de mogelijkheden op de arbeidsmarkt voor achtergesteld jongeren in ontwikkelingslanden zouden kunnen vergroten. Als er echter geen stages beschikbaar zijn of als de stages worden gelopen onder onzekere voorwaarden, kan een programma als Projoven ineffectief zijn. Als gevolg hiervan moeten het programma op zo'n manier worden uitgevoerd dat de institutionele regelingen de juiste stimulansen opleveren die de effectiviteit vergroten: i) stimulansen voor de deelnemers om de training op te pakken en af te ronden; i) stimulansen voor de trainingorganisaties om scholingsprogramma's van hoge kwaliteit aan te bieden en stageplaatsen te vinden voor alle deelnemers; en iii) stimulansen voor stagebedrijven om training op te nemen in hun investeringsbeleid en gepaste voorwaarden te bieden (schriftelijk contract). Het aanmoedigen van kortere, meer flexibele training als deelnemers de training niet afronden is nutteloos, evenals een afgestudeerde van YJTP die onvolledig voorbereid is voor banen die beschikbaar zijn op de arbeidsmarkt. Tenslotte zouden YJTPs aangevuld moeten worden met een integrale hervorming van de markt voor scholing. Als trainingsaanbieders niet worden gereguleerd, kan worden verwacht dat deelnemers blijven uitvallen en dat stages niet geschikt zijn. 
Summary in Dutch 


\section{Curriculum Vitae}

Henry Espinoza Peña was born in Callao, Peru, on January 31'st, 1979. He graduated from high school at Liceo Naval Lizardo Montero in 1995. He studied economics at Universidad del Pacífico (Lima, Peru) from 1996 to 2001.

From 2002 to 2005, he worked as a researcher at the Research Centre for Development Studies - CEDEP (Lima, Peru) where he carried out research and consultancies in employment issues and poverty dynamics in Peru. He also participated in the impact evaluation of diverse social programmes.

In August 2005, Henry Espinoza moved to the Netherlands to study a Master in Social Protection and Public Policy at the Maastricht Graduate School of Governance (MGSoG). For his Master Thesis he analyzed the role of the free availability of the tenure bonus CTS (Compensación por tiempo de servicio), a non-wage labour cost in Peru, as an in-work benefit scheme. Using micro-simulations techniques, he assessed CTS' impact at reducing poverty and suggested some proposals for reform. This thesis was awarded with the Stichting Wetenschapsbeoefening for the best Master Thesis at the Faculty of Humanities and Science (FHS) of Maastricht University.

After concluding his Master studies, Henry joined the PhD programme of the MGSoG in September 2006. As a Research Fellow, Henry worked on his dissertation which evaluates the effects of job-training programmes on economically disadvantaged youths in Peru. In addition, he participated as a tutor and lecturer in the courses of Public Policy Analysis and Econometrics which were taught in the Master Programme of the MGSoG. 


\section{MGSoG Dissertation Series}

\section{Florian Tomini}

Between Family and Friends

Understanding the Interdependency of Private Transfers

MGSoG Dissertation Series, nr 15 (2010)

Michał Polalowski

The Institutional Transformation of Social Policy in East Central Europe:

Poland and Hungary in comparative and historical perspective

MGSoG Dissertation Series, nr 14 (2010)

Maha Ahmed

Defining, Measuring and Adressing Vulnerability:

The Case of Post Conflict Environments

MGSoG Dissertation Series, nr 13 (2010)

Pascal Beckers

Local Space and Economic Success

The role of spatial segregation of migrants in the Netherlands

MGSoG Dissertation Series, nr 12 (2011)

\section{Victor Cebotari}

Complicting Demands in Ethnically Diverse Societies

Ethnopolitical Contention and Identity Values in Europe

MGSoG Dissertation Series, nr 11 (2010)

Dennis Gyllensporre

Competing and Complementary Perspectives on the EU as a Crisis Management Actor:

An Examination of the Common Security and Defence Policy through the Lenses of Idealism and Realism

MGSoG Dissertation Series, nr 10 (2010)

Judit Vall Castello

Business Cycle and Policy Effects on Labour Market Transitions of Older and Disabled Workers in Spain

MGSoG Dissertation Series, nr. 9 (2010)

Keetie Roelen

False Positives or Hidden Dimentions: the definition and measurement of child poverty

MGSoG Dissertation Series, nr. 8 (2010)

Denisa Maria Sologon

Earning Dynamics in Europe

MGSoG Dissertation Series, nr. 7 (2010)

Melissa Siegel

Money and Mobility: Migration and Remittances

MGSoG Dissertation Series, nr. 6 (2010)

Jessica S. Hagen-Zanker

Modest Expectations: Causes and effects of migration on migrant households in source countries

MGSoG Dissertation Series, nr. 5 (2010) 
Mirtha R. Muniz Castillo

Human Development and Autonomy in Project Aid: Experiences from four bilateral projects in Nigaragua and El Salvador

MGSoG Dissertation Series, nr. 4 (2009)

Christiane Arndt

Governance Indicators

MGSoG Dissertation Series, nr. 3 (2009)

Britta Augsburg

Microfinance - Greater Good or Lesser Evil?

MGSoG Dissertation Series, nr. 2 (2009)

Geranda Notten

Measuring and Managing Poverty Risks

MGSoG Dissertation Series, nr. 1 (2008) 